\title{
Evaluation of Heat Pump Water Heater Performance and Optimization Strategies In Cold Climates
}

\author{
by \\ Jayson Bursill, B.A.Sc., Mechanical Engineering \\ University of British Columbia
}

A thesis submitted to the Faculty of Graduate and Postdoctoral Affairs in partial fulfillment of the requirements for the degree of

Master of Applied Science

in

Sustainable Energy

Carleton University

Ottawa, Ontario

(C) 2015, Jayson Bursill 


\section{Abstract}

Energy costs will continue to rise as the societally imposed scarcity of fossil fuels continues. For Canada, and the world, to meet the energy demand of the population, measures need to be taken to reduce energy demand while increasing the use of renewable energy. This thesis investigates the feasibility of innovative domestic hot water technology. A heat pump water heater was instrumented and installed to test Canadian Standards Association standard CSA-F379.1 draw profiles under various set-point conditions while drawing heat from the surrounding indoor space at the evaporator of the heat pump. Several set-point conditions were tested using the experimental apparatus to characterize the performance of both the heat pump and the electric booster heater. This data was then analyzed and used to calibrate a TRaNsient SYstem Simulation (TRNSYS) model. The TRNSYS model used a series of basic hydronic components to simulate the thermal and electrical conditions experienced by the HPWH unit, and was designed to facilitate an extension of the physical setup to conditions that would be difficult to timely and cost effectively test. The Generic Optimization Program software was then coupled with TRNSYS to run parametric black box simulations that optimized a characteristic equation to find the optimal design and operational parameters. The results of these simulations indicated that the operating costs for HPWH units in basement installations would not be heavily affected by the local climate, but instead strongly dependent on local utility cost ratios between electricity and heating fuel. It was found that minimal and similar set-points between the heat pump and booster heater, as well as a utility ratio near the nominal coefficient of performance, would provide the best cost performance for HPWH units. 


\section{Acknowledgements}

I would like to thank my colleagues within the Solar Energy Systems Laboratory and Delta Controls Laboratory who have provided friendship, guidance, and mentorship over the duration of my thesis. These people include, but are not limited to, Adam Wills, Brent Huchuk, Brock Conley Burak Gunay, Chris Baldwin, Daniel Bowie, Darcy Gray, David Ouellette, Jacek Khan, Jenny Chu, Kevin Khalaf, Nina Dmytrenko, Patrick Smith, and Sebastien Brideau.

I would like to thank my supervisor, Dr. Cynthia Cruickshank, for the support, guidance, and patience she has provided for the last 2 years.

I would like to acknowledge the financial support I have received from the Natural Sciences and Engineering Research Council (NSERC) Smart Net-zero Energy Buildings Strategic Research Network and NSERC.

Finally, I would like to thank my family for their support throughout all my endeavors. Without the support of my Mother Shelley, Father Barry, Aunt Francine and Uncle Darryl, I would not be where I am today. 


\section{Table of Contents}

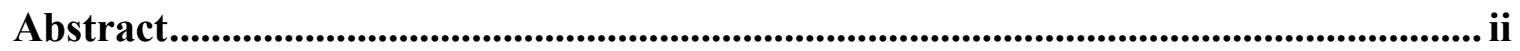

Acknowledgements ............................................................................................................................. iii

Table of Contents ........................................................................................................ iv

List of Tables ............................................................................................................................... vii

List of Illustrations...................................................................................................... viii

1 Chapter: Introduction ........................................................................................................... 1

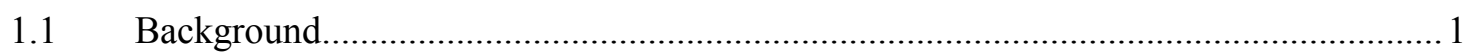

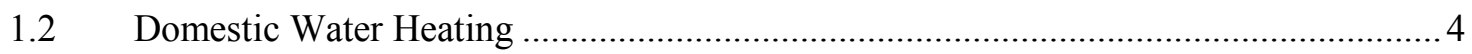

$1.3 \quad$ Heat Pump Water Heater Test Apparatus.............................................................. 8

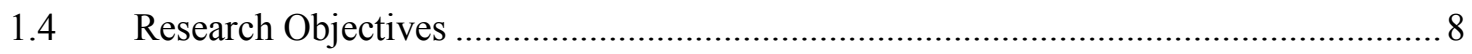

1.5 Contribution to Research ....................................................................................... 10

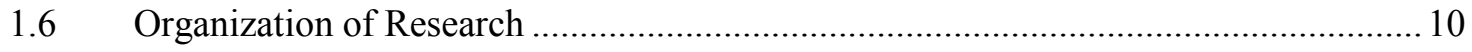

2 Chapter: Literature Review................................................................................ 12

2.1 Domestic Hot Water and Heat Pump Water Heaters................................................... 13

$2.2 \quad$ Heat Pumps

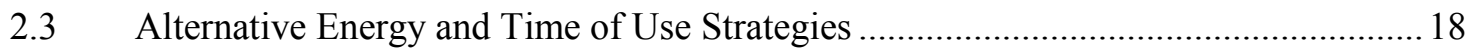

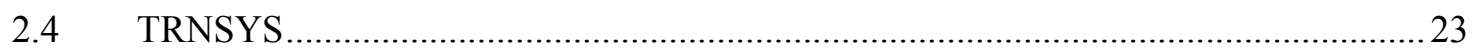

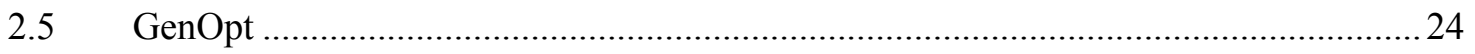

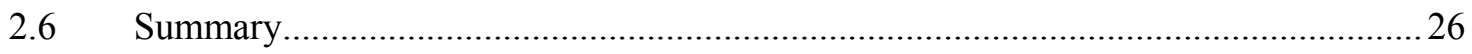

3 Chapter: Experimental Design ................................................................................ 28

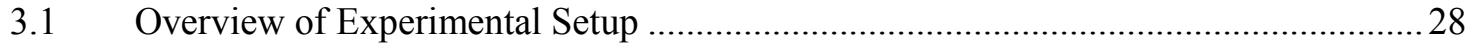

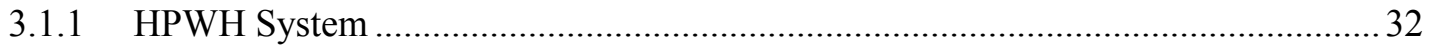

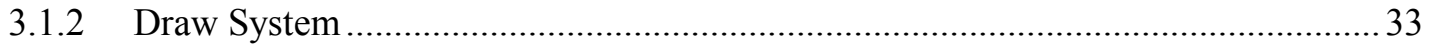




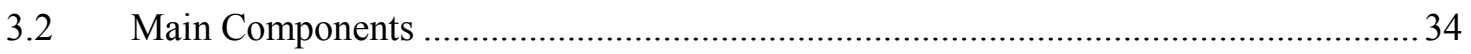

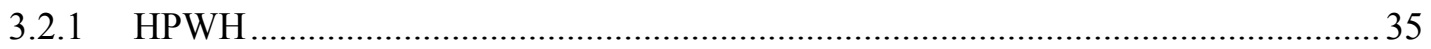

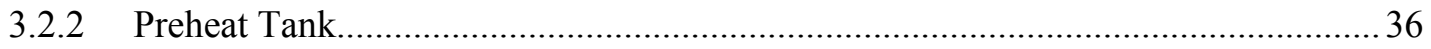

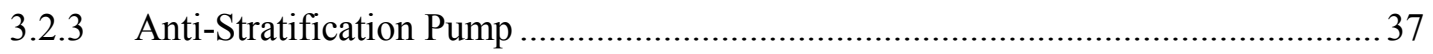

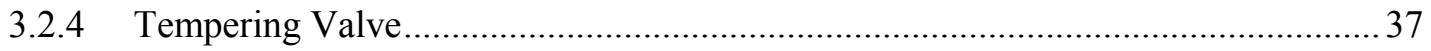

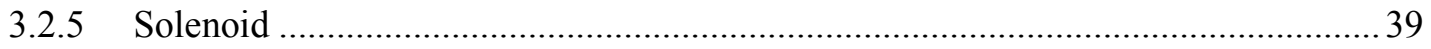

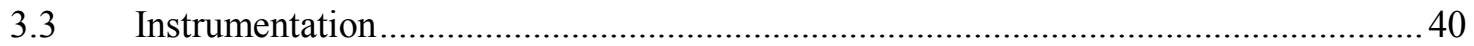

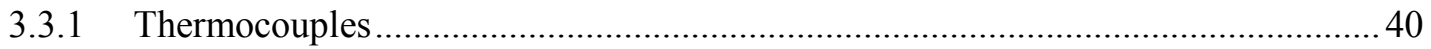

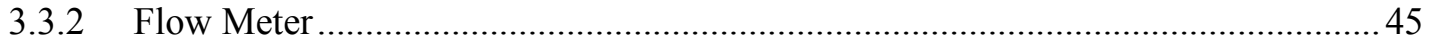

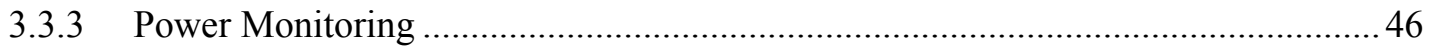

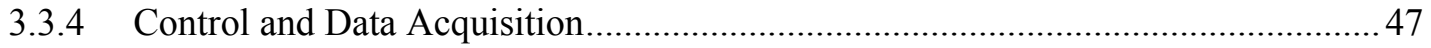

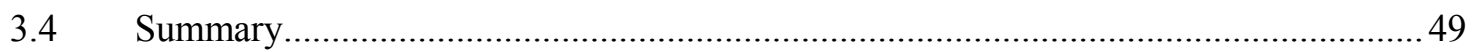

4 Chapter: System Modelling .......................................................................... 50

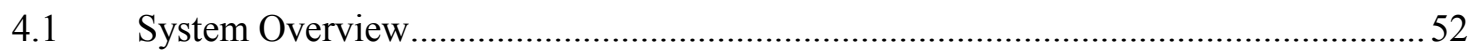

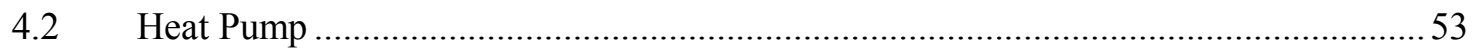

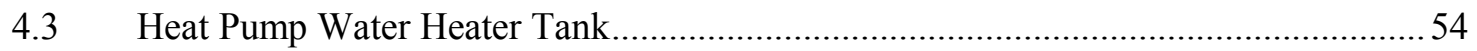

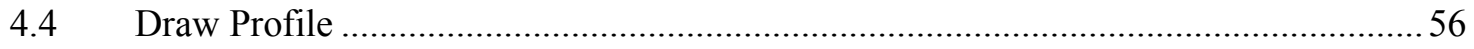

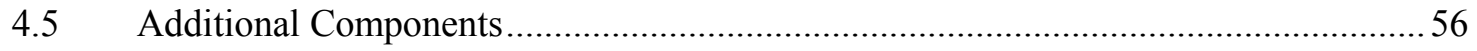

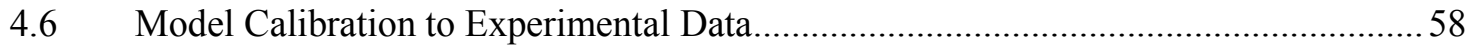

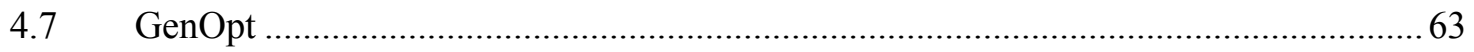

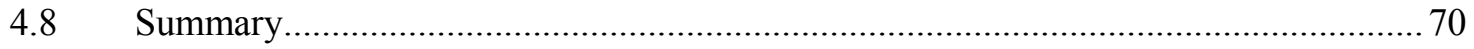

5 Chapter: Results................................................................................................................ 71

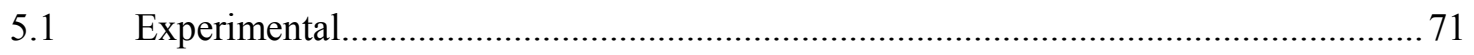

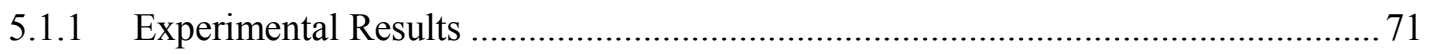

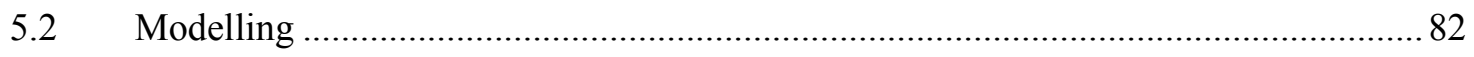

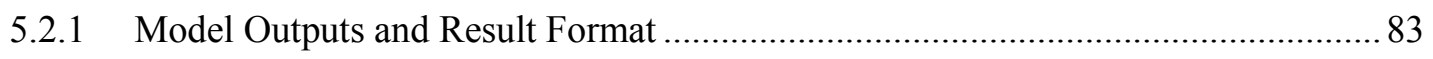




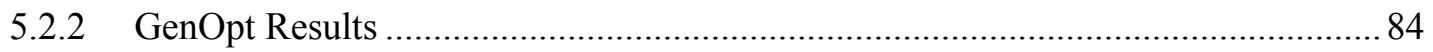

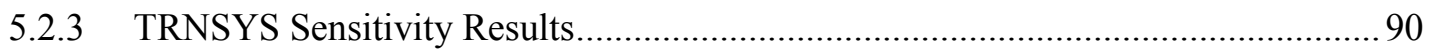

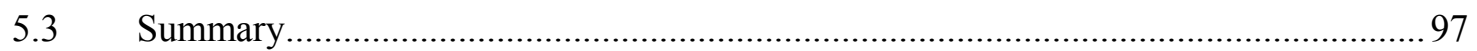

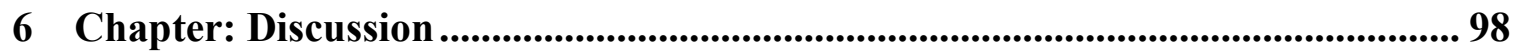

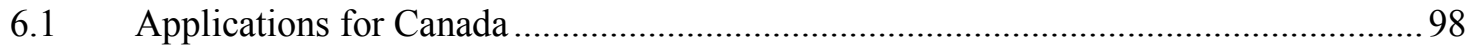

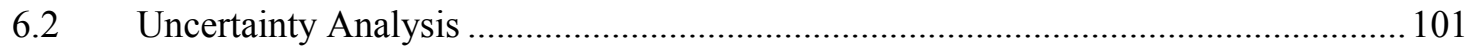

$6.3 \quad$ Summary

7 Chapter: Conclusions and Future Work ........................................................ 106

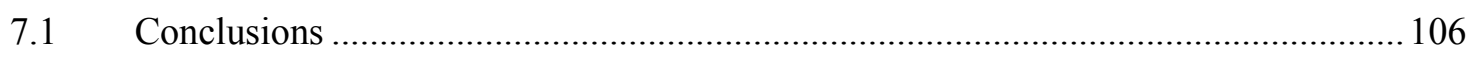

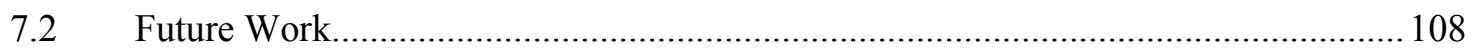

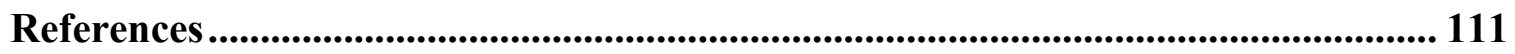

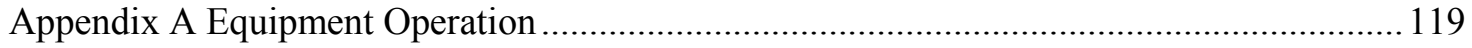

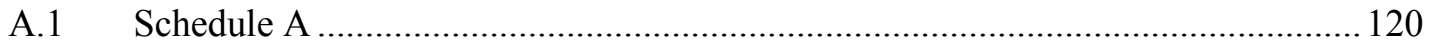

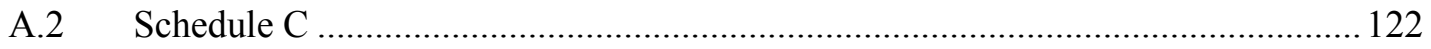

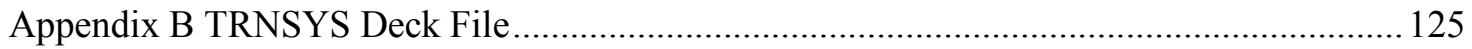




\section{List of Tables}

Table 2-1: Literature Review Highlights ................................................................... 27

Table 3-1: CSA-F379.1 DHW Draw Schedules ................................................................ 34

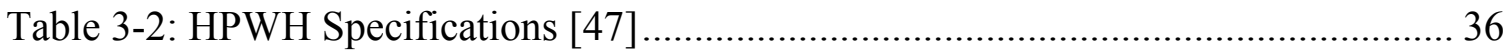

Table 3-3: Error of Temperature Measurement Documented from Calibration $\left({ }^{\circ} \mathrm{C}\right)$....... 44

Table 3-4: I/O Used for the Experimental Apparatus ................................................... 48

Table 4-1: HPWH Experimental Run Parameters for Model Calibration .......................... 59

Table 4-2: Utility Cost Summary for GenOpt Simulations ................................................ 65

Table 4-3: Typical TRNOpt Variable Specifications …………………......................... 68

Table 4-4: Particle Swarm and Hooke-Jeeves Parameters ............................................. 69

Table 5-1: Experimental Energy Results Summary (Schedule A) …………………...... 79

Table 5-2: Experimental Energy Results Summary (Schedule C)................................... 80

Table 5-3: Summary of GenOpt Parameters Analyzed with Respect to Table 4-3 .......... 85

Table 5-4: Energy Use Reduction of Design Parameters .............................................. 92

Table 6-1: Systematic Error and Sample Values for Experimental Equipment ............. 104

Table 6-2: Sensitivity Factor Roots for Net Power and COP ......................................... 104 


\section{List of Illustrations}

Figure 1-1: Residential Secondary Energy Consumption in Canada in 2012 ................... 2

Figure 1-2: Domestic Water Heater Market Share in Canada in 2012 [5] ........................ 4

Figure 1-3: Market Share by Year for Water Heaters - (Top) Electrical (Bottom) Other

$[11]$

Figure 1-4: Stock Controls for the Heat Pump Water Heater .......................................... 6

Figure 1-5: Domestic Water Heater Market Share in the USA in 2010 ............................ 7

Figure 2-1: HPWH COP for All United States Climates [13] ....................................... 14

Figure 2-2: HPWH Breakeven Cost for All United States Climates [13] ....................... 15

Figure 3-1: HPWH Diagram - (Top) Heat Pump Cycle and (Bottom) Packaged Unit.... 29

Figure 3-2: System Diagram of Hydronic Components for the HPWH Draw Test

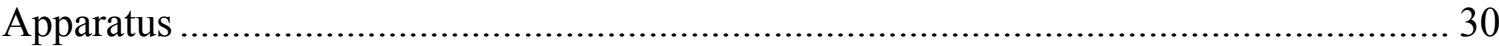

Figure 3-3: Mixing and Measuring Portion of Draw System ............................................ 31

Figure 3-4: Heat Pump Water Heater Unit - (a) Exterior and (b) Compressor Unit........ 35

Figure 3-5: Tempering Equipment - (a) Preheat Tank and (b) Tempering Valve ........... 38

Figure 3-6: Anti-Stratification Pump ……………………….................................... 39

Figure 3-7: Normally Closed Solenoid Valve for Draw Profile Control........................... 40

Figure 3-8: Custom Thermowell for Fluid Stream Temperature Measurement ................ 41

Figure 3-9: Pipe Tee Fitted with Thermocouple Probe on the HPWH Tank Drain Line. 44

Figure 3-10: In Line Flow Meter to Measure the Active Flow Rate ................................ 45

Figure 3-11: Greeneye Power Monitoring System - (a) Control Panel and (b) Current

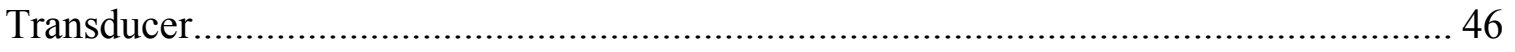

Figure 3-12: LabVIEW VI for the HPWH Testing Apparatus ......................................... 47 
Figure 3-13: NI cRIO 9024 Data Acquisition Controller 48

Figure 4-1: HPWH Temperature Control Flow Chart ............................................... 53

Figure 4-2: Temperature Rise of Heat Pump Nodes 1, 2, and 3 at $50^{\circ} \mathrm{C}$ Set-point ......... 61

Figure 4-3: Temperature Rise of Heat Pump Nodes 1, 2, and 3 at $62^{\circ} \mathrm{C}$ Set-point ......... 61

Figure 4-4: Rate of Temperature Rise Relative to $\gamma$ (Set-point - Current Node

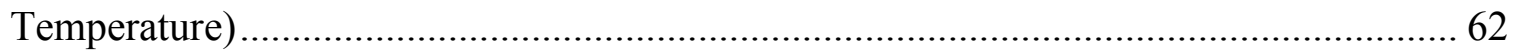

Figure 4-5: Comparison of Model and Experimental Temperature and Power for $70^{\circ} \mathrm{C}$

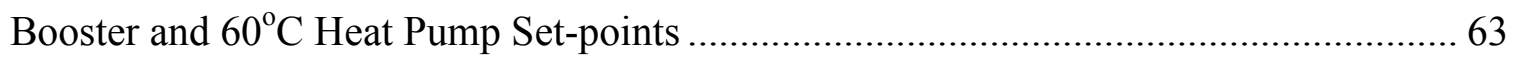

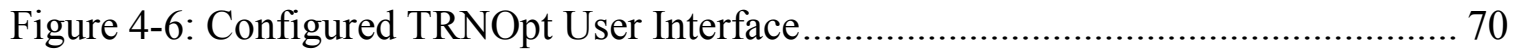

Figure 5-1: HPWH Temperature and Power Profile for Schedule C and $72^{\circ} \mathrm{C}$ Booster and

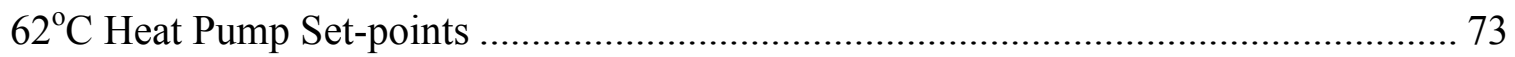

Figure 5-2: HPWH Temperature and Power Profile for Schedule $\mathrm{C}$ and $55^{\circ} \mathrm{C}$ Booster and

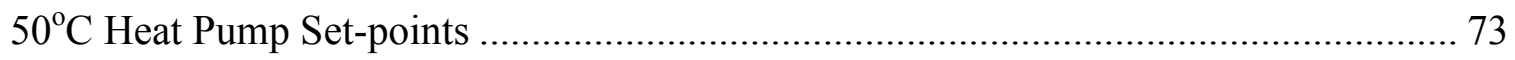

Figure 5-3: Schedule A for $72^{\circ} \mathrm{C}$ Booster and $62^{\circ} \mathrm{C}$ Heat Pump Set-points .................... 76

Figure 5-4: Schedule A for $55^{\circ} \mathrm{C}$ Booster and $50^{\circ} \mathrm{C}$ Heat Pump Set-points ................... 76

Figure 5-5: Schedule $\mathrm{C}$ for $72^{\circ} \mathrm{C}$ Booster and $62^{\circ} \mathrm{C}$ Heat Pump Set-points ................... 77

Figure 5-6: Schedule $\mathrm{C}$ for $55^{\circ} \mathrm{C}$ Booster and $50^{\circ} \mathrm{C}$ Heat Pump Set-points ................... 77

Figure 5-7: Relative HPWH Energy Usage for Various Set-point Combinations (3D) ... 81

Figure 5-8: Relative HPWH Energy Usage for Various Set-point Combinations (Contour)

Figure 5-9: Parameter Progression for Design Optimization (Ottawa) ........................... 86

Figure 5-10: Result Progression for Design Optimization (Ottawa) ............................. 86

Figure 5-11: Parameter Progression for Performance Parameter Optimization (Ottawa) 89 
Figure 5-12: Result Progression for Performance Parameter Optimization (Ottawa) ...... 89

Figure 5-13: Sensitivity Results for Design Parameters ............................................. 91

Figure 5-14: Booster Energy Use at Various Booster and HP Set-points ...................... 93

Figure 5-15: Heat Pump Energy Use at Various Booster and HP Set-points .................. 94

Figure 5-16: HPWH Energy Consumption Breakdown at a Booster Heater Set-point of

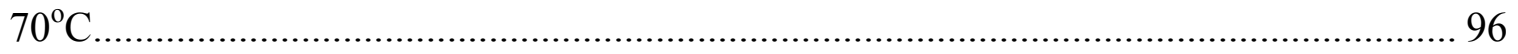

Figure 5-17: HPWH Energy Consumption at Various Booster and HP Set-points.......... 96

Figure A-0-1: Equipment Utilization for $50^{\circ} \mathrm{C} \mathrm{HP}$ and $55^{\circ} \mathrm{C}$ Booster Set-point Test

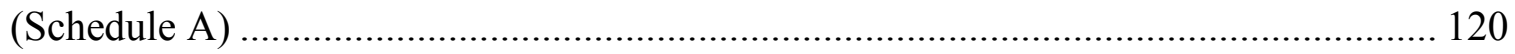

Figure A-0-2: Equipment Utilization for $55^{\circ} \mathrm{C} \mathrm{HP}$ and $60^{\circ} \mathrm{C}$ Booster Set-point Test (Schedule A) 120

Figure A-0-3: Equipment Utilization for $55^{\circ} \mathrm{C} \mathrm{HP}$ and $65^{\circ} \mathrm{C}$ Booster Set-point Test (Schedule A) 121

Figure A-0-4: Equipment Utilization for $60^{\circ} \mathrm{C} \mathrm{HP}$ and $70^{\circ} \mathrm{C}$ Booster Set-point Test (Schedule A) 121

Figure A-0-5: Equipment Utilization for $62^{\circ} \mathrm{C} \mathrm{HP}$ and $72^{\circ} \mathrm{C}$ Booster Set-point Test (Schedule A) 122

Figure A-0-6: Equipment Utilization for $50^{\circ} \mathrm{C} \mathrm{HP}$ and $55^{\circ} \mathrm{C}$ Booster Set-point Test (Schedule C). 122

Figure A-0-7: Equipment Utilization for $55^{\circ} \mathrm{C} \mathrm{HP}$ and $60^{\circ} \mathrm{C}$ Booster Set-point Test (Schedule C). 123

Figure A-0-8: Equipment Utilization for $55^{\circ} \mathrm{C} \mathrm{HP}$ and $65^{\circ} \mathrm{C}$ Booster Set-point Test (Schedule C). 123 
Figure A-0-9: Equipment Utilization for $60^{\circ} \mathrm{C} \mathrm{HP}$ and $70^{\circ} \mathrm{C}$ Booster Set-point Test

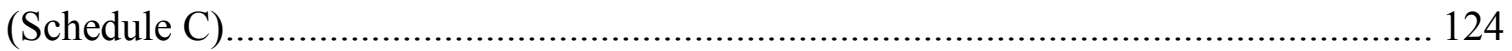

Figure A-0-10: Equipment Utilization for $62^{\circ} \mathrm{C} \mathrm{HP}$ and $72^{\circ} \mathrm{C}$ Booster Set-point Test

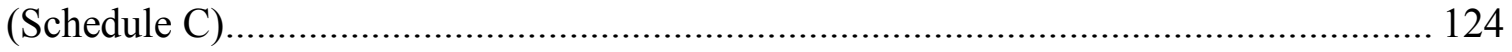




\section{Nomenclature}

\begin{tabular}{ccc} 
Symbol & Description & Units \\
$T$ & Temperature & ${ }^{\circ} \mathrm{C}$ \\
$R$ & Resistance & $\Omega$ \\
$C J C$ & Cold Junction Temperature & ${ }^{\circ} \mathrm{C}$ \\
$Q$ & Heat Transfer & $\mathrm{W}$ \\
$m$ & Mass & $\mathrm{kg}$ \\
$c_{\mathrm{p}}$ & Specific Heat & $\mathrm{kJ} / \mathrm{kg}{ }^{\circ} \mathrm{C}$ \\
$t$ & Time & $\mathrm{s}$ \\
$\gamma$ & Temperature Difference & ${ }^{\circ} \mathrm{C}$ \\
$m$ & Slope & \\
$b$ & Y-intercept & \\
$E$ & Energy & $\mathrm{J}$ \\
$C O P$ & Coefficient of Performance & $\mathrm{Kg} / \mathrm{m}^{3}$ \\
$\rho$ & Density & $\mathrm{L}$ \\
$V T$ & Volume & \\
\hline & Uncertainty &
\end{tabular}




\section{Subscripts}

$\begin{array}{cr}\text { space } & \text { Surrounding Space } \\ \text { therm } & \text { Thermal } \\ \text { elec } & \text { Electrical } \\ \text { net } & \text { Net Total } \\ \text { compressor } & \text { Compressor } \\ \text { booster } & \text { Booster } \\ \text { fan } & \text { Fan } \\ \mathrm{R} & \text { Random Uncertainty }\end{array}$




\section{Chapter: Introduction}

\subsection{Background}

Heat pump water heater (HPWH) units have been commercially available for decades, and have had considerable popularity outside of North America [1]. While currently accounting for less than $1 \%$ of the hot water market in North America, HPWH technology will likely see a significant rise in use due to new mandates from the US Department of Energy (DOE) [2] [3]. The new mandate from the US DOE (effective in 2015) will prescribe the use of HPWH units in lieu of electric water heaters where the tank capacity is over 208 L (55 US Gal) [4]. This corresponds with dwelling occupancy of 4 people or more, and would affect most detached homes. Due to Canada's close relations with the US, it is likely that policy changes could occur to extend the mandate further north.

Secondary energy use in Canada is dominated by space heating due to the prevalence of cold winters, as indicated in Figure 1-1 [5] [6]. Domestic water heating is the second largest end use, and as an end use with less load variance based on geography, provides an opportunity for widespread implementation of technological advancements. Ontario electricity prices have risen significantly in the last decade, and peak use rates of nearly doubled off-peak are reflective of the reliance on costly power [7]. Heat pump water heater technology can reduce both water heating and space cooling energy use (and demand) in the cooling season, and still provide a net reduction in energy consumption when compared to electric resistance water heating in the heating season. This can have a 
double effect on residential secondary energy consumption in Canada by reducing the cooling energy demand peak in the cooling season.

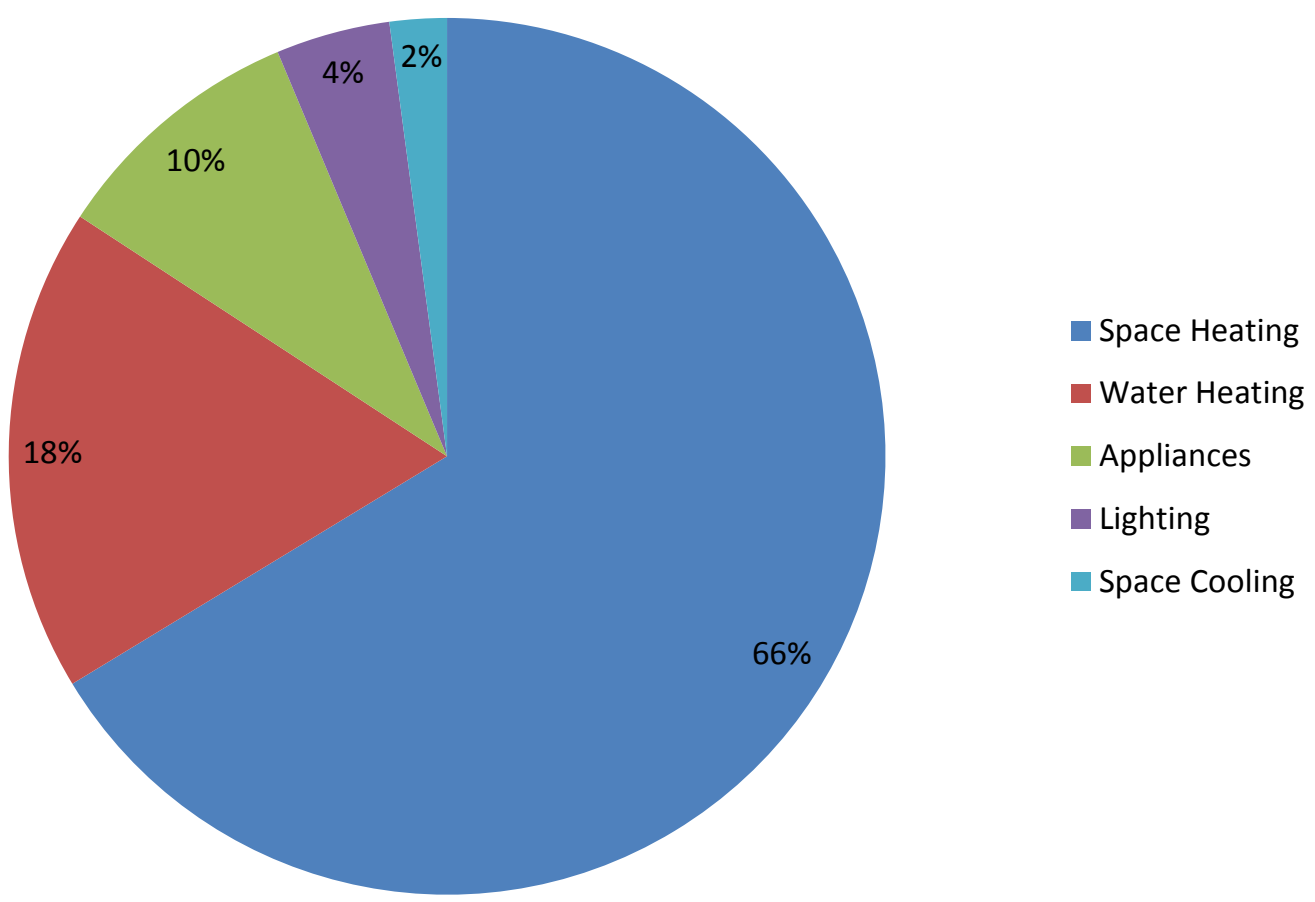

Figure 1-1: Residential Secondary Energy Consumption in Canada in 2012

Some research currently exists on stock HPWH units in North America that provides a good base for the work detailed in this thesis. The National Renewable Energy Laboratory in Golden, Colorado has investigated the performance of several HPWH units in numerous US climates, and found that when used in homes with electrically powered space heating systems, they can reduce energy use with respect to electric water heaters [2]. This includes the cities of Seattle and Chicago, which have similar climates to their nearby Canadian cities such as Vancouver and Toronto. However, studies stating the 
effectiveness of varying HPWH parameters in Canada are scarce. From these findings, a research gap for Canadian studies of HPWH systems was identified.

The goal of this work is to take an existing commercial HPWH and modify the controls to determine if changes can be made to improve performance in cold climates. To extend the results over several conditions, a model was developed in TRNSYS (TRaNsient SYstem Simulation) using experimental results. The TRNSYS program is a software simulation environment that can model thermal energy systems and components using numerical methods [8], and solves for all outputs simultaneously with each time step using a solver engine. The TRNSYS results were acquired using an experimental setup to simulate daily draw profiles from the Canadian Standards Association as per CSA-F379.1, the standard for packaged domestic hot water systems [9]. Under a series of different test conditions, the performance of the HPWH was characterized and the TRNSYS model was calibrated using experimental data for each test run. This model was then parametrically optimized in GenOpt (Generic Optimization Tool) using the hybrid particle swarm optimization (PSO) and Hooke-Jeeves methods to determine the optimal physical parameters with respect to energy consumption for the system under a series of different conditions. Results suggest that HPWH performance for indoor packaged air source HPWH units is not significantly affected by outdoor climate conditions. A larger emphasis is placed on the ratio of electrical and heating utility rates, because the heating energy is partially drawn from the indoor space where the HPWH is located. Taking that into consideration, it was found that HPWH technology can be a viable solution with respect to energy in Canada when the ratio of energy cost of heating and electrical energy is closest to the average coefficient of performance (COP) of the unit. 


\subsection{Domestic Water Heating}

Twenty percent of the domestic hot water heating systems found in Canadian homes are classified as having an electric energy source, as shown in Figure 1-2 [5]. These water heating units require a high grade of energy, and as a result of high electricity prices (relative to natural gas per unit of energy), have trended downward in use over the last 25 years. Conversely, water heaters classified as "Other" have seen an increase in usage over the last 12 years, which includes heat pump water heaters. These trends are shown in Figure 1-3.

Natural gas water heaters have the largest market share, and at the time of this research provide the lowest energy cost hot water heating system. The assumed regime of HPWH market expansion is in place of existing electric units, where the life cycle cost has been proven to be competitive in the USA [10].

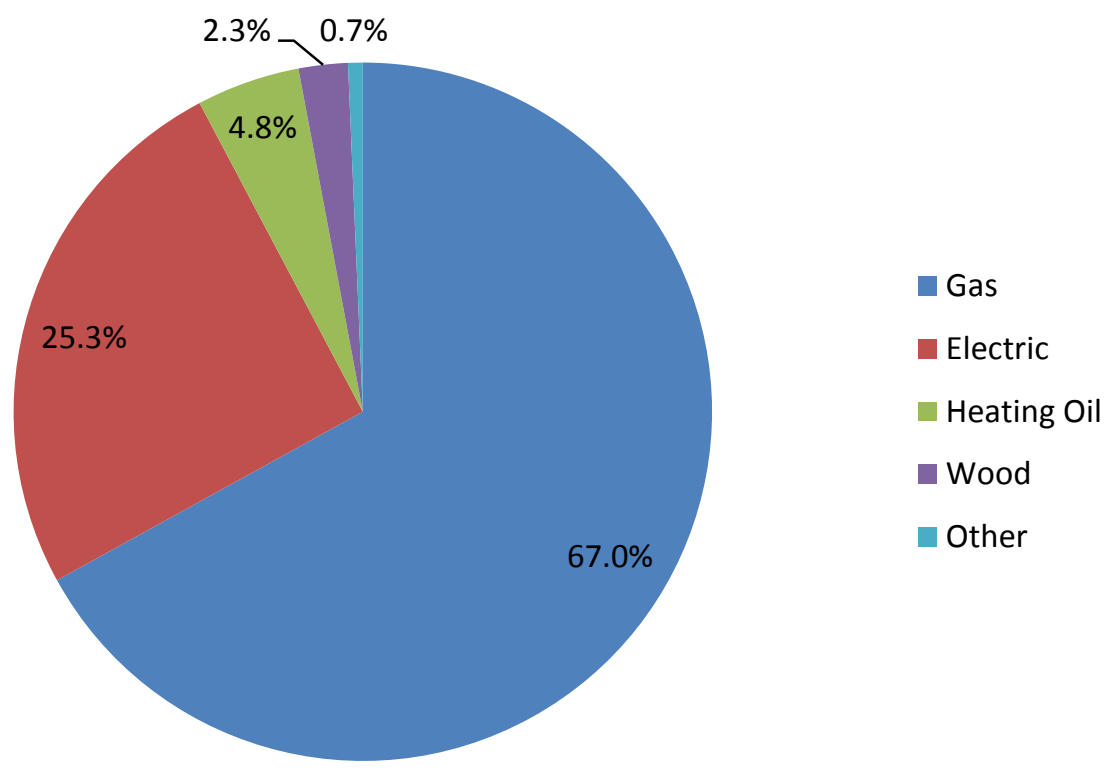

Figure 1-2: Domestic Water Heater Market Share in Canada in 2012 [5] 

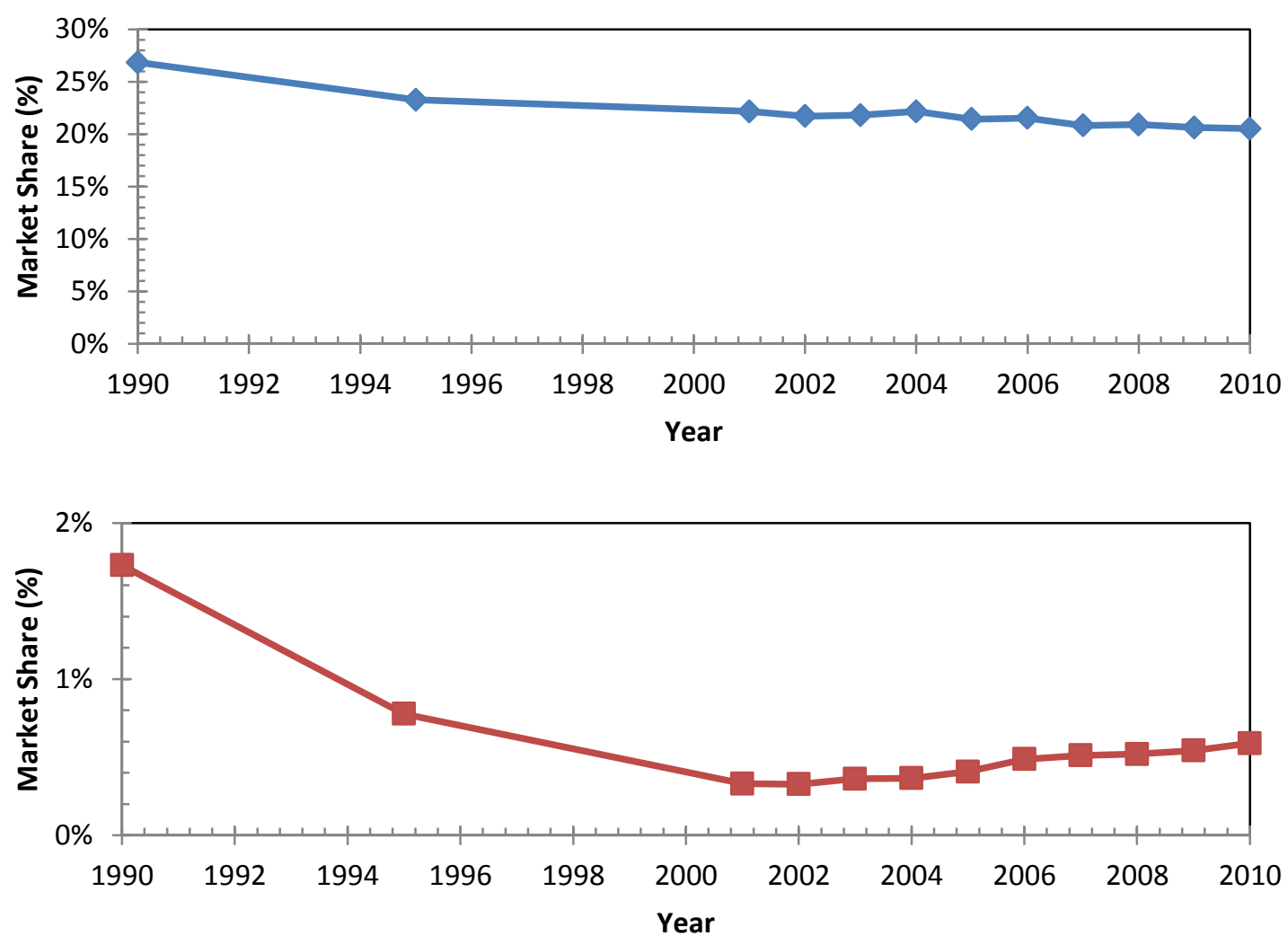

Figure 1-3: Market Share by Year for Water Heaters - (Top) Electrical (Bottom) Other [11]

Purely electric water heaters are unlikely to be phased out due to the lack of alternative utilities in remote regions of Canada, and given recent trends, are generally undesirable due to their high energy cost. This provides a relevant niche for HPWH technology to serve if proven to be less energy intensive than standard electric water heating. As with any energy-using equipment, the payback period for HPWH units will decrease as utility prices increase, which could provide opportunities for implementation in locations with high electricity prices and significant electric water heater usage such as the Canadian North.

While water heating is not the largest end use in Canada, the packaged nature of standard units provides the ability to easily install complex systems. Unlike advanced 
heating and cooling systems, usually only one piece of equipment needs to be installed and maintained, and likely minimal retrofitting beyond the unit itself and some minor plumbing augmentation is required. Additionally, advanced control systems are not a requirement to interface with most packaged water heating units. In the case of the unit tested in this thesis, only the booster heater and heat pump set-points needed to be set via a set of potentiometers in the stock configuration, as shown in Figure 1-4.

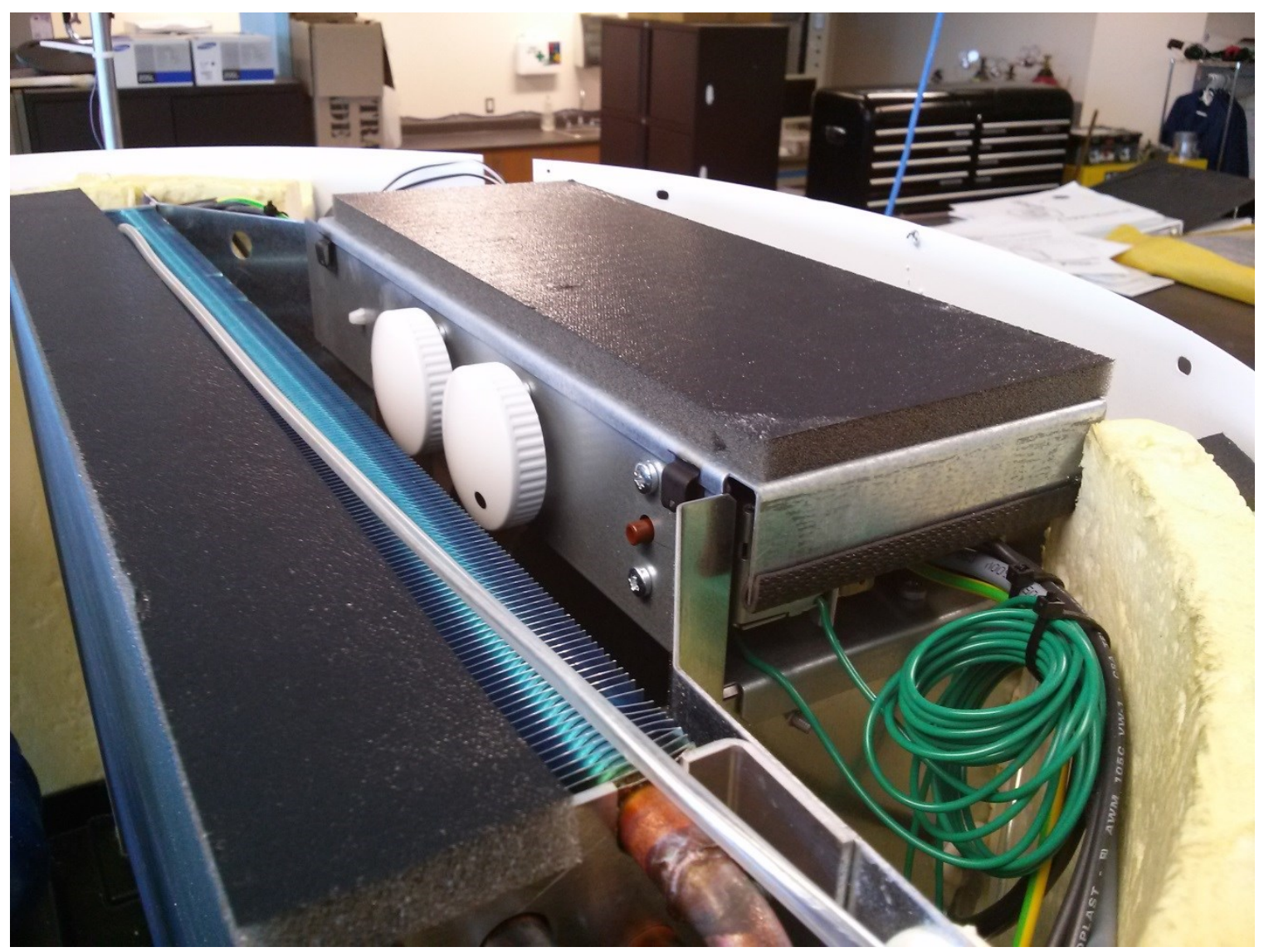

Figure 1-4: Stock Controls for the Heat Pump Water Heater

An important aspect of this work was to determine geographical regions that could see the greatest benefit from implementing HPWH technology in a standalone basement installation for domestic hot water (DHW). As such, utility prices for major 
Canadian cities were obtained for the most common and second most common hot water heating utilities (as defined by Natural Resources Canada) and tabulated in Table 4-2 [5]. These data were then used with the open source optimization software GenOpt [12] to determine the Canadian city that would be most suitable to support a standalone installation.

Further analysis of heat pump water heaters using unique control configurations could be of benefit as well. Some research has already been done on HPWH technology in the US, but it has been largely limited to stock packaged units with favorable results in warm, humid climates. Extension of the model and experimental setup in this work could be beneficial to modify control strategies for better performance in regions throughout North America, including the small existing market of HPWH in the US shown in Figure 1-5 [2].

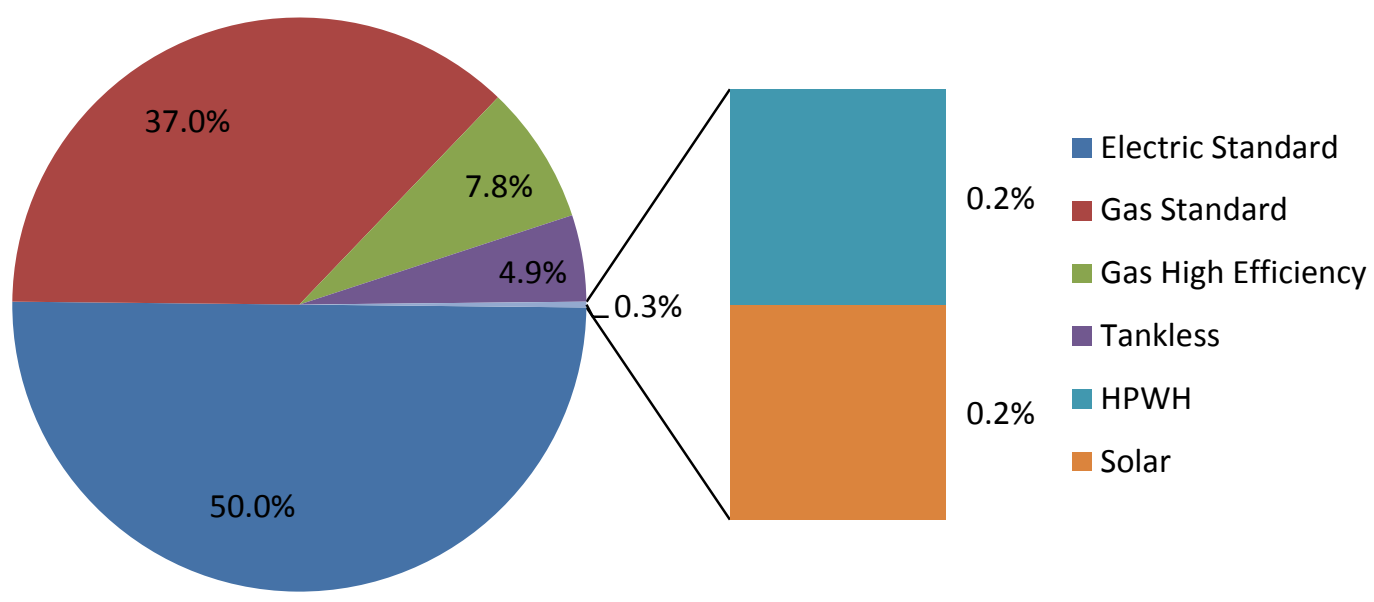

Figure 1-5: Domestic Water Heater Market Share in the USA in 2010 


\subsection{Heat Pump Water Heater Test Apparatus}

The use of an experimental test apparatus is pivotal to accurately observing and modelling the phenomena present in hot water heating. Simulation is an excellent tool to determine relative performance of equipment in a cost effective manner, but unforeseen physical phenomena are likely to be missed if this is the sole analysis technique. For this reason, a robust draw testing apparatus was designed to interface with a HPWH unit.

Standard compliance was identified as a key requirement, and CSA-F379.1 was identified as the most relevant draw standard to adhere with for this research. This standard was based upon having a flow rate of $11.5 \mathrm{~L} / \mathrm{min}$ at the outlet of the tank when the drain is active, and to draw predefined water volumes at intervals and quantities that varied with respect to assumed dwelling size. Typical daily volumes were $150 \mathrm{~L}, 225 \mathrm{~L}$, and $300 \mathrm{~L}$ for occupancies of 1-2, 2-4, and 5+ respectively, and were represented by Schedules A, B, and C [9].

An experimental setup was constructed that could automate the draw profiles, and control the HPWH set-points. While using apparatus for this purpose is fairly common, this particular installation was designed for robust operation and draw profiles, and the ability to integrate with other lab equipment for future coupling arrangements. The future addition of an air side tempering system would significantly improve the range of testing and consistency between testing different heat pump conditions.

\subsection{Research Objectives}

The overall goal of the research presented in this thesis is to evaluate the performance of a commercial HPWH unit, and to determine its suitability for Canadian regions based on 
experimental and simulation results. To meet these goals, the research had the following objectives which are presented within this thesis:

- Design an experimental test apparatus to monitor a domestic heat pump water heater over extended periods while maintaining consistent conditions;

- Design a draw system to automatically simulate a variety of draw profiles;

- Design and size system components to be installed in the experimental setup;

- Construct the heating and draw systems within a laboratory and install and test the equipment;

- Install and program the data acquisition and control system;

- Install the necessary instrumentation to monitor the test apparatus;

- Calibrate the instrumentation and determine the uncertainty of the coefficient of performance (COP) and energy use measurements;

- Develop a TRNSYS model of the experimental apparatus to model the performance of the HPWH and extend the experimental data set over regimes that would take significant time to test; and

- Implement GenOpt optimization routines to determine recommended operating conditions.

This work is the first phase in a multi-year project to determine the feasibility of heat pump water heater systems in Canada. Future work will include different configurations and control settings to simulate unique charging strategies and outdoor air side conditions. 


\subsection{Contribution to Research}

This work contributed the following:

1. Design, construction, and instrumentation of a complete experimental testing apparatus to determine the energy performance of a commercial HPWH unit.

2. Determination of the energy performance of the HPWH through both experimentation and simulation.

3. Determination of the optimal operating points for the unit based on set-points and local utility rates.

\subsection{Organization of Research}

The information outlined in this thesis documents research that has been conducted over the last two years, and is divided into the following chapters:

Chapter 1 - Introduction: An introduction of water heating technologies, test apparatus, and an outline of the thesis.

Chapter 2 - Literature Review: A review of literature on domestic hot water heating, heat pumps, alternative water heating strategies, TRNSYS models of similar systems, and GenOpt.

Chapter 3 - Experimental Design: A detailed description of the test apparatus and a description of the components installed.

Chapter 4 - System Modelling: An outline of how the model was constructed in TRNSYS, calibrated to the experimental data, and optimized using GenOpt.

Chapter 5 - Results: A summary of the experimental, modelling, and optimization studies. 
Chapter 6 - Discussion: A discussion of the applications of HPWH technology in Canada based on the results, and an uncertainty analysis.

Chapter 7 - Conclusion and Future Work: A summary of the findings from this thesis and an outline of future direction for the work. 


\section{Chapter: Literature Review}

Heat pump water heater units have been commercially available in North America since the 1950s, and have been widely used in Asia over the last few decades [1]. Despite noted incremental efficiency over more common water heater designs [2] [10] [13], HPWH units have not been able to capture more than $1 \%$ of the water heater market in North America [2] [3]. Additionally, the United States government has recently mandated that all electric water heaters over 55 gallons (210 liters) have an energy factor greater than unity to make HPWHs part of energy regulation [14]. Energy Factors are defined as the quotient of the thermal energy added to the water tank over a day, and the energy added to the tank from the fuel source (e.g. electricity for electric water heaters, and natural gas for natural gas water heaters). Different energy factors are prescribed for different hot water tank sizes and types. Due to Canada's close relationship with the United States, it is likely that NRCan would follow suit if the technology can prove viable in colder climates. Maguire et al. identified the feasibility of HPWHs in several American climates through examining the performance and economic factors of several different models, and have overlaid the data on geographical maps [10] [13]. Permission was granted by Jeff Maguire to reference the figures from his publications in this thesis [15].

Literature relevant to HPWHs was reviewed as part of this study, with a focus on the following: domestic hot water usage, heat pumps, alternative energy water heating, TRNSYS studies, and the GenOpt tool. 


\subsection{Domestic Hot Water and Heat Pump Water Heaters}

Domestic hot water accounts for roughly $17 \%$ of total secondary energy consumption in the residential sector [5]. It is second only to space heating, which accounts for $63 \%$. In order to accurately account for domestic hot water loads, significant investigation of domestic hot water draw profiles and heating strategies was executed.

Dickinson [16] investigated different draw strategies for a multi tank solar domestic hot water system. He used CSA F379.1 standard for draw profiles, and applied them to different tank configurations and operating strategies. Significant analysis was undertaken on the effects of stratification on a thermal energy storage system, and demonstrated the importance of minimizing high flow rates that can disturb stratification. Further analysis of different discharge configurations is described in Dickinson et al..

Rating the performance of domestic hot water heaters is also of significant importance. Morrison et al. have done significant work in the area of performance characterization and modeling of HPWHs [17]. Initial TRNSYS models of wrap-around coil HPWH units were developed by Morrison in 1994 that can be adapted for current versions of TRNSYS with equipment code modifications [18].

The National Renewable Energy Laboratory, located in Golden, Colorado, has also conducted research with regards to HPWH units. Jeff Maguire et al. compared many different domestic hot water technologies over different climates in the United States including: gas storage, gas tankless, condensing storage, electric storage, heat pump, and solar water heaters [2]. Units were divided into groups of gas and electric water heaters, and found that for the majority of climates solar gas and solar electric had the lowest source energy usage, respectively. Due to the importance of economic factors, life cycle 
costs were also assessed for each technology. Maguire et al. found that relative to other water heating technologies, and in the absence of incentives, gas storage and HPWH units were dominant in minimizing energy use over most climates in the United States [10] [2]. In particular, HPWH units use the least energy in instances where they will see mid to high water daily water volume draws [2], such as with CSA-F379.1 Schedules B or $\mathrm{C}$.

Maguire identified that the wet bulb temperature had the largest impact on HPWH unit energy performance [13]. The wet bulb temperature performance is due to the latent energy in the air that can be removed during a dehumidification process. For this reason, HPWH located in humid southern climates had the best performance and lowest life cycle cost. Utility rates also had a large effect on the economics of a HPWH. A key contribution of Maguire et al. was geographical overlays of HPWH performance information for the United States. Figure 2-1 demonstrates the performance of HPWH units over all United States climates:
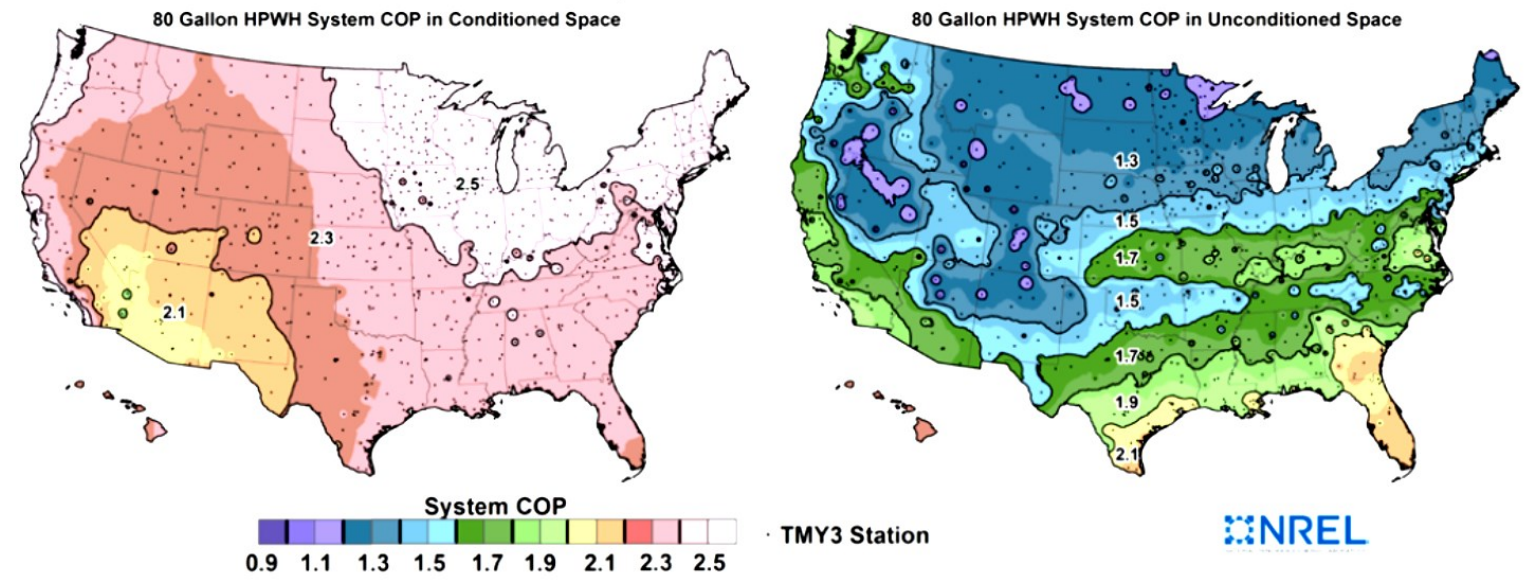

Figure 2-1: HPWH COP for All United States Climates [13] 


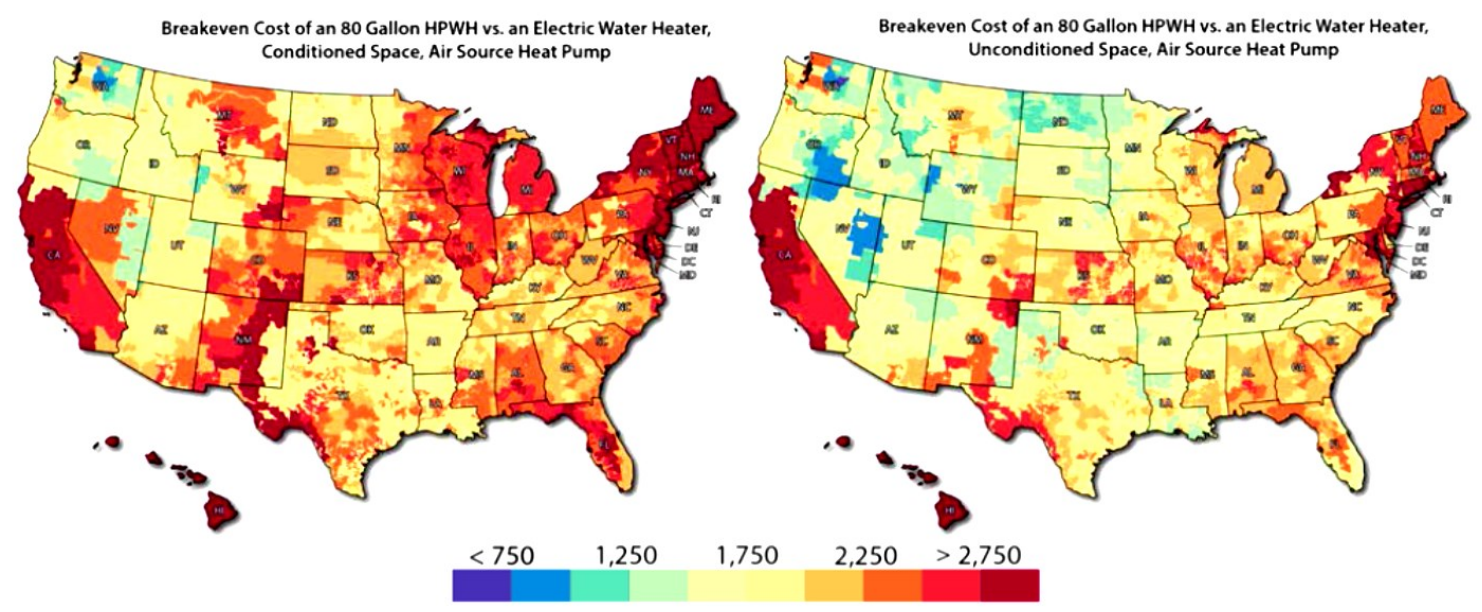

Figure 2-2: HPWH Breakeven Cost for All United States Climates [13]

In Figure 2-1, the lighter colors represent higher heat pump energy performance.

It is clear that the heat pump will have a better COP in warmer environments, and this is demonstrated by the improved performance in southern climates and conditioned spaces. Figure 2-2 shows the breakeven costs for purchasing a HPWH unit, where the higher the breakeven costs, the more justifiable the technology choice. Cooler climates or ones with inexpensive electricity are in the less effective portion of the diagram where the breakeven cost is below $\$ 1000$. Meanwhile, other regions such as the Northeastern seaboard and coastal California have high breakeven costs, and could likely justify the purchase of a HPWH unit as an energy efficient water heating alternative.

\subsection{Heat Pumps}

Heat pumps (HP) are chosen as heat sources because of their ability to efficiently transfer heat from one space to another. Gou et al. found ways to optimize the heat pump operation in a HPWH. They identified the following parameters can have a significant effect on HPWH performance: refrigerant, system architecture, ambient temperatures, 
and water temperatures [19]. Due to the lack of flexibility in refrigerant and system architecture, Gou et el. primarily varied the ambient temperature and water temperatures using an environmental chamber to simulate the Shanghai climate. Gou et el. found that the COP could vary from 2.82 to 5.51 depending on the season and time of day [19].

Groff provided market analysis figures in his report on heat pumps in North America [20]. Market penetration of heat pumps has increased over the last decade. Currently they are commercially available in sizes up to $220 \mathrm{~kW}$, but largely are specified for residential applications [20]. The potential of HPWH market growth is demonstrated by the manufacturer diversity that has been generated over the last 15 years. Also notable is the 1600 percent growth in HPWH sales from 2006 to 2012 within North America $[20]$.

Another climate that has been investigated with HPWH technology is Athens, Greece. Panaras et al. simulated a solar assisted HPWH system, and found that up to $70 \%$ energy savings can be achieved in warm climates [21]. It was also found that HPWH systems are less energy efficient than solar thermal systems, but that is without taking the capital costs and utility prices into account. Additionally, the importance of carefully choosing heat pump and electric backup heater set-points is highlighted [21].

Bourke and Bansal modeled HPWH units in the New Zealand climate to determine their validity when compared to the New Zealand standard NZS 4234 for hot water heater performance testing. It was found that there was a $12 \%$ discrepancy between the referenced standard and alternate methods of performance calculation [22]. Additionally, with modified hot water draw profiles, it was found that solar thermal water heating systems were not optimal in New Zealand because of the large volume of 
unusable water in the lower portion of a stratified tank. This low temperature region could also be a potential source of legionella. Furthermore, Bourke and Bansal found that air source heat pumps would have better energy performance in temperate coastal climates than in the hot New Zealand climate [22].

Further emphasis of the importance of climate when considering HPWH technology is given by Aye et al. through their comparative analysis of thermosyphons, air source heat pump water heaters, and solar assisted heat pump water heaters in several Australian cities [23]. Aye et al. identified that thermosyphons could have better energy efficiency than air source heat pump water heater for very hot climates, but for more moderate Australian conditions a HPWH is recommended.

The policy implications of water heater efficiency also need to be considered in a comprehensive analysis. Lloyd et al. introduced the concept of energy security, and the importance of conveying information effectively to the policy makers [24]. Solar fraction (percent of the time that solar energy can provide sufficient power to the hot water system) and COP are also introduced as metrics to determine heat pump performance. It was also identified that there was limited literature on experimental performance of HPWH units, and the data that did exist saw significant discrepancy between lab and in situ performance.

Chu designed and tested a solar assisted heat pump system to highlight the sensitivity of many advanced heat pump system parameters such as COP, flow rate, and heat pump capacity to system design parameters [25]. The importance of efficient thermal stratification was also noted. Additionally, the thoroughness of the TRNSYS 
modelling in her work provides a framework for the design of complex heat pump driven systems.

The Florida Solar Energy Center has expressed interest in domestic hot water heater performance comparisons since the early 1990's, with Merrigan and Parker's report comparing electric resistance, heat pump, desuperheater, and solar thermal systems [26]. The significant difference in utility prices and capital costs from 1990 to 2014 highlights the emphasis that is being placed on efficient water heating. Merrigan and Parker found that solar thermal systems were the best at peak demand reduction, while HPWH systems were a close second in the Florida climate [26].

Life cycle analysis is one of the most comprehensive methods to determine heat pump performance using long term operational savings as demonstrated by Beshr et al. [27]. As a result, a lifecycle performance technique was developed for air source heat pumps based on climate conditions. Beshr et al. used typical meteorological year version 3 (TMY3) data to define the climate conditions for each region simulated because of its open availability and weather period relevance. Typical meteorological year 3 data takes the most typical weather data for a location from the time span of 1976 to 2005. The tool accounted for several sources of emissions to minimize the GHG footprint of heating equipment.

\subsection{Alternative Energy and Time of Use Strategies}

Coupling HPWH technology with other alternative water heating sources may improve energy performance in the heating season for indoor installations. While an investigation was not executed in this thesis, future work may yield results that improve 
the feasibility of packaged systems in Canada. As such, a review of relevant alternative energies and strategies was conducted.

Solar driven provides an alternative to fossil fuels. However, as with any technology that has a capacity factor (quotient of average output over maximum output) significantly lower than parity, accommodations must be made to reduce energy use when availability is limited. This demonstrated the important link between solar technology and time of use strategies to either feed thermal storage or target peak energy shaving [28].

With regard to photovoltaics (PV), a surplus of low grade silicon from computer manufacturing waste has improved mass production [29]. In the early 1990's prices for PV modules were as high as $\$ 10$ per watt [30] which largely rendered them not economically feasible for most applications. Prices gradually reduced over the next decade to the point where they were priced at roughly $\$ 4$ per watt in 2008 [29]. The global recession of 2009 increased competition and drove the cost of PV down 50\% [29]. Further price reductions can be seen through outsourcing to Chinese produced modules, which are currently priced at roughly $\$ 1$ per watt [29]. Competition within the PV industry has reduced module cost for many applications, including some heat pump systems. The importance of energy security, as highlighted in Lloyd et al., provides additional motivation for efficient PV powered systems [24].

Genkinger et al. evaluated the economic feasibility and environmental impact of simulated solar and PV assisted air source heat pump units. For the Swiss climate, it was found that PV and solar thermal technology had roughly the same economic and environmental feasibility [31]. Primary factors were determined to be the mild climate, 
shipping costs, and utility prices. These factors can significantly vary the results of life cycle analysis as used in Genkinger et al. [31].

Climate based solar thermal coupling with heat pump water heaters has been evaluated in the Mediterranean due to their warm climate with relatively high insolation. Panaras et al. have performed such an analysis for the Greek climate using a component modelling approach. They found this hydronic coupled combination proved to reduce DHW energy consumption by up to $70 \%$ [21]. Set-points of the system had a significant effect on the overall efficiency of the system. The coupling of solar thermal to the system was determined to also reduce the use of the auxiliary resistance heater.

Solar thermal technology is popular in areas with high insolation. ClearSky Advisors conducted an evaluation with regard to the current state of solar thermal technology in Canada [11]. According to their figures, the solar thermal industry is seeing a plateau or even a possible contraction with diminishing sales dating back to 2010 [11]. This was attributed to the rise of PV technology during this timeframe due to the feed in tariff program in Ontario and the high capital costs associated with solar thermal systems. Currently most of the revenue generated from solar thermal exports is from evacuated tube module shipments to China [11]. In Canada, glazed flat plate collectors are the most popular, where their application is primarily domestic hot water and pool heating systems due to their modularity [11].

Luukkonen et al. conducted a survey of PV applications in Canada for 2012. It was found that PV module prices have been steadily decreasing over the last decade, and Canadian producers have experienced economic growth [32]. Despite significant outsourcing to Asia (largely due to lower module production costs than could be achieved 
in Canada), the PV industry as a whole has seen growth. While a large portion may have been from policy stimulus such at MicroFIT, the interest in PV for cold climates has also been supported [32].

Weiss and Mauthner provided an assessment of the international solar thermal market. Data was collected from 55 countries that totaled roughly two thirds of the world's population and over $90 \%$ of the global solar thermal market [33]. The current growth may be attributed to Chinese developments, for which the demand is largely evacuated tube collectors. China is responsible for the majority of world energy growth, and tends to skew the results in most cases. It is noted that China's solar thermal capacity is eight times the capacity of the next largest market, the United States [33]. According to the report, Canada does not even rank in the top 10 worldwide of installed capacity. Additionally, markets that have seen significant solar thermal popularity in the past, namely Australia and Europe, are seeing market contraction as of the 2009/2010 fiscal year [33].

Cost optimization of photovoltaic systems is important when coupling with any electrical system. Ren et al. analyzed parameters that can be modified to correctly size PV arrays for the best economic performance. Several equations are solved simultaneously using a customized program to arrive at the desired capacity for a respective building load. Additionally, Athena, an economics analysis program [34], was used to acquire life cycle data for the materials involved in the production and installation of the modules. Ren et al. found that optimal capacity was a function of the following variables: capital cost, interest rate, systems efficiency, and electricity sale rate [34]. 
$\mathrm{Li}$ and Yang highlighted the importance of accurate analysis of solar irradiation characteristics when integrating solar technology was highlighted. Their analysis of a solar assisted HPWH system included a preheat tank to condition the water for the Hong Kong climate. The indirect heat pump system analyzed performed proportionally with increasing collector area, and inversely with increasing water delivery temperature [35]. The importance of minimizing the storage temperature was also highlighted. Correct use of tilt angle was important.

Sterling and Collins [36], as well as Chu [25], have analyzed solar assisted heat pumps, that is, systems where the evaporator of the HPWH is connected to a solar collector to boost performance by raising the heat source temperature. Both studies used TRNSYS to simulate the performance of an indirect solar assisted heat pump system, and Chu conducted experimental tests to determine the accuracy of the TRNSYS model. Sterling and Collins found that solar assisted systems could greatly reduce the overall electrical demand of a water heating system relative to a standard electric resistance system [36]. Chu conducted a sensitivity analysis with the TRNSYS model, and found the optimal values for the construction of the experimental apparatus through a sensitivity analysis of the free energy fraction. In this case, a free energy fraction, or portion of energy that is collected from the sun and not supplied by utilities, of over $50 \%$ could be obtained [25]. Both studies found that sizing the heat pump correctly was the most sensitive factors on economics and total energy consumption. 


\section{$2.4 \quad$ TRNSYS}

Effective experiments require careful modelling to determine appropriate input parameters. The TRNSYS software has been the tool of choice for modelling hydronic systems as far back as the early 1990's [18] [37]. This is supported by Morrison's extensive work with solar heat pump water heater models in that time frame [18]. Further work with TRNSYS modelling of solar thermal systems has been more recently performed by Baldwin [38], Dickinson [16], and Cruickshank [39]. Although the terminal hydronic equipment varies in their cases, the solar input is of the same format.

The hot Australian climate provides significant motivation for Morrison's research on solar assisted HPWHs [37]. Some work in 1994 included modelling a HPWH with a wrap-around coil condenser to characterize the difference in performance from different configurations [18]. This simulation was done in TRNSYS 15 using code based object formatting. Modifications to TRNSYS Type 38 (plug flow tank) were used to accurately model the HPWH configuration [37]. Further work from Morrison included the development and maintenance of TRNAUS, a series of extensions for TRNSYS that could be used for solar water heating [40]. It is notable that the extensions were developed for Australian climates, so it is possible that they may not be fully adaptable to all climates in their current form.

Baldwin developed a TRNSYS model to demonstrate the efficiency of solar absorption chilling [38]. In this work, a solar thermal collector system is tied to a Climatewell absorption chiller to simulate the charging and discharging cycles. Additional work by Baldwin included the detailed design and construction of a test 
apparatus for the Climatewell unit [38]. The methodology demonstrated in this work is applicable to instrumentation and hydronic related projects.

Cruickshank investigated the stratification of an identical system, and found that there was a strong correlation between minimizing the heated region and overall system thermal performance [39]. Apart from the importance of the discharge profile in a standard DHW system, the charging flow rates were determined to be similarly critical to system performance. Dickinson investigated the charging and discharging of a multi-tank solar thermal DHW system, and the importance of different draw profiles [41]. In both cases, TRNSYS modelling determined the variables of highest sensitivity for further testing.

\subsection{GenOpt}

GenOpt is a generic optimization tool developed at Lawrence Berkeley National Laboratory for the purpose of optimizing user-defined objective functions using external programs with an open source approach [12]. Through this software, deterministic and heuristic approaches are available to improve the efficiency of combinatory testing using independent variables. These iterative simulations cover a large number of test cases with a large number of input parameters. Further detail of the mathematics behind all of the methods used by GenOpt can be found in the GenOpt user manual by Wetter [12].

Peeters et al. used GenOpt to solve an optimization problem for a simulation in ESP-r using a hybrid of the particle swarm optimization (PSO) and Hooke-Jeeves coordinate search techniques [42]. ESP-r is a building simulation program that is maintained through the user community [43]. The PSO technique is described as being 
effective at locating global minima with the help of social behavior algorithms based on stochastic functions, while the Hooke-Jeeves technique is more effective at finding local minima because it is constantly averaging. For visualization purposes, the PSO technique is based on the motion of a flock of birds (as far as including social and cognitive acceleration variables), while the Hooke-Jeeves technique is based on rectilinear acceleration. Both of these techniques are limited in determining the absolute minimum because the purpose of optimization is to reduce the number of iterations necessary. As such, the entire sample space cannot be explored to verify the solution. Scaling the problem from a smaller sample space where the solution can be confirmed mitigates this problem.

Further detail on the Hooke-Jeeves technique is given in a text by Chinneck that outlines several optimization techniques [44]. Similar to a coordinate search, the HookeJeeves technique moves in a grid fashion through the input parameters. It uses both large pattern moves, and more refined exploratory searches to determine the gradient toward the minimum of the output function. A noted difference between a standard coordinate search and Hooke-Jeeves is the acceleration factor, which permits a degree of "overshoot" on the input parameters to decrease the amount of time required to reach the minimum. This was found to generally decrease the amount of simulation time required to find the optimal output function value. 


\subsection{Summary}

This chapter presented a thorough analysis of existing literature, and suggests that additional research is necessary on HPWH use in moderate to cold climates. System optimization and identification of favorable regions for HPWH technology could be of value to the research community and Canada as a whole. In particular, the work done by the National Renewable Energy Laboratory (NREL) in Golden, Colorado has provided HPWH energy performance data for American cities in moderately cold climates, which can be compared to the results for some Canadian cities in colder regions. The discovery that HPWHs can be economical when compared to electric resistance heaters in Chicago, Illinois [13] provides a datum for Canadian research. A brief summary of the highlights of this literature review is given in Table 2-1.

Further analysis of parameters such as refrigerant properties could demonstrate the feasibility of different heat pump designs for the colder climates investigated. Additionally, predictive methods for determining water use and energy peaks could provide value to improving system energy efficiency. 


\begin{tabular}{|c|c|}
\hline Authors & Conclusions \\
\hline G. Panaras et al. & $\begin{array}{l}\text { Up to } 70 \% \text { energy savings can be achieved } \\
\text { by using HPWHs in warm climates such as } \\
\text { Athens, Greece. }\end{array}$ \\
\hline A. Genkinger et al. & $\begin{array}{l}\text { Combining HPWH units with PV or solar } \\
\text { thermal will yield roughly the same } \\
\text { economic feasibility in Switzerland (2012). }\end{array}$ \\
\hline J. Guo et al. & $\begin{array}{l}\text { Under proper conditions, favorable HPWH } \\
\text { economic performance can be achieved in } \\
\text { Shanghai, China. }\end{array}$ \\
\hline J. Maguire et al. & $\begin{array}{l}\text { HPWHs can be economically favorable in } \\
\text { many US climates, and in some situations } \\
\text { can even be a cheaper solution than natural } \\
\text { gas. Even colder climates like Chicago and } \\
\text { Seattle see energy savings with a HPWH } \\
\text { relative to a standard electric system. }\end{array}$ \\
\hline L. Peeters et al. & $\begin{array}{l}\text { GenOpt can be used to solve complicated } \\
\text { optimization problems using an open } \\
\text { source approach and numerous inputs. } \\
\text { Hybrid techniques can mitigate the } \\
\text { tendency for stopping at local minima in } \\
\text { nonlinear functions with a large number of } \\
\text { inputs. }\end{array}$ \\
\hline
\end{tabular}




\section{Chapter: Experimental Design}

This chapter provides a detailed description of the experimental apparatus that was designed and built to test the performance of a heat pump water heater. A description and schematic of the system is provided, and further detail is given for the major equipment used in the apparatus. A description of the controls and data acquisition system is also provided, followed by the methodology for calibrating the draw system.

\subsection{Overview of Experimental Setup}

The experimental setup used for this study was designed, constructed and commissioned at Carleton University to characterize the performance of a $300 \mathrm{~L}$ (80 US Gal) HPWH unit intended for residential use. An illustrative diagram of the HPWH is shown in Figure 3-1.

In addition to the HPWH tank, the system studied included the preheat tank, tempering valve, flow meter, and solenoid. To provide greater granularity in operational set-points the factory controls were overridden. A 136 L (30 US Gal) electric hot water tank was used to preheat the water to maintain stable inlet water conditions. At the outlet of the HPWH a water draw system was attached. This system consisted of a tempering valve to ensure the water delivered by the draw was at $55^{\circ} \mathrm{C}$ regardless of the tank temperature (with makeup from the HPWH inlet water line), a flow meter to measure the volume and flow rate of the draw, and a solenoid valve to regulate the volume of the draw. The system was plumbed such that water would first pass through the preheat tank, then through the HPWH for testing, and to the draw assembly where it is discharged to 
the drain. This setup allows consistent but flexible inlet water temperatures, and numerous draw options. Figure 3-2 shows a diagram of the heat pump cycle and system.

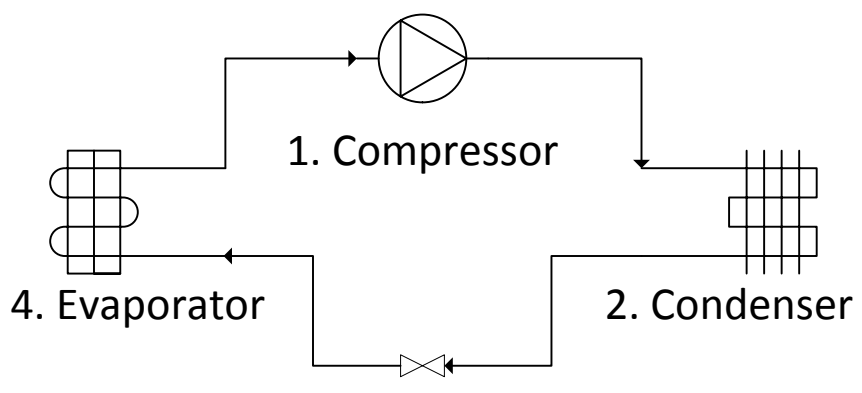

3. Expansion Valve
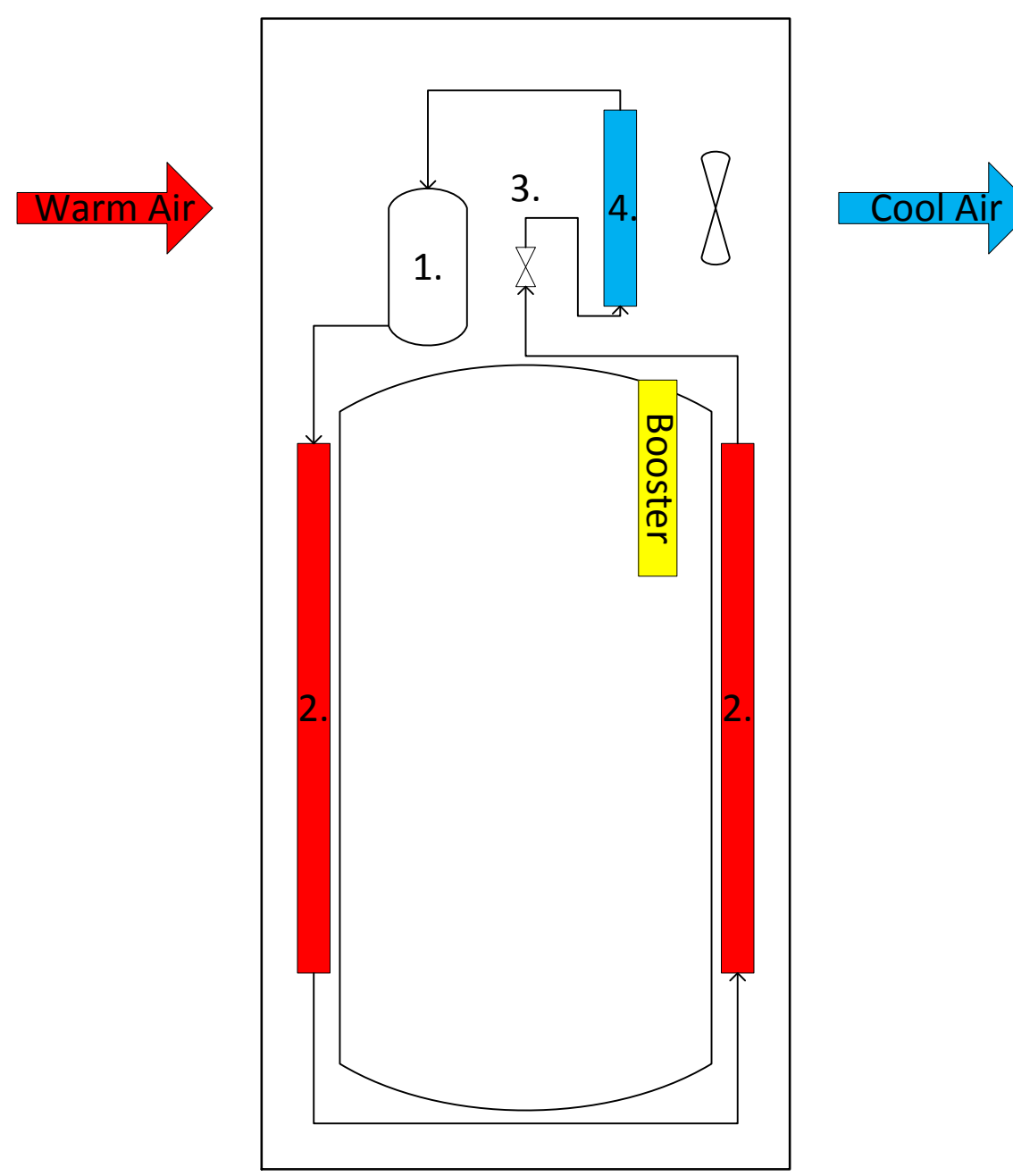

Figure 3-1: HPWH Diagram - (Top) Heat Pump Cycle and (Bottom) Packaged Unit 


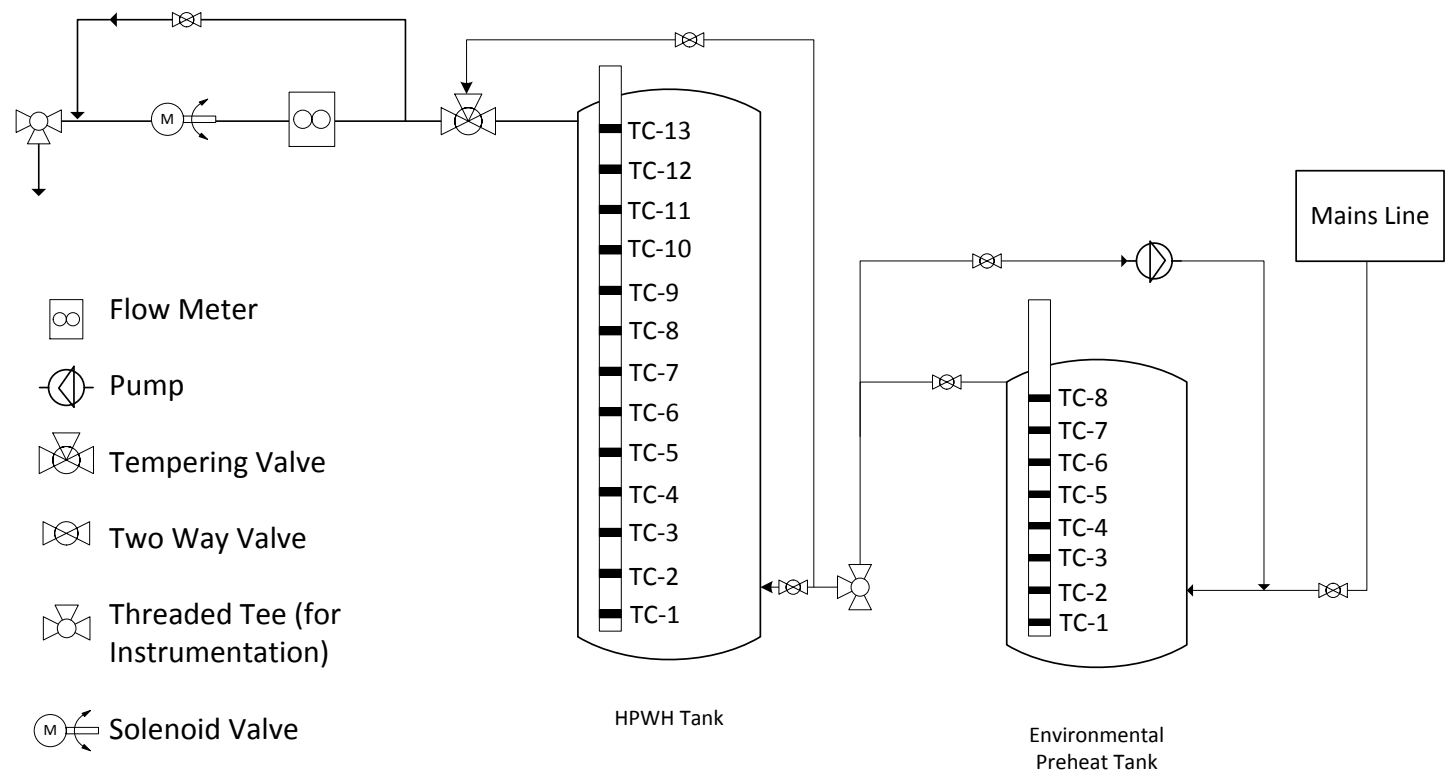

Figure 3-2: System Diagram of Hydronic Components for the HPWH Draw Test Apparatus

Experimental tests were able to simulate a day's worth of water consumption in as little as 13 hours with the smallest draw profile in CSA-F379.1 (Schedule A). Additional time allowed the system to reach steady state after the draw test was complete. The initial tank temperature corresponded with the tank reaching the desired temperature at the setpoint nodes (TC-13 for the booster heater, TC-10 for the heat pump) before the test began. Initial preheat water temperature was set to $26^{\circ} \mathrm{C}$ with a deadband of $0.1^{\circ} \mathrm{C}$ to ensure the mains water was not coming in at a higher temperature to maintain consistent inlet water conditions for the HPWH (temperatures as high as $25^{\circ} \mathrm{C}$ were observed for the mains water during experimental tests). The draws were conducted at a flow rate of 11.5 $\mathrm{L} / \mathrm{min}$ as per CSA-F379.1. Between draws, the tank was allowed to reach the setpoint temperature and stabilize. The mixing and measuring portion is shown in Figure 3-3. 


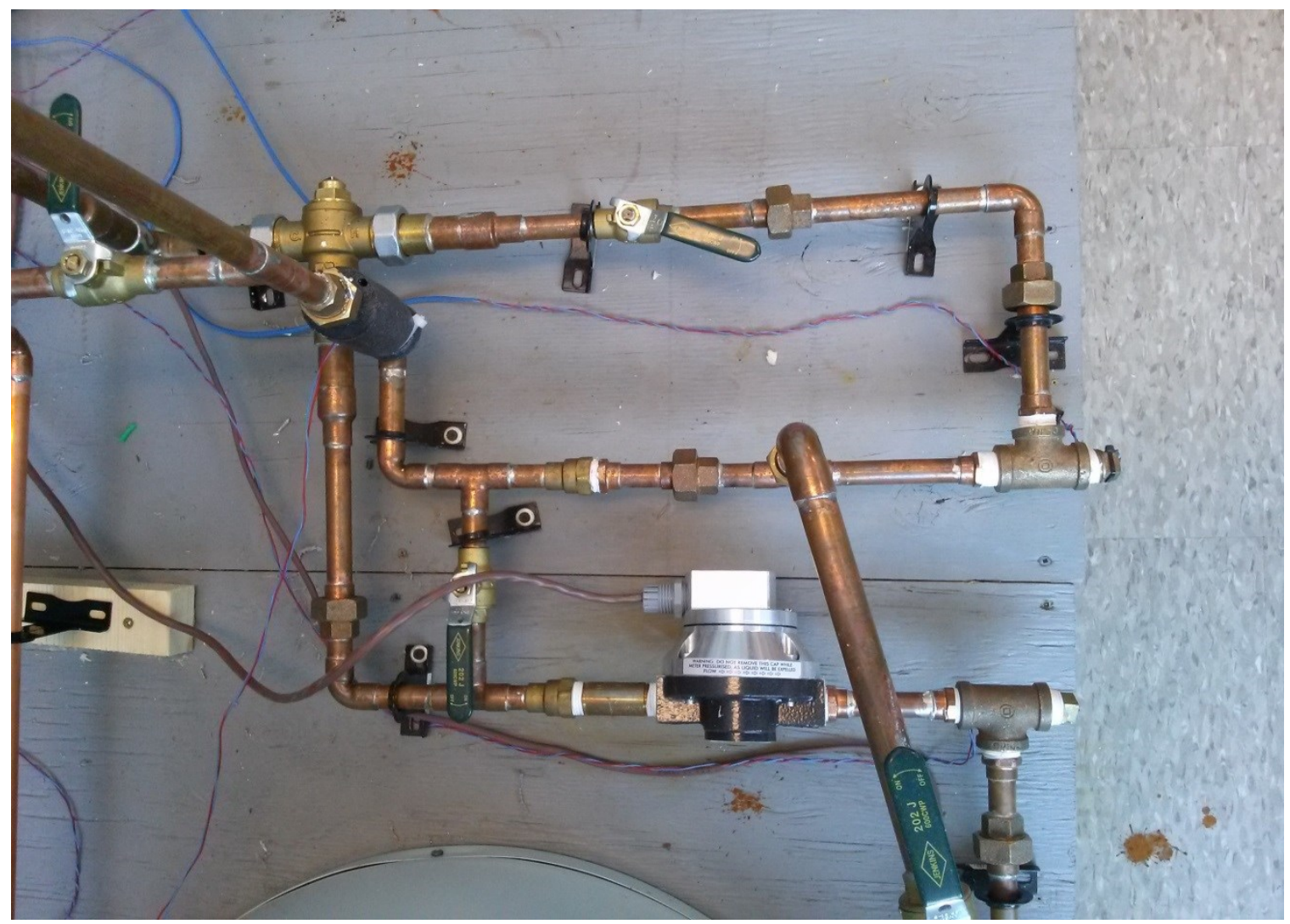

Figure 3-3: Mixing and Measuring Portion of Draw System

A Laboratory Virtual Instrument Engineering Workbench (LabVIEW) program [45] was selected for the data acquisition system due to the availability and interoperability with existing systems within the laboratory. The LabVIEW program initiated the first draw at the beginning of the test (Hour 7), and monitored all data points until several hours after the final draw. The LabVIEW data acquisition system had a sample interval of 30 seconds to match the Greeneye power monitor system minimum.

The CSA-F379.1 draw profiles programmed into the draw graphical user interface by volume and time after test initiation. The interface could accommodate up to 48 draws at variable time intervals. Once the previously mentioned fields were input, and an output file name was chosen, simply running the LabVIEW VI would start the test. By design, 
the draw profile program could run autonomously until completion. This provided flexibility for running chains of draw profiles over extended periods of time.

Draws would continue at the volumes and intervals entered into the LabVIEW graphical user interface, and the HPWH would activate as necessary to meet the defined set-point and node conditions. Measurements of tank temperatures were obtained via thermocouples at the water inlet, water outlet, air inlet grid, air outlet grid and vertical stratification probe as per Figure 3-2. The vertical stratification probe consists of a series of vertically stacked and evenly spaced thermocouple to measure temperatures at different vertical depths within the tank.

These readings were then collected with the power monitoring readings of the tank, and used to determine thermal and electrical performance. Further details of this system are discussed in the sections that follow.

\subsubsection{HPWH System}

The apparatus was fully instrumented with Type $\mathrm{T}$ thermocouples to measure the temperature of the HPWH tank at 13 equally spaced $0.1 \mathrm{~m}$ intervals over the tank height of $1.4 \mathrm{~m}$ as per Figure 3-2, leaving a $0.05 \mathrm{~m}$ space between the tank wall and the nearest measuring point. Eight thermocouples were also placed at equal $0.1 \mathrm{~m}$ intervals in the preheat tank to determine if the tank is at a uniform temperature to make up for the water draw. A mixing pump was plumbed from the outlet of the preheat tank to the inlet to prevent stratification. Additional thermocouples were placed at the HPWH tank inlet, outlet, and after the mixing valve. To measure the air temperatures on the HPWH, an array of 5 thermocouples were placed in an " $\mathrm{X}$ " configuration at both the air inlet and 
outlet to determine the average temperature at both sides of the air stream. Power monitoring of the equipment in the HPWH was enabled through the use of a Greeneye Monitor system [46]. This system used a series of current transducers and a conversion factor to determine the energy consumption at a 30 second sampling interval.

The HPWH controls were overridden by replacing the potentiometer controlled thermostats with relays, and control was facilitated by a National Instruments microcontroller via the LabVIEW interface [45]. This same controller and interface combination was used for the data acquisition of the thermocouples and flow meters. To maintain tank temperature, an input node, set-point temperature, and deadband were specified for both the heat pump and the booster heater. Excessive equipment oscillation, which can cause additional equipment wear, is prevented by using a hysteresis loop in the code. Although it is beyond the scope of this thesis, additional conditions can also be placed on the experimental apparatus to limit the equipment demand based on the hour of the test, which facilitates peak shaving and solar availability testing.

\subsubsection{Draw System}

Hot water draws on the HPWH adhere to CSA-F379.1 requirements, the standard for Domestic Hot Water Systems [9]. This standard includes 3 different typical draw profiles that have been characterized through extensive field study. Schedule A is specified for 1-2 occupants (150 L/day), Schedule B is specified for 3-4 occupants (225 L/day), and Schedule $\mathrm{C}$ is specified for $5+$ occupants $(300 \mathrm{~L} /$ day). The most appropriate draws for a HPWH unit of the size tested in this study (300 L) would be Schedules B and C to prevent oversized testing. However, there is still merit in using 
Schedule A to help with model calibration and to expedite testing due to the 2 hour shorter test run time. The draw profiles considered in this study are detailed in Table 3-1, which is arranged by the hour of the day, and draw volume for the respective schedule.

Table 3-1: CSA-F379.1 DHW Draw Schedules

\begin{tabular}{c|ccc}
\hline & \multicolumn{3}{|c}{ Draw Volume (L) } \\
\hline Hour & Schedule A & Schedule B & Schedule C \\
7 & 5 & 10 & 10 \\
8 & 25 & 25 & 25 \\
9 & 0 & 5 & 25 \\
10 & 45 & 45 & 45 \\
11 & 0 & 5 & 25 \\
12 & 5 & 10 & 10 \\
13 & 0 & 5 & 5 \\
14 & 0 & 0 & 0 \\
15 & 0 & 0 & 0 \\
16 & 0 & 10 & 15 \\
17 & 5 & 25 & 25 \\
18 & 10 & 45 & 45 \\
19 & 30 & 25 & 25 \\
20 & 20 & 10 & 30 \\
21 & 0 & 5 & 10 \\
22 & 0 & 0 & 5 \\
\hline Total & 150 & 225 & 300 \\
\hline
\end{tabular}

\subsection{Main Components}

The complete experimental apparatus consisted of many hydronic components plumbed together in an open system to accept unheated mains water and discharge tempered domestic hot water. This section will discuss the major components within the HPWH system setup, including the heat pump water heater, preheat tank, antistratification pump, tempering valve, and solenoid. 


\subsubsection{HPWH}

The primary purpose of the experimental apparatus was to test the performance of a commercially available HPWH unit. For this research a Steibel Eltron Accelera 300 unit was installed and tested in the SBES laboratory. The unit contains a $0.50 \mathrm{~kW}$ single stage air source heat pump with a nominal COP of 3.18, and a $1.69 \mathrm{~kW}$ electric booster heater at conditions where the ambient air is at $15^{\circ} \mathrm{C}$ and $70 \% \mathrm{RH}$, inlet water is at $15^{\circ} \mathrm{C}$, and both the booster and HP set-points are at $60^{\circ} \mathrm{C}$. The exterior and compressor of the unit are shown in Figure 3-4.

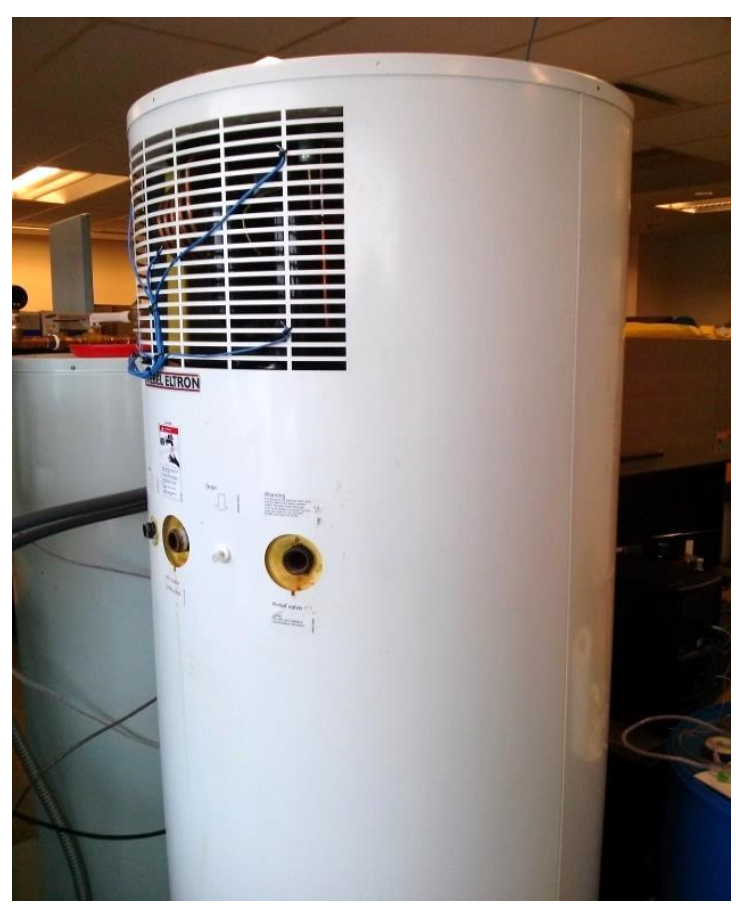

(a)

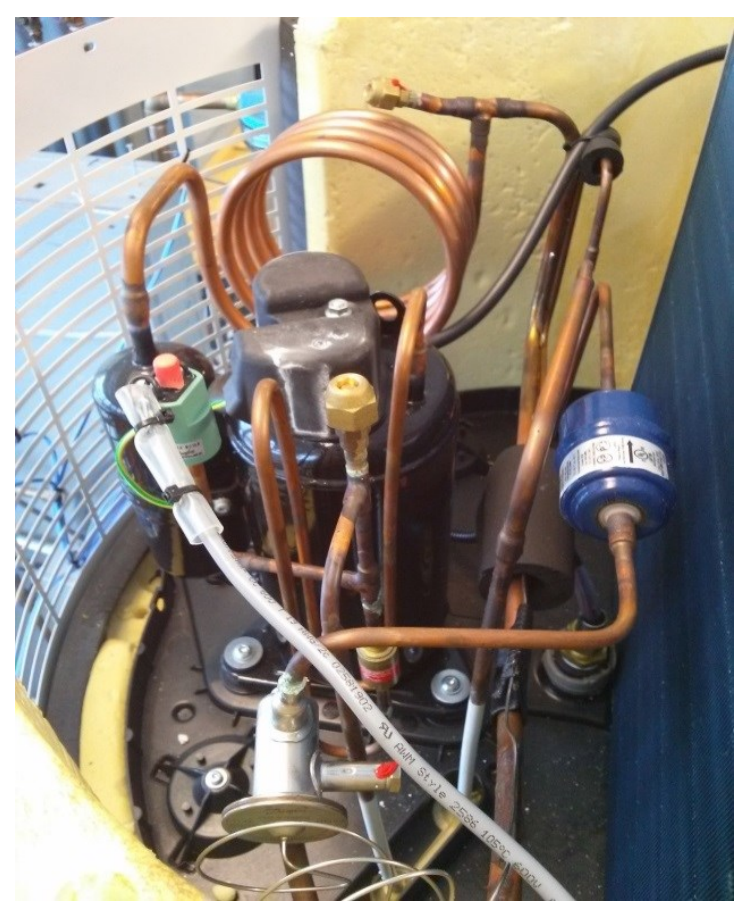

(b)

Figure 3-4: Heat Pump Water Heater Unit - (a) Exterior and (b) Compressor Unit

The tank itself was cylindrical and composed of glass lined steel. With a height of $1.4 \mathrm{~m}$ and diameter of $0.66 \mathrm{~m}$, the aspect ratio of the tank was consistent with most tanks 
in the $300 \mathrm{~L}$ volume range despite the tanks unusual height. Most of this additional height was used to house the evaporator coil to draw warm air into the refrigeration system.

The heat pump was charged with $0.9 \mathrm{~kg}$ of R134a refrigerant. This refrigerant is primarily used in "high temperature" domestic applications. Further HPWH technical specifications are summarized in Table 3-2 as listed in the installation manual [47].

Table 3-2: HPWH Specifications [47]

\begin{tabular}{c|c}
\hline HPWH Property & Value \\
\hline Tank Volume & $303 \mathrm{~L}$ \\
Tank Height & $1.90 \mathrm{~m}$ \\
Tank Diameter & $0.66 \mathrm{~m}$ \\
Insulation Material & Spray Foam \\
Insulation Thickness & $0.05 \mathrm{~m}$ \\
Overall Tank Loss & $5 \mathrm{~kJ} / \mathrm{h}-\mathrm{m}^{2}-\mathrm{K}$ \\
Coefficient & \\
Air Flow Rate & $150 \mathrm{~L} / \mathrm{s}$ \\
Maximum Power & $2.20 \mathrm{~kW}$ \\
Consumption & $0.50 \mathrm{~kW}$ \\
Rated Power Consumption & \\
Heat Pump & $1.69 \mathrm{~kW}$ \\
Power Consumption, & \\
Booster Heater & $1.70 \mathrm{~kW}$ \\
Heating Output Heat Pump & 3.18 \\
Coefficient of Performance &
\end{tabular}

\subsubsection{Preheat Tank}

To condition the inlet water of the HPWH, an $80 \mathrm{~L}$ hot water tank (Giant 142ETE-3F7M) was connected in line between the HPWH and the mains supply. This 
tank was instrumented much like the HPWH with an 8 thermocouple long probe to measure the water temperature at different heights. A maximum deadband between the top and bottom of the tank was maintained using the anti-stratification pump, and a minimum temperature was maintained by activating the integrated electric immersed heater. The set-point temperature of the preheat tank was always higher than the incoming mains water temperature to maintain consistent inlet conditions. Low temperature mains water tests could only be performed if the mains water was already at a low temperature because it was not possible for the current configuration to cool the incoming water. This was a value engineering decision based on capital cost and implementation difficulty with the current equipment. The preheat tank is shown in Figure 3-5.

\subsubsection{Anti-Stratification Pump}

Stratification in the preheat tank was mitigated with the use of a reverse flow pump. This pump was connected such that the outlet water from the tank was pumped back to the inlet to promote mixing and a near uniform vertical temperature profile within the tank. A Grundfos UPS 15-58 FC multiple speed pump was selected for this application because variable speed control was not required. The anti-stratification pump is shown in Figure 3-6.

\subsubsection{Tempering Valve}

In many of the HPWH test scenarios, the water temperature at the top of the tank was significantly higher than the desired delivery temperature of $55^{\circ} \mathrm{C}$. As in many 
commercial and residential hot water systems, a tempering valve was implemented to maintain a safe and consistent delivery temperature. A Heatguard HG110-HX tempering valve was used, and connected to receive water from the outlet of the HPWH, the preheat tank outlet line, and discharge to the solenoid and drain line. The tempering valve is shown in Figure 3-5.

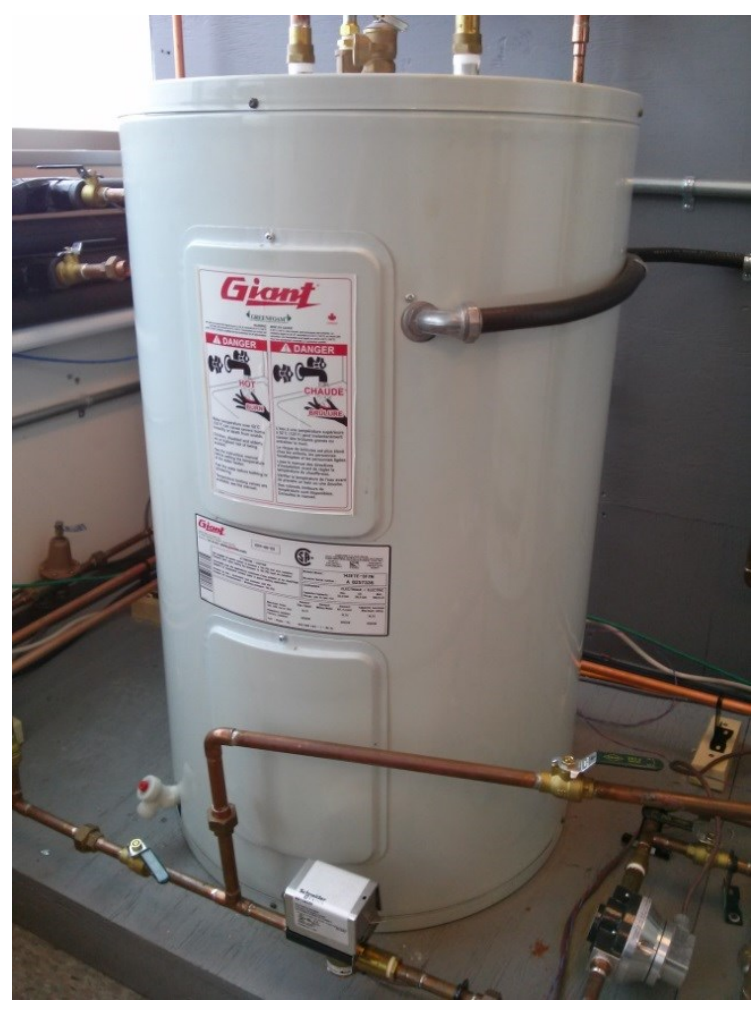

(a)

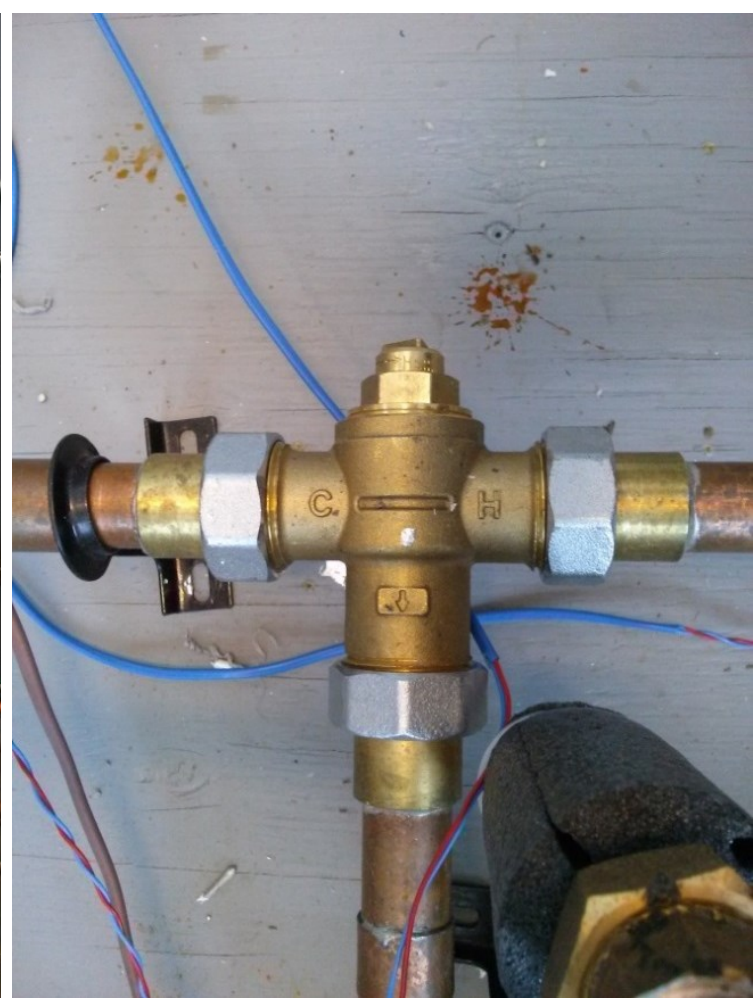

(b)

Figure 3-5: Tempering Equipment - (a) Preheat Tank and (b) Tempering Valve 


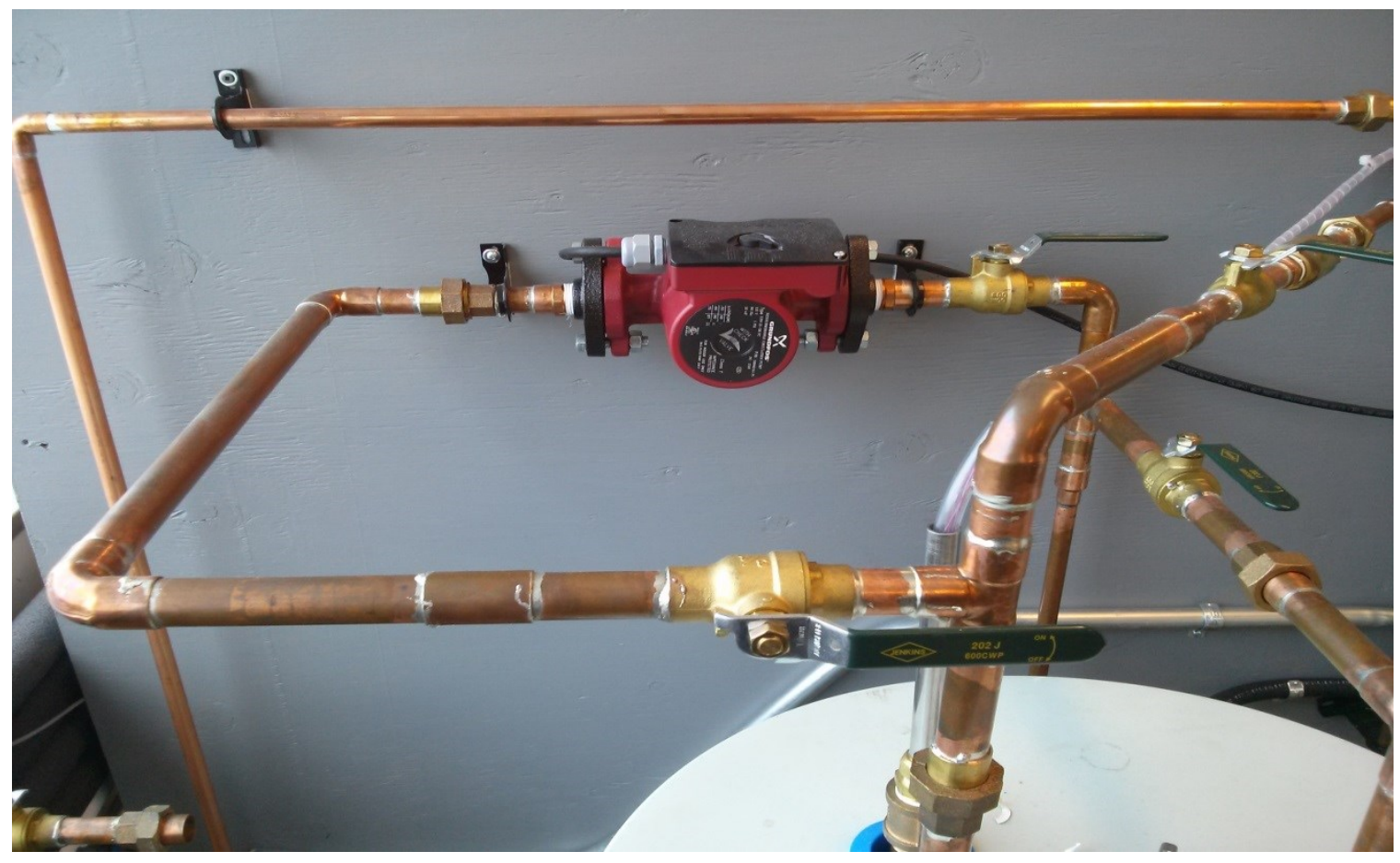

Figure 3-6: Anti-Stratification Pump

\subsubsection{Solenoid}

Automation of the CSA-F379.1 draw profiles was made possible through the use of a solenoid valve. The solenoid valve was controlled via the National Instruments data acquisition controller using the LABView interface. Incremental time differences from the beginning of the test and their respective volumetric water draw were specified in the interface, and the system would run autonomously until all of the draws were completed. A Schneider AG13A020 normally closed solenoid was actuated using a $0-10$ VDC signal from the National Instruments controller. The solenoid is shown in Figure 3-7. 


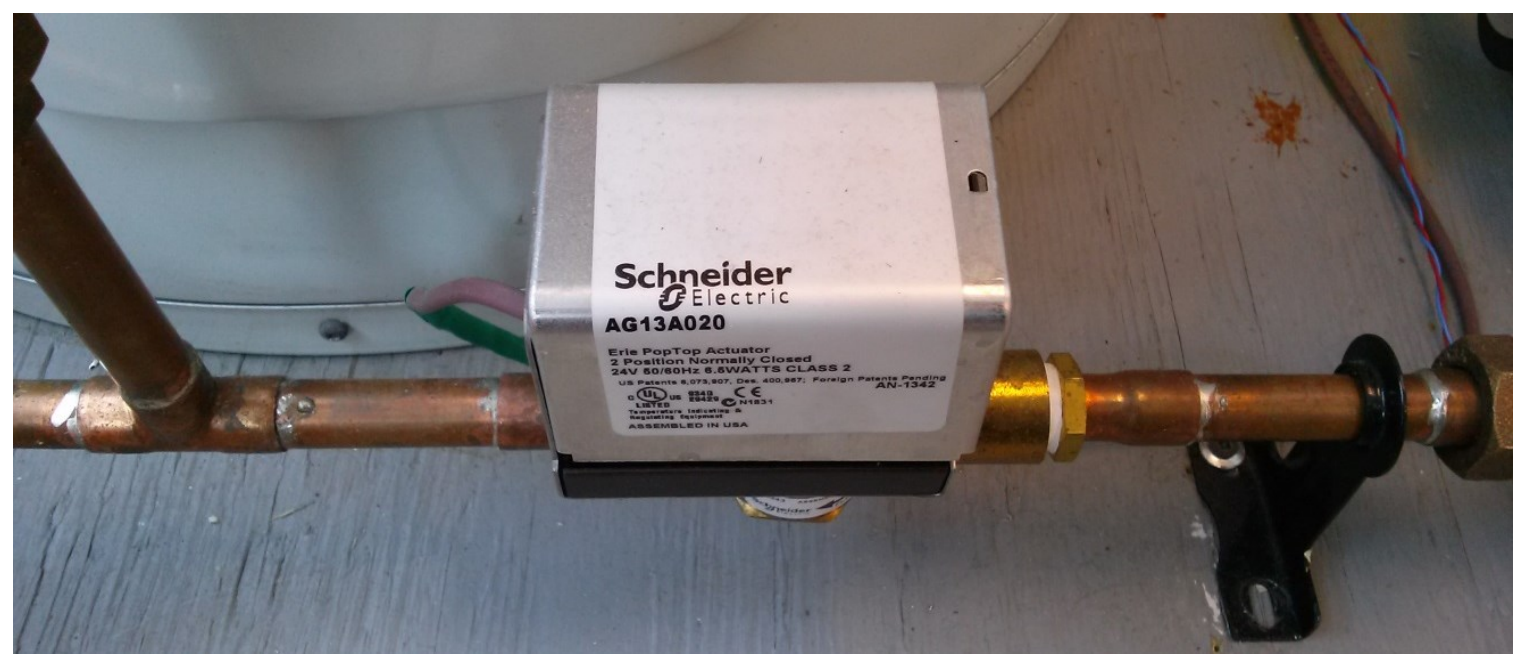

Figure 3-7: Normally Closed Solenoid Valve for Draw Profile Control

\subsection{Instrumentation}

Monitoring and controlling the HPWH test apparatus was a pivotal component of this research, and as such, warranted the use of a high precision data acquisition controller and supporting sensors. A National Instruments CRIO controller was used for thermal monitoring and hydronic actuation, and a Greeneye Power Monitor was used to record electrical energy consumption with current transducers.

\subsubsection{Thermocouples}

Thermocouples were used extensively throughout the HPWH test apparatus for their accuracy. A thermocouple consists of two dissimilar, joined metals that generate an electromotive force proportional to the observed temperature when compared to a resistance temperature detector (RTD) with a known temperature. This RTD is commonly referred to as the cold junction temperature. A curve fit, found from spoollevel calibrations, is then applied to the obtained electromotive force to determine the temperature with a high degree of accuracy [48]. In this study, Type T thermocouples 
were used that consist of copper and constantan. Both 30 gauge and 24 gauge thermocouples were used depending on the application. In the temperature probes for the hot water tanks the thinner 30 gauge wire was necessary to fit the thermocouple wires all the way down to the bottom node. Custom thermowells were used to provide high accuracy fluid readings within the fluid stream as seen in Figure 3-8. Thermowells facilitate accurate temperature measurements by allowing the thermocouple to be in contact with a crimped tube that is in contact with the center of the fluid stream.

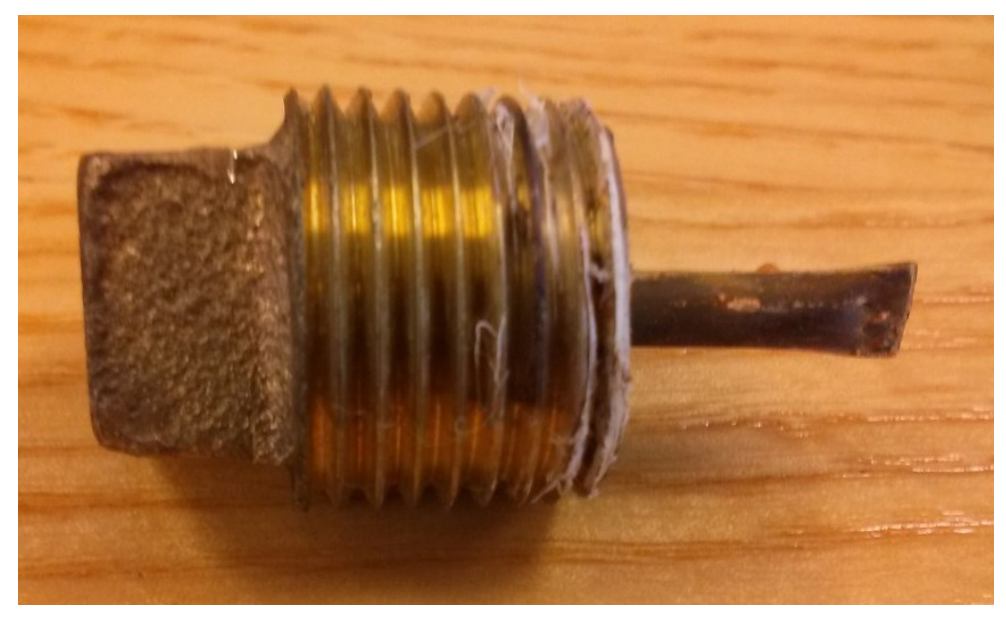

Figure 3-8: Custom Thermowell for Fluid Stream Temperature Measurement

For this study, thermocouples were placed at many points on the apparatus. The extensiveness of their coverage includes the following:

- from the bottom to the top of the preheat tank at $10 \mathrm{~cm}$ intervals

- from the bottom to the top of the HPWH tank at $10 \mathrm{~cm}$ intervals

- in a "X" pattern at the air inlet for the HPWH evaporator

- in a "X" pattern at the air outlet for the HPWH evaporator

- at the mains water inlet for the HPWH tank

- at the heated water outlet for the HPWH tank

- at the mixing valve outlet 
The calibration process involved using a uniform temperature bath (Fluke 7102) to maintain a temperature of $\pm 0.02^{\circ} \mathrm{C}$ from the target calibration temperatures (an incremental range from $5^{\circ} \mathrm{C}$ to $90^{\circ} \mathrm{C}$ ) throughout the bath to compare the voltage obtained from the data acquisition system to a platinum RTD factory calibrated to an accuracy of $\pm 0.02^{\circ} \mathrm{C}$. Equation 3.1 was found using the bath for temperatures from $0^{\circ} \mathrm{C}$ to $100^{\circ} \mathrm{C}$ and represents the temperature as a function of RTD resistance.

where:

$$
T=0.000997 * R^{2}+2.308 * R-240.845
$$

$T$ is temperature in ${ }^{\circ} \mathrm{C}$

$R$ is resistance in ohms

Equation 3.1 has a good fit (coefficient of determination roughly equal to 1). The regression error was found to be an order of magnitude smaller than the RTD instrumentation error, and was thus determined negligible [38].

The National Instruments data acquisition system is based upon using different input/output cards for different applications, such as thermocouples. To measure the thermocouple temperature readings, a NI 9124 card was selected. This card measures the cold junction temperature using a built-in thermistor with an instrumentation error of $\pm 0.25^{\circ} \mathrm{C}$ [45]. The curve fit for the National Instruments connected thermocouples was found using the RTD and the temperature bath in a calibration process. The test itself encompassed the use of the RTD as a reference temperature, and a thermocouple sample from each spool as the test specimen. The temperature bath was incremented from $5^{\circ} \mathrm{C}$ to $95^{\circ} \mathrm{C}$ at $2^{\circ} \mathrm{C}$ intervals. These bounds were chosen to prevent localized freezing or boiling. At each temperature increment, a reading was taken every 5 seconds for three minutes, and the average readings for both the RTD and thermocouple sample were compared. 
Since thermocouples can only measure the temperature difference between the tips of the thermocouple, the value of the cold junction compensation (CJC) is directly added to the thermocouple temperature reading. The results of the calibration procedure yielded the following relations for temperature and voltage for 30 gauge and 24 gauge wire in Equations 3.2 and 3.3, respectively.

$$
\begin{gathered}
T=0.00109 * \mathrm{~V}^{6}+0.00615 * \mathrm{~V}^{5}-0.0799 * \mathrm{~V}^{4}+0.212 * \mathrm{~V}^{3} \\
-0.708 * \mathrm{~V}^{2}+24.65 * \mathrm{~V}-0.186+\mathrm{CJC} \\
T=0.00258 * \mathrm{~V}^{6}-0.00374 * \mathrm{~V}^{5}-0.0633 * \mathrm{~V}^{4}+0.227 * \mathrm{~V}^{3} \\
-0.741 * \mathrm{~V}^{2}+24.68 * \mathrm{~V}+0.091+\mathrm{CJC}
\end{gathered}
$$

where:

Tis temperature in ${ }^{\circ} \mathrm{C}$

$\mathrm{V}$ is voltage in $\mathrm{mV}$

CJC is cold junction compensation temperature in ${ }^{\circ} \mathrm{C}$

After obtaining the relation between the voltage reading and observed temperature, the compounded error of the thermocouple measurement system must be determined to ensure that it is not significant with respect to the desired temperature reading. Sources of error include but are not limited to intrinsic equipment error, calibration process error, curve fit error, and non-uniformity of media.

Equipment data and analog to digital sensitivity were taken into account, and the errors were tabulated for the calibration process in ${ }^{\circ} \mathrm{C}$ as shown in Table 3-3. 
Table 3-3: Error of Temperature Measurement Documented from Calibration $\left({ }^{\circ} \mathrm{C}\right)$

\begin{tabular}{c|cc}
\hline Error Source & 30 Gauge Wire Error & 24 Gauge Wire Error \\
\hline CJC - Calibration & 0.25 & 0.25 \\
CJC - Experimental & 0.25 & 0.25 \\
Regression Error & 0.237 & 0.157 \\
RTD & 0.02 & 0.02 \\
Digital Multi Meter & 0.0397 & 0.0397 \\
Bath Uniformity & 0.02 & 0.02 \\
Voltage Error - Calibration & 0.175 & 0.175 \\
Voltage Error - Experimental & 0.175 & 0.175 \\
Total Uncertainty & 0.49 & 0.46 \\
\hline
\end{tabular}

As shown in Table 3-3, only the regression error was different between the two wire gauges used. The root mean squared of the compounded error was found to be $\pm 0.49^{\circ} \mathrm{C}$ for the 30 gauge wire and $\pm 0.46^{\circ} \mathrm{C}$ for the 24 gauge wire, respectively. A thermocouple probe fitted pipe tee is shown in Figure 3-9.

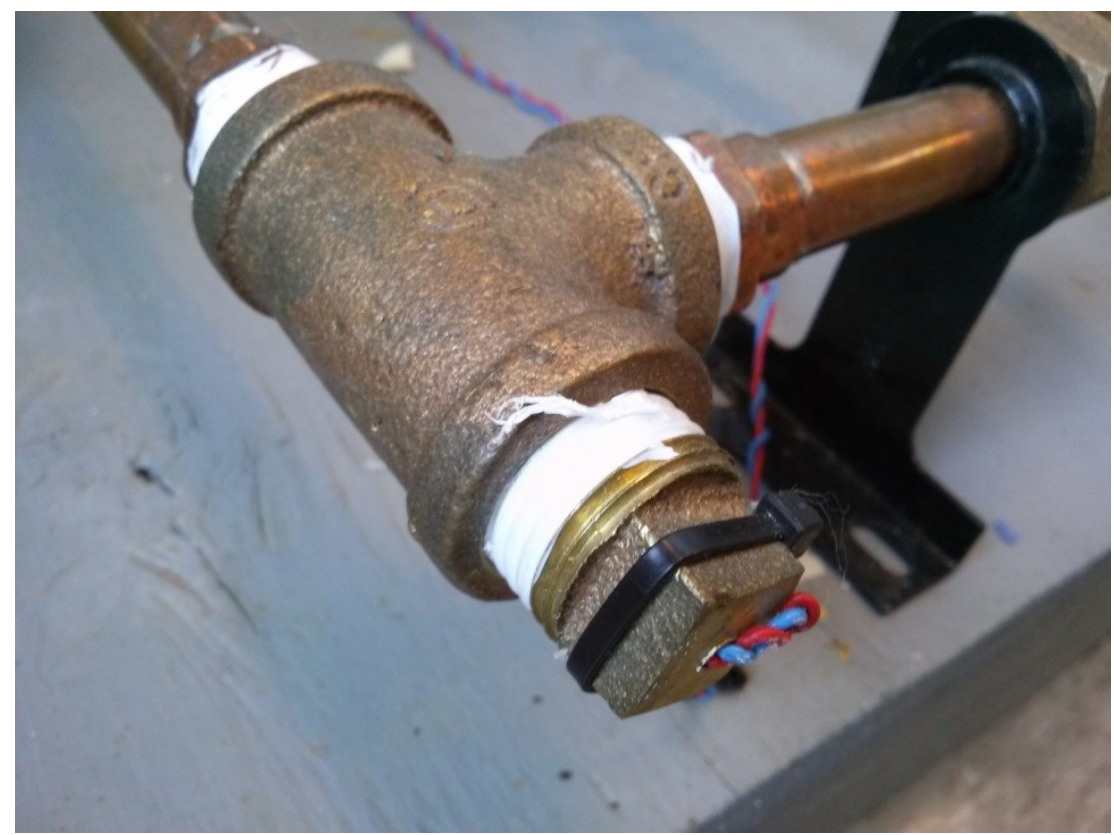

Figure 3-9: Pipe Tee Fitted with Thermocouple Probe on the HPWH Tank Drain Line 


\subsubsection{Flow Meter}

The use of an in-line positive displacement flow meter was essential to the draw profile automation process. These particular flow meters were chosen because they provide a good balance between accuracy and cost when compared to other commercially available flow meters. Positive displacement flow meters work by triggering a pulse each time the enclosed oval gears rotate due to fluid motion. These pulses are then counted by a pulse input on the data acquisition system. The $24 \mathrm{~V}$ pulse transmitter is called a Reed Switch. Using the counted pulses, a flow rate can be determined using the elapsed time. Both factory calibrated uncertainty and pulse count uncertainty are present in this variety of flow meter. This study used a Brooks BM-04 flow meter designed for use in $1 / 2$ inch pipe applications, with a working temperature of up to $80^{\circ} \mathrm{C}$, flow rates between 1 and 30 liters per minute and instrumental accuracy of $0.5 \%$ [49]. The flow meter used to measure the draw from the HPWH tank is shown in Figure 3-10.

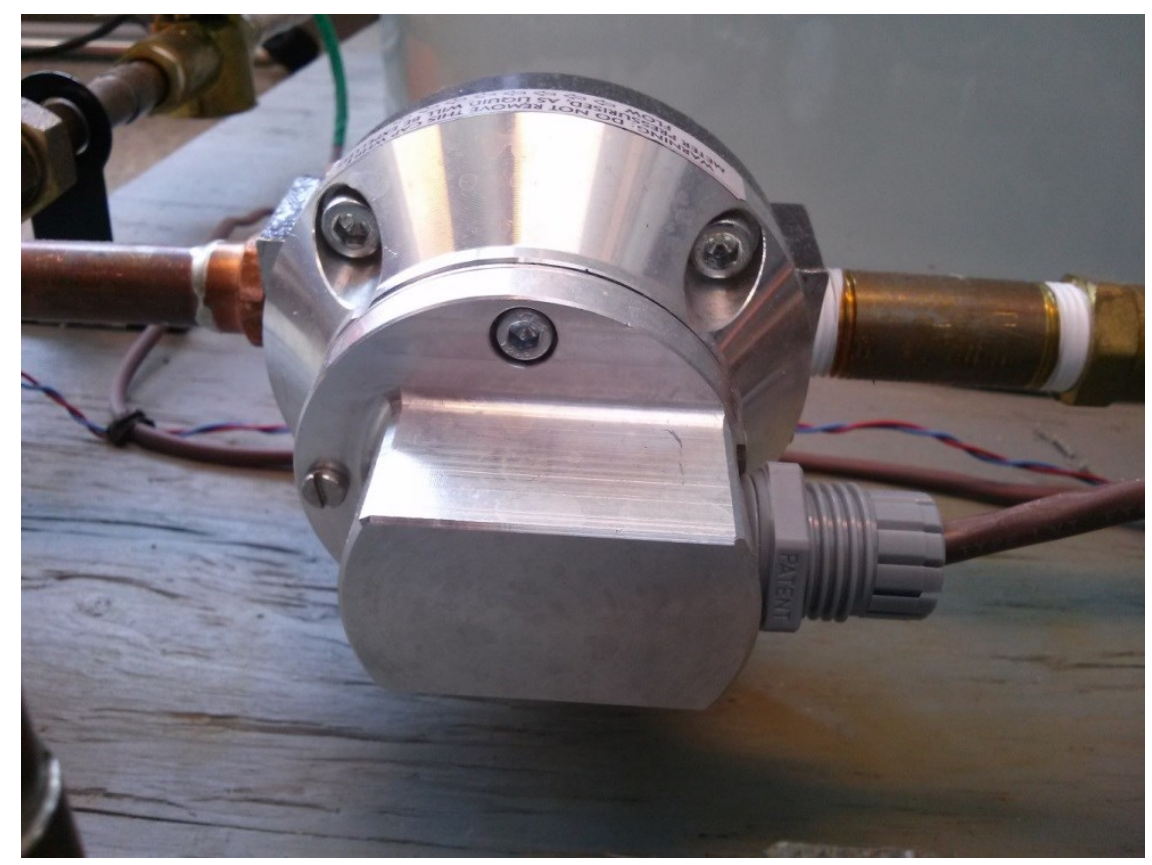

Figure 3-10: In Line Flow Meter to Measure the Active Flow Rate 


\subsubsection{Power Monitoring}

Current transducers were used to monitor the power consumption of the major equipment in the HPWH system. The Greeneye power monitoring system was used to measure the current at 30 second intervals, and the result was integrated to estimate the energy consumption of the electrical auxiliary heaters, heat pump compressor, and fan. The power monitor system logs the average current observed at each transducer over a 30 second interval, and records the power consumed in Joules. A Python interface was used to $\log$ the data locally to a computer, where it could be extracted for analysis. The power monitoring system is accurate to within $1 \%$ from factory calibrated error.

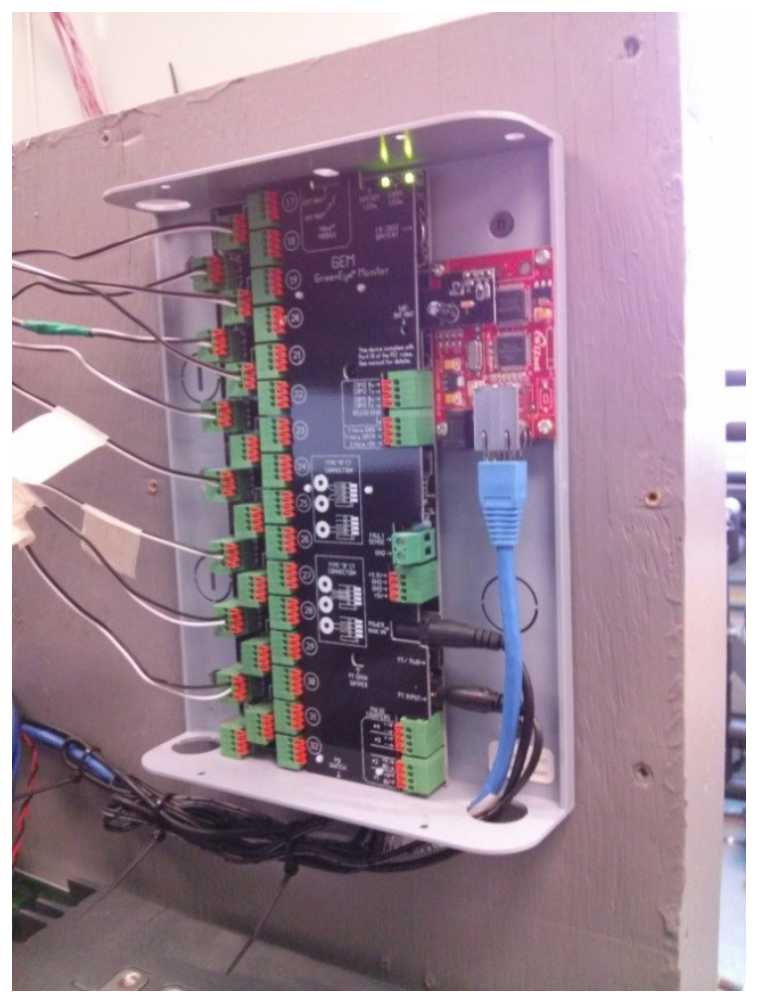

(a)

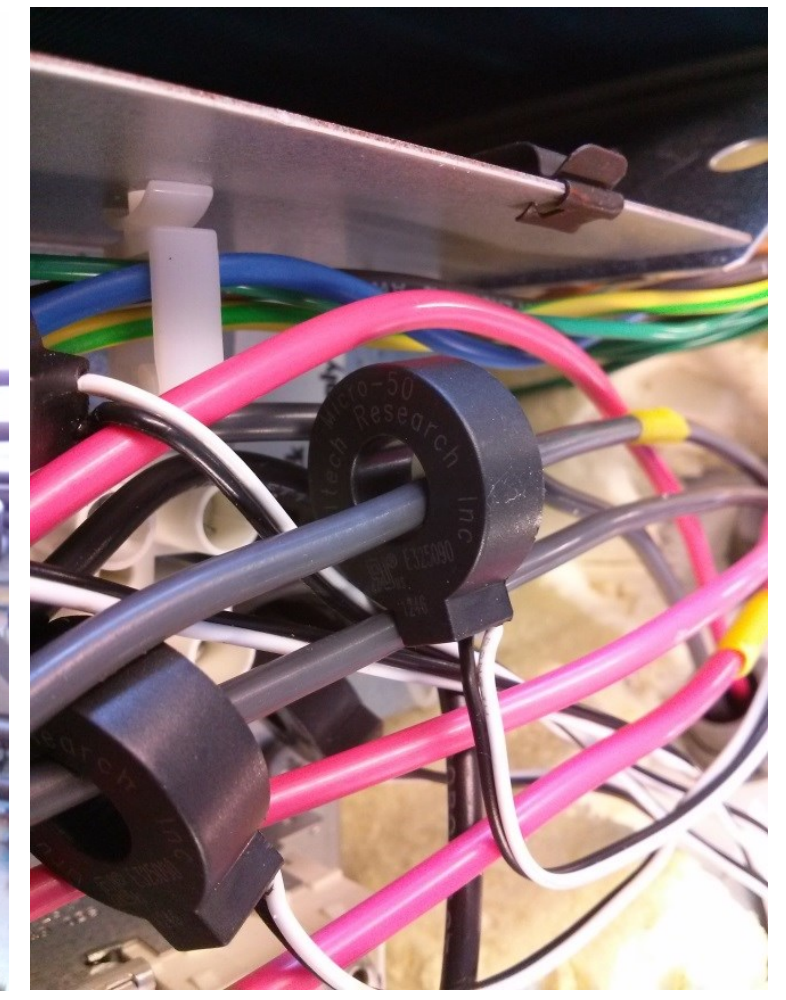

(b)

Figure 3-11: Greeneye Power Monitoring System - (a) Control Panel and (b) Current Transducer 


\subsubsection{Control and Data Acquisition}

A National Instruments controller was selected for this application, along with the LABView interface. A summary of the input and output modules implemented is given in Table 3-4. A LabVIEW Virtual Interface (VI) was used as a graphical user interface for the apparatus. In the background the VI runs code in a workflow based language that closely resembles traditional block diagrams, and allows the user to better visualize race conditions that can occur within the programming. The VI displays the data from the point modules in real time, and logs all data to an exportable .csv file that can be used for further analysis. A screen shot of the VI can be seen in Figure 3-12.

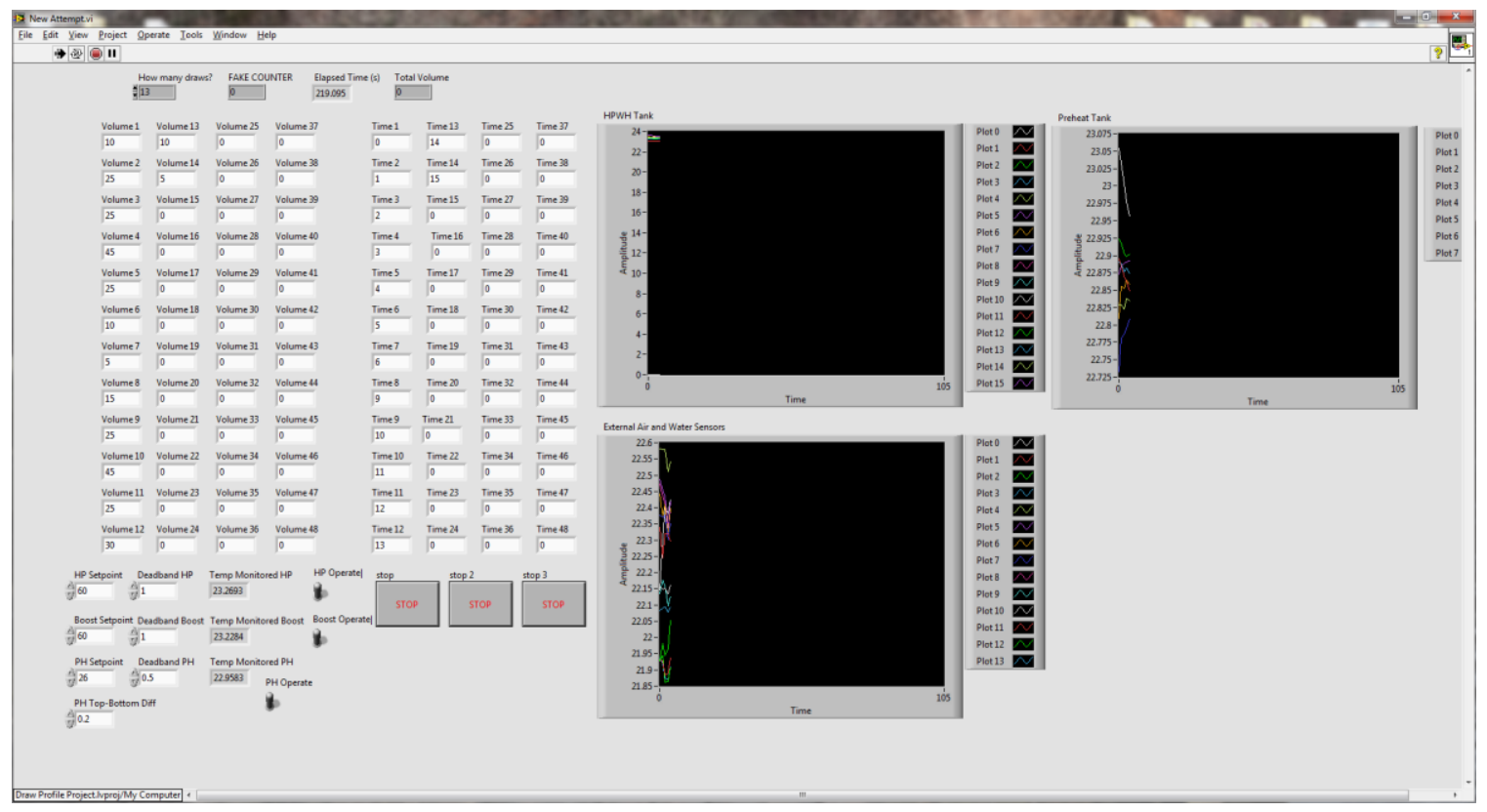

Figure 3-12: LabVIEW VI for the HPWH Testing Apparatus 
Table 3-4: I/O Used for the Experimental Apparatus

\begin{tabular}{|c|c|c|c|c|}
\hline I/O Module & I/O Type & Quantity & Points & Use \\
\hline NI 9214 & $\begin{array}{c}\text { Isothermal } \\
\text { Thermocouple } \\
\text { Input }\end{array}$ & 2 & 32 & $\begin{array}{l}\text { Thermocouple } \\
\text { measurement }\end{array}$ \\
\hline NI 9476 & $\begin{array}{l}\text { 24VDC Digital } \\
\text { Output }\end{array}$ & 1 & 16 & $\begin{array}{l}\text { Power to flow } \\
\text { meters and } \\
\text { relay control } \\
\text { for pumps and } \\
\text { heating } \\
\text { equipment }\end{array}$ \\
\hline NI 9422 & $\begin{array}{l}\text { 24VDC Digital } \\
\text { Input }\end{array}$ & 1 & 8 & $\begin{array}{l}\text { Pulse counting } \\
\text { for flow meter }\end{array}$ \\
\hline
\end{tabular}

The data acquisition controller used for the HPWH system is show in Figure 3-13.

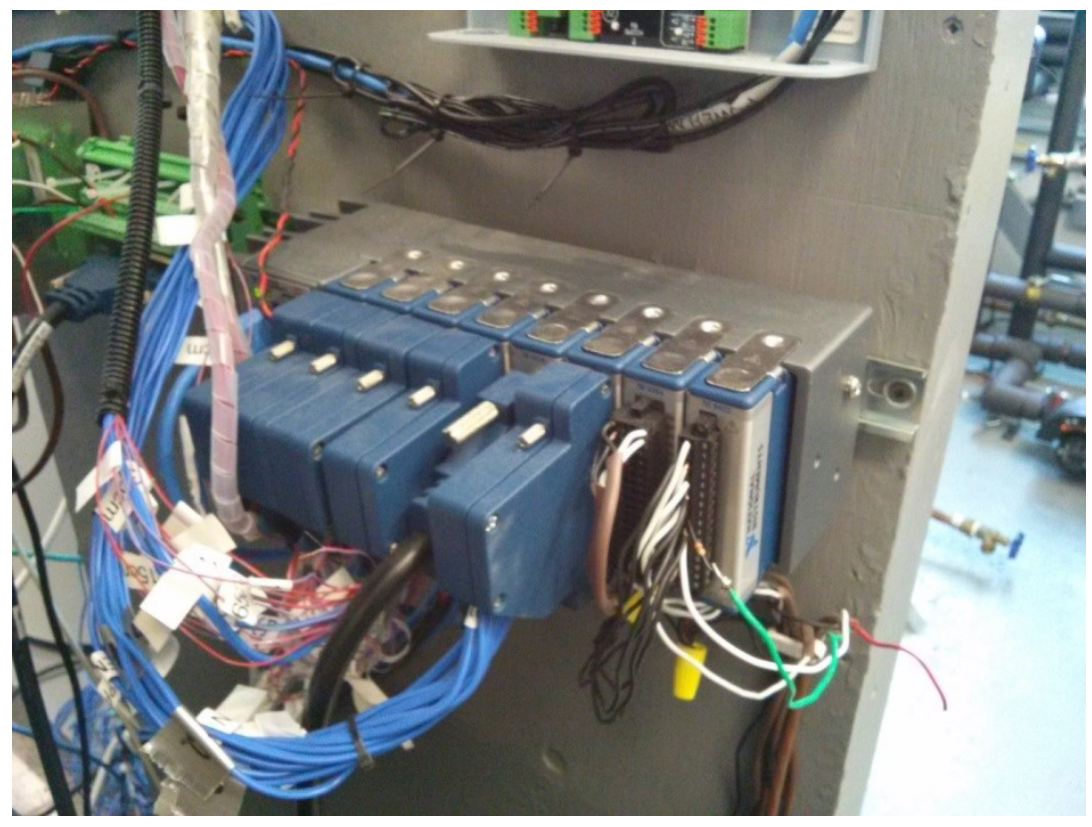

Figure 3-13: NI cRIO 9024 Data Acquisition Controller 


\subsection{Summary}

This chapter provided a detailed description of the experimental apparatus and its instrumentation through schematics, photographs, and equipment descriptions. The next chapter will cover the system modelling through TRNSYS, and the optimization process executed through GenOpt. 


\section{Chapter: System Modelling}

System modelling of the HPWH system was an important task for this research. Each experimental run took upwards of 15 hours, and the ability to accurately estimate the system performance was paramount in determining the validity of each test. For this reason, a TRNSYS model was developed based on Thermal Energy System Specialists (TESS) library components and linearized equations to calibrate the model to the experimental data.

The TRNSYS program was designed to model transient thermal processes, and is composed of a library of components known as "Types" that can be used to model complete systems. System models are constructed in the "Simulation Studio", where they are written to a "deck" file that is used in the solver engine. Types are modelled as a function of their inputs and parameters, which are linked and defined by the user. The mathematical functions within the components are solved using defined time steps, which progress simultaneously and iteratively until convergence is obtained using the TRNSYS successive method. The outputs from each time step are then used as the inputs in the following time step.

The HPWH performance was tested under a variety of conditions using a TRNSYS model represented by the deck file in Appendix B. A time step of 30 seconds was chosen because it matched the minimum logging interval of the experimental data acquisition system. Smaller time steps could potentially cause perturbations in the model output, and would not improve granularity relative to the experimental data to which the model was calibrated. The model was continuous, and contained algebraic and integral 
equations. Convergence was determined using the TRNSYS successive method, and was achieved for all time steps using the default criteria of $0.001{ }^{\circ} \mathrm{C}$ for temperature and $0.05 \%$ for flow rates within 20 iterations per time step.

The HPWH unit had to be divided into 2 separate TRNSYS subroutines (referenced as Types in TRNSYS) in order to accurately model the effects of both the heat pump performance map and the wrap-around coil heat exchanger. The TESS library Type 938 was used to model the heat pump, and is based on the air source heat pump subroutine from the standard library. In particular, the environmental heat draw and heat transfer to water are presented in individual outputs. Type 1237 was used to model the wrap-around coil condenser tank configuration, and is built upon the Type 534 structure which is used to model cylindrical tanks with immersed heat exchangers. Both tank types allow for the breakdown of heat sources at the node level, and can facilitate the nonuniform heat transfer from the auxiliary (booster) heater and the heat pump to the tank nodes. In this model, a tank with 13 nodes was used to best reflect the physical division of the tank in the experimental setup. A forcing function generated by a data reader was used to simulate the draw profiles of typical dwellings as per CSA-F379.1. Curve fits were applied to the experimental data to linearize heating curves, where the dependent variable is the heat applied to the node from the heat pump condenser, and the independent variable is the temperature difference between the set-point and the instantaneous node temperature. Conformity of the model to the experimental data was found to be within $10 \%$ for total energy consumption and temperature node thermal deviation. This model could then be extended to account for further testing that would take several months and additional equipment. 


\subsection{System Overview}

The heat pump water heater system was modelled using TRNSYS to predict and verify system performance under a variety of different physical operating conditions. Initially the results of the simulations were to be verified iteratively with the experimental apparatus, but due to a tank rupture, this was not a possibility within the timeline of this thesis. For the sake of reasonable simplification, the preheat portion of the experimental system was excluded from the model, and a constant inlet temperature was assumed. This is justified by the $0.1{ }^{\circ} \mathrm{C}$ differential held between the top and bottom regions of the preheat tank with the anti-stratification pump. The model had to be arranged for both numerical output (using online plotters and printers) and optimization. In the numerical output configuration, heat pump performance, temperature profiles, and control signals were recorded in an exportable comma separated value file to be compared with the respective experimental values. In the optimization configuration, a single optimization function was defined within the model, and was evaluated with many different input combinations using a hybrid method of particle swarm optimization and Hooke-Jeeves coordinate search. The fitness function is described in Section 4.7. Both configurations had the same main equipment, which included the heat pump serving the HPWH, the HPWH wrap-around condenser tank, and the draw apparatus. Figure 4-1 shows the HPWH temperature control strategy via flow chart. The temperature control process is dictated by the temperature of defined nodes, the set-point, and the deadband. When the set-point node is defined, its current temperature is logged on each scan from the controller. This value is then compared to the set-point defined in the LabVIEW program 
where the deadband is factored in to prevent excessive equipment switching. If the current temperature is less than the set-point minus the deadband, then the heating equipment activates, if not, then it remains inactive. The inverse process occurs for heating equipment deactivation.

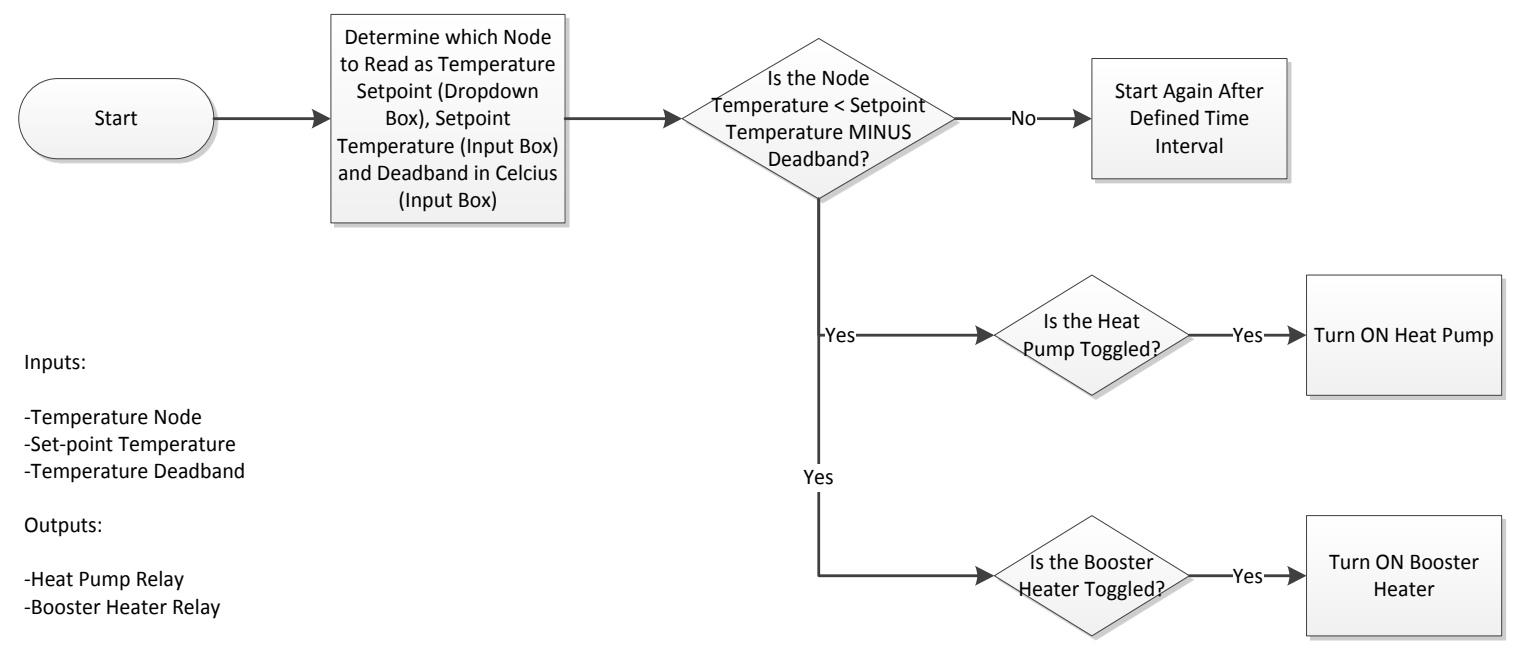

Figure 4-1: HPWH Temperature Control Flow Chart

\subsection{Heat Pump}

The complexity of the packaged HPWH system necessitated the use of advanced TRNSYS components from the TESS component library including both the HPWH heat pump and the wrap-around coil condenser tank [50]. Noted as Type 938, the heat pump is a variant of the standard single stage air to water heat pump but with the heat source and heat sink reversed to facilitate the transfer of heat from the ambient air to the water tank. This type was chosen because the performance map technique it uses (in lieu of a first principles technique) allowed for an accurate way to characterize the performance of the HPWH unit experimentally tested. This was supported by the literature review [19] [31] 
[22] [35]. In contrast, a first principles technique would require additional instrumentation to obtain similar results. Also, unlike other heat pump options, this type was created specifically for HPWH units.

Activation was based on a control signal from a Type 1502 aquastat with an input set-point and deadband statically defined for each simulation. Variation in system power draw was determined using the performance map based on manufacturer data in conjunction with the previously mentioned base control algorithm. Other heat pump properties including the fan power, fan airflow rate, total rated heating capacity, and rated compressor power were obtained from the owner's manual [47], while other properties such as the specific heat and density of the refrigerant were obtained from standard R134A tables [51]. Due to the consistent conditions of the laboratory where the experiments took place, and the CSA-F379.1 draw tests, some of the HPWH inputs such as inlet air temperature, inlet air humidity ratio, inlet air pressure, and inlet liquid flow rate were set as constants to reduce the complexity of the model calibration. The laboratory heating system held the temperature at $22^{\circ} \mathrm{C}$ with a deadband of $\pm 1{ }^{\circ} \mathrm{C}$ and limited humidity control. During the period of testing, the relative humidity measured by the building automation system fluctuated in a range from $25-35 \%$.

\subsection{Heat Pump Water Heater Tank}

Type $1237-1$ is the wrap-around coil condenser tank from the TESS library, and was selected for this task. This type is based on the Type 534 vertical cylindrical storage tank with immersed heat exchanger model, with modifications to account for the external effects of the wrap-around coil [50]. The primary feature of both tank options that was 
desirable was the ability to break down heat sources to the node level, thus facilitating pre-processing and enhanced fits to experimental data.

Type 1237-1 is designed to have the refrigerant flow rate and temperature from the Type 938 heat pump received as an input, but it was found that using this method did not accurately model the physics of the tank. Due to known issues with immersed heat exchanger models in TRNSYS, this was not unexpected [52]. In most cases with TRNSYS, the geometry of heat sources with complex geometry is modelled using simple shapes as approximations. In the case of the HPWH tank, the complex geometry and thermal interaction within the condenser generated significantly different simulation results from the experimental findings. This issue left two primary options for achieving a reasonable model of the HPWH wrap-around coil tank: the creation of a new TRNSYS type to model the transient tank properties using experimental data, or the use of calculators to feed each node with a fraction of the total heat pump heat output determined using an experimental curve fit. The former option was chosen to increase transparency and allow for different HPWH units to easily be substituted using the same model framework. Additionally, a separate compiler would be required to convert the Fortran code behind TRNSYS into an executable Type. The process used to calibrate the tank node heat input is outlined in detail in Section 4.6.

Numerous parameters and inputs are offered for the Type 1237-1 vertical cylindrical storage tank with wrap-around heat exchanger to characterize the geometry and heat transfer properties. Due to the experimental calibration workaround, many of the tank inputs and parameters for the wrap-around heat exchanger could be neglected. The vertical nodes were sized at $10 \mathrm{~cm}$ in length, and consisted of the entire cross section of 
the tank about the vertical axis. The heat transfer fraction of the total heat pump output was experimentally determined and applied in a calculator, while verified via the stratified fluid temperature profile from each node. Using the method detailed in Section 4.6, a single linear relationship was developed for all nodes of the tank. This relationship was used to augment the heat pump performance and output through the use of equation calculators in TRNSYS.

\subsection{Draw Profile}

The draw profile was modelled using a Type 9a data reader to feed binary values to a calculator based on the observed time to regulate flow. The chosen 30 second time step was the smallest time step that could regulate the draw volume of $5 \mathrm{~L}$ at the CSA-F379.1 prescribed $11.5 \mathrm{~L} / \mathrm{min}$ flow rate and matched the logging interval of the experimental configuration. A similar strategy involving data readers was used to model the shift in utility rates in Ontario as a result of time of use charges. In the case of the draw profile, the draw rate from the calculator was fed to a mixing valve that determined the amount of hot water required to meet the delivery temperature of $55^{\circ} \mathrm{C}$, essentially modelling the physical tempering valve. Schedule A, B, and C draw profiles were generated for use with the data reader to allow for the simulation of various domestic hot water needs.

\subsection{Additional Components}

Additional components that were used in the TRNSYS model beyond the heat pump, tank, and draw system included a mixing valve, weather file, and printer. These 
components were assisted by TRNSYS calculators where necessary. The mixing valve is a basic tempering valve that uses steady state steady flow assumptions to perform an enthalpy balance on the merging fluid streams. This allows the model to find the required volume of water to be drawn from the tank to meet the DHW heating load. The Type 15-6 Typical Meteorological Year 2 weather file was used to determine the inlet mains water temperature, and allow for expanded use in determining outdoor air temperatures and solar insolation in future iterations of the model. Typical meteorological year 2 data takes the most typical weather data for a location from the time span of 1961 to 1990. More current weather files from the Carleton campus weather station are recommended to better represent local conditions. To facilitate step-wise parameter output, a Type 25 printer was used to feed output data to a comma separated file that could be post-processed at a later time. It is notable that when coupling TRNSYS with GenOpt (using TRNOpt) there can be no Type 25 printers present in the model. This is likely due to the required write action of the printer that may impede the temporary output storage in the TRNOpt script.

Calculators were used to define equations and values for the GenOpt optimization process and to provide curve fits to the experimental data. A description of this calibration process is provided in Section 4.6.

The TRNSYS control card was used to define several values that could both remain static, or be changed in parametric runs through the TRNOpt GenOpt interface. The primary static value, the simulation time step, was held at 30 seconds because it provided enough resolution to observe transient effects during the tank draw period, and also was long enough to avoid excessive oscillation during the 24 hour run time. 
Additionally, the 30 second time step allowed for easy integration with the Type 9 data reader to facilitate the draw and time of use (TOU) profiles. Other parameters included in the control cards for manipulation in the optimization process were the tank insulation value, tank volume, indoor air temperature, inlet node location, outlet node location, heat pump nominal power, heat pump tank coverage, booster heater length, booster nominal power, and heat pump evaporator air flow. These values were determined to be potentially variable during the HPWH design process, and thus were examined to determine the trends towards good energy use design for the unit. Meanwhile, only the indoor air temperature and heat pump evaporator air flow are variable outside of the design process. The significance and trends of these variables will be discussed further in the GenOpt Results section.

\subsection{Model Calibration to Experimental Data}

Multiple heat pump set-points, booster set-points, and draw profiles were tested with the HPWH apparatus to characterize the thermal performance of the system. A setpoint difference between the heat pump and the booster heater was maintained to assist with characterizing the system response to each respective piece of equipment. Schedules A and C (the smallest and largest total volume of draws from CSA-F379.1) were tested to see both extremes of heating equipment run time. The set-point and draw parameters that were executed are outlined in Table 4-1. 
Table 4-1: HPWH Experimental Run Parameters for Model Calibration

\begin{tabular}{c|ccc}
\hline Run Number & Heat Pump Set-point $\left({ }^{\circ} \mathrm{C}\right)$ & Booster Set-point $\left({ }^{\circ} \mathrm{C}\right)$ & Draw Profile \\
\hline 1 & 50 & 55 & $\mathrm{~A}$ \\
2 & 50 & 55 & $\mathrm{C}$ \\
3 & 55 & 60 & $\mathrm{~A}$ \\
4 & 55 & 60 & $\mathrm{C}$ \\
5 & 55 & 65 & $\mathrm{~A}$ \\
6 & 55 & 65 & $\mathrm{C}$ \\
7 & 60 & 70 & $\mathrm{~A}$ \\
8 & 60 & 70 & $\mathrm{C}$ \\
9 & 62 & 72 & $\mathrm{~A}$ \\
10 & 62 & 72 & $\mathrm{C}$ \\
\hline
\end{tabular}

The temperature profiles and equipment power draw for each run were tabulated and used to find the temperature rise for each node with respect to time. The effect of the lower temperature heat pump condenser with respect to the booster heater was found to conform to basic heat transfer theory. The heat rate to the node was defined as $Q$ in Equation 4.1, where $m$ is the mass of water in each node, $c_{\mathrm{p}}$ is the pressure constant, and $\frac{d T}{d t}$ is the rate of temperature increase in each node. Note that the product of $m c_{\mathrm{p}}$ can be assumed to be a constant since all of the nodes are assumed to have equal volume and stable thermal properties throughout the heating process.

$$
Q=m c_{\mathrm{p}} \frac{d T}{d t}
$$

The rate of temperature increase in each node was defined using an experimental curve fit adhering to basic heat transfer principles where $\frac{d T}{d t}$ is a function of the temperature difference between the set-point for the node, $\gamma$, and the current temperature in Equation 4.2. Both $\frac{d T}{d t}$ and $\gamma$ had to be found experimentally, and $\frac{d T}{d t}$ had to be estimated 
using linear regression as seen in Figure 4-2 and Figure 4-3 for the highest and lowest tested heat pump set-points. The defining function, $f(\gamma)$, was determined to be linear using power, logarithmic, and linear regression techniques, and had a reasonable correlation coefficient of 0.75 in the linear case. A plot of the temperature rise rate with respect to $\gamma$ is shown in Figure 4-4, where one standard deviation of the data is indicated by the shaded region. Possible sources of non-linearity could have been heat transfer between nodes of booster heater, heat transfer through the wall of the tank, and reducing condenser fluid temperature as greater distance from the compressor is reached.

$$
\frac{d T}{d t}=f(\gamma)=m \gamma+b
$$

This technique was only used to define the heat pump heating performance because the surface temperature of the booster heater was found to be high enough to not have a significant effect on the thermal response of the tank from waveform analysis. A basic heat source could be added to adequately model the thermal response of the booster. Additionally, the vertical regimes of the tank where the booster heater, heat pump, both, or neither had the most effect could be found by analyzing the temperature rise rate relative to the temperature difference from the set-point. From this, it was found that the booster heater had a length of roughly $30 \mathrm{~cm}$ and served the top 3 nodes, the heat pump began at the top of the tank and stopped $25 \mathrm{~cm}$ from the bottom. Heat pump condenser coverage was found to be all nodes except the bottom 2 and approximately half of the $3^{\text {rd }}$ from the bottom. This was confirmed through exploratory testing after the tank failed. 


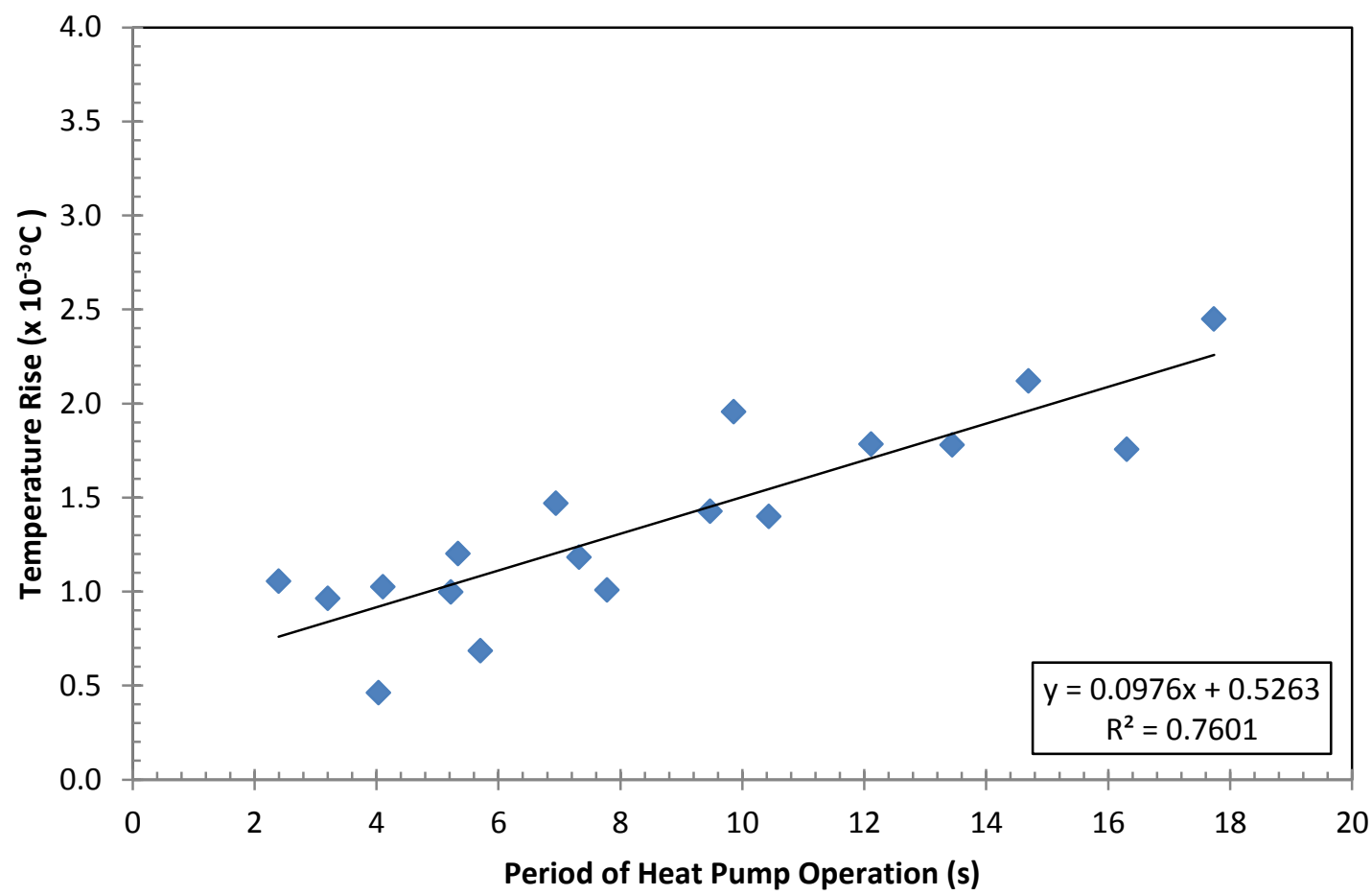

Figure 4-2: Temperature Rise of Heat Pump Nodes 1, 2, and 3 at $50^{\circ} \mathrm{C}$ Set-point

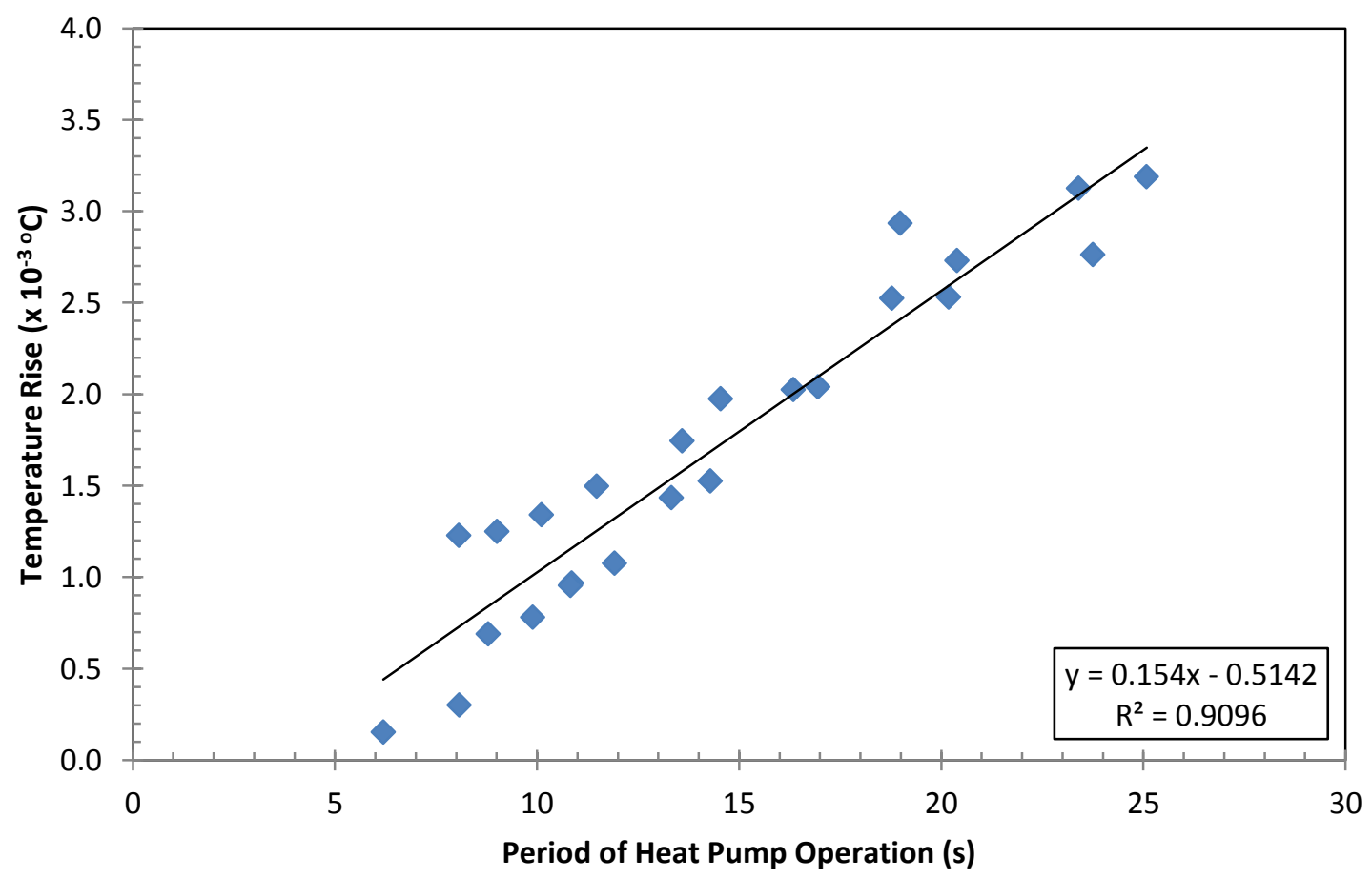

Figure 4-3: Temperature Rise of Heat Pump Nodes 1, 2, and 3 at $62^{\circ} \mathrm{C}$ Set-point 


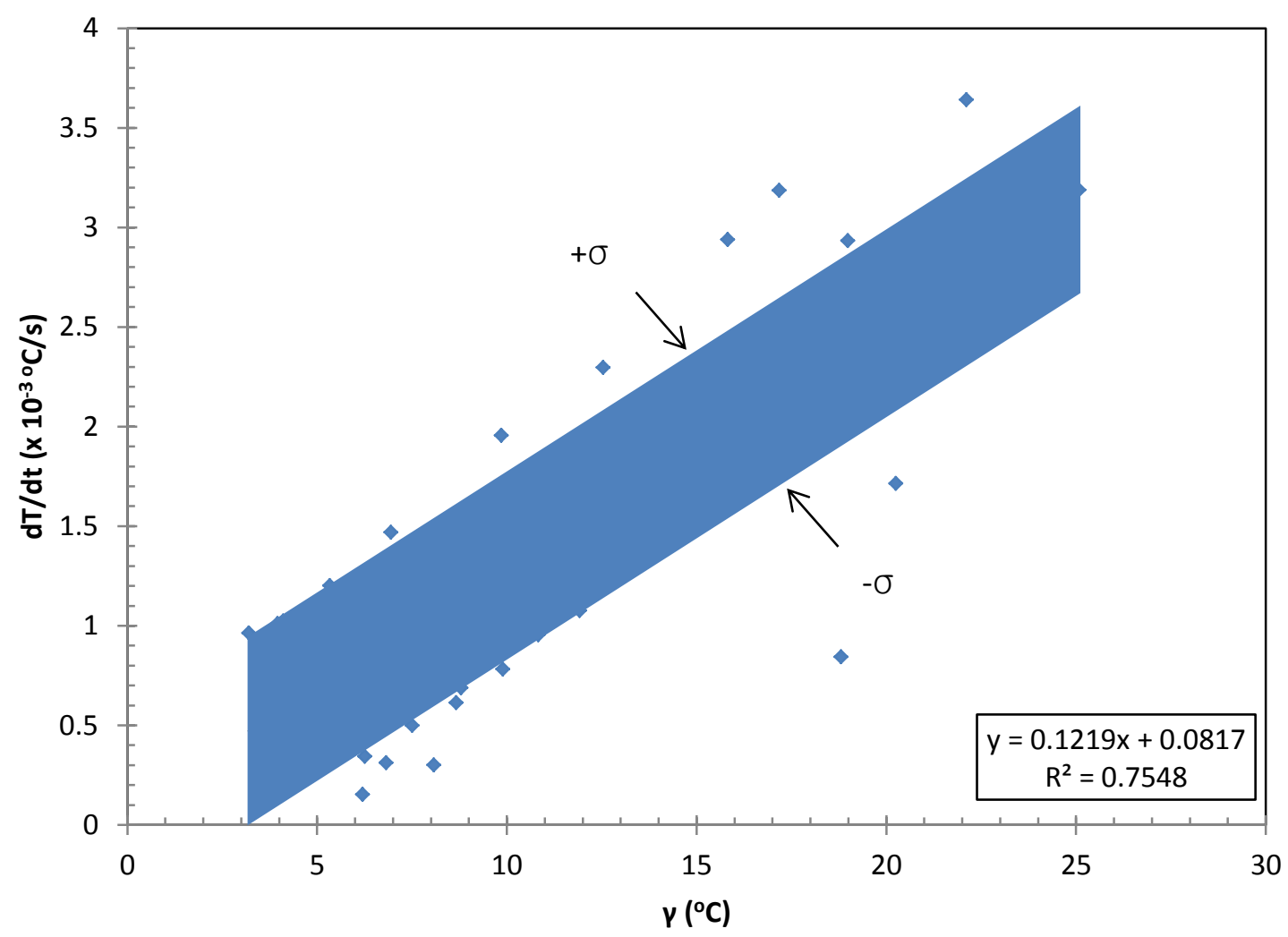

Figure 4-4: Rate of Temperature Rise Relative to $\gamma$ (Set-point - Current Node Temperature)

The solution for $m$ and $b$ for Equation 4.2 could be extracted from the linear regression results of Figure 4-4 and applied to the TRNSYS model. Some minor additional scaling was required to accommodate the $m$ and $c_{\mathrm{p}}$ terms of Equation 4.1, but the slope of the heating process from the heat pump was accurately assessed using this technique.

The results of the data driven modelling approach were applied to the TRNSYS model, and then compared to the experimental results over several set-point combinations. As a result, the temperature profiles for select vertical temperature nodes of the tank were observed to have waveform conformity between the simulation and experimental results. Additionally, the electrical energy consumption for all set-point 
combinations deviated by no more than $10 \%$. The results fora booster set-point of $70^{\circ} \mathrm{C}$ and heat pump set-point of $60^{\circ} \mathrm{C}$ are shown in Figure 4-5.
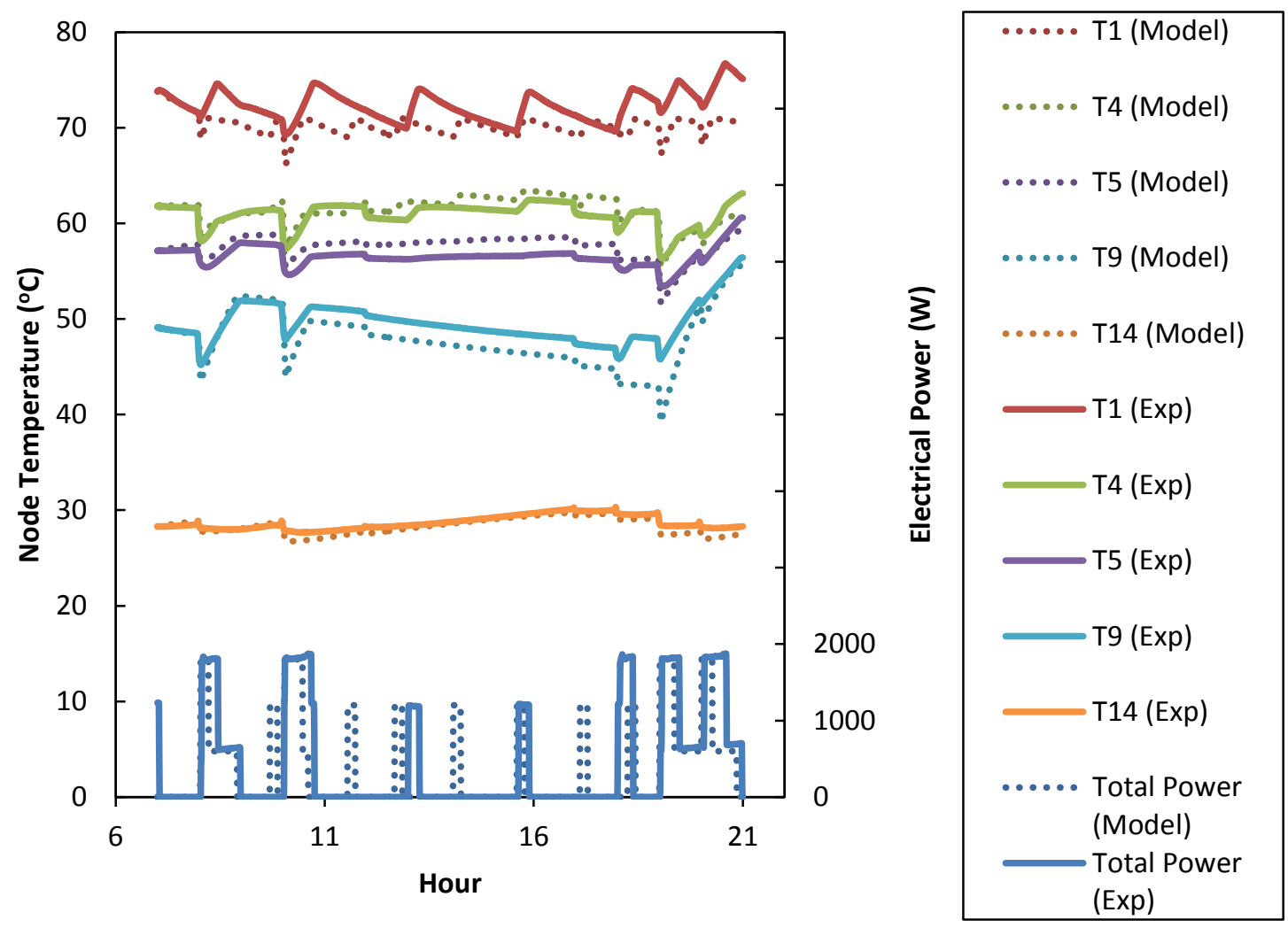

Figure 4-5: Comparison of Model and Experimental Temperature and Power for $70^{\circ} \mathrm{C}$ Booster and $60^{\circ} \mathrm{C}$ Heat Pump Set-points

\subsection{GenOpt}

In an effort to optimize design and operation of the HPWH, GenOpt was coupled with TRNSYS to implement advanced optimization techniques to minimize energy use by varying several inputs simultaneously. The results of this analysis did not include initial, operational, or maintenance costs. As a result, the optimization shifted toward unique optimal values for the energy case. 
GenOpt uses the previously defined techniques to alter defined parameters in an effort to minimize a cost function. For these simulations the cost function from Equation 4.3 was used to characterize the energy consumption of the HPWH system and achieve an optimal minimum.

$$
\begin{aligned}
\text { Energy Cost }=\text { Electricity Cost } *(\text { Heat Pump Energy }+ \text { Booster Energy }) \\
+ \text { Evaporator Energy } * \text { Heating Cost }
\end{aligned}
$$

Using this simplified equation, GenOpt operates to find an energy use minimum that accounts for both the electrical energy consumption of the unit itself and the impact on the heating system from the thermal interaction of both the condenser (tank side) and evaporator (surrounding space side) of the heat pump. Equation 4.3 also allows for many different utility rate combinations to be used to determine the optimal HPWH parameters for each region. A limitation of Equation 4.3 is the assumption that the evaporator energy is extracted from the surrounding space as a lumped heat source. Local utility rates were acquired for several major Canadian cities, as well as some international locations to demonstrate the cost benefit of the technology and provide an annual operational cost estimate. A summary of the locations and respective utility rates simulated is provided in Table 4-2. The primary heating source for each city was determined using provincial comprehensive energy use tables from Natural Resources Canada by selecting the most common heating source and their cost of electricity and heat per joule [5]. 
Table 4-2: Utility Cost Summary for GenOpt Simulations

\begin{tabular}{c|cccccc}
\hline City & $\begin{array}{c}\text { Electricity } \\
\$ / \mathrm{kWh}\end{array}$ & $\begin{array}{c}\text { Electricity } \\
\$ / \mathrm{J}\end{array}$ & $\begin{array}{c}\text { Principle } \\
\text { Heat Source }\end{array}$ & $\begin{array}{c}\text { Principle } \\
\text { Heat } \\
\text { Source } \\
\$ / G J\end{array}$ & $\begin{array}{c}\text { Principle } \\
\text { Heat Source } \\
\$ / \mathrm{J}\end{array}$ & $\begin{array}{c}\text { Principle } \\
\text { Heat/Electric } \\
\text { Cost Ratio }\end{array}$ \\
\hline Vancouver & 0.0752 & $2.09 \times 10^{-8}$ & Natural Gas & 8.66 & $8.66 \times 10^{-9}$ & 0.415 \\
Edmonton & 0.0658 & $1.83 \times 10^{-8}$ & Natural Gas & 4.19 & $4.19 \times 10^{-9}$ & 0.229 \\
Toronto & 0.0880 & $2.44 \times 10^{-8}$ & Natural Gas & 2.10 & $2.10 \times 10^{-9}$ & 0.086 \\
Ottawa & 0.0880 & $2.44 \times 10^{-8}$ & Natural Gas & 2.10 & $2.10 \times 10^{-9}$ & 0.086 \\
Montreal & 0.0557 & $1.55 \times 10^{-8}$ & Electricity & 15.47 & $1.55 \times 10^{-8}$ & 1.000 \\
Halifax & 0.1495 & $4.15 \times 10^{-8}$ & Heating Oil & 29.65 & $2.96 \times 10^{-8}$ & 0.714 \\
Whitehorse & 0.1087 & $3.02 \times 10^{-8}$ & Heating Oil & 32.89 & $3.29 \times 10^{-8}$ & 1.089 \\
Yellowknife & 0.2853 & $7.93 \times 10^{-8}$ & Heating Oil & 33.36 & $3.34 \times 10^{-8}$ & 0.421 \\
Berlin & 0.1839 & $5.11 \times 10^{-8}$ & Natural Gas & 988.73 & $9.89 \times 10^{-7}$ & 19.354 \\
& 1.6536 & $4.59 \times 10^{-7}$ & Natural Gas & $3,887.75$ & $3.89 \times 10^{-6}$ & 8.464 \\
\hline
\end{tabular}


For Ontario, where time of use rates occur and a static utility rate is not the case, a time of use profile was used to determine the optimal design and operation parameters. The findings of this optimization process were compared to using a blended rate that was weighted for the time period of each energy rate. It was determined that a time of use rate would not change the results of the optimization simulations from what was found using a static blended rate. As a result, only the blended rate was used for analysis in this thesis as shown in Table 4-2.

The coupling of TRNSYS and GenOpt was handled by a TESS utility called TRNOpt. This is a program that includes a coupling script and a GUI that allows the user to define the necessary TRNSYS and GenOpt parameters for an optimization simulation. In TRNOpt, the simulation must be set up sequentially starting with the variables, followed by the optimization equation, and finally with the optimization parameters. With respect to the variables, both continuous and discrete are allowed. Most variables in this optimization were of the continuous variety. To define these variables, a minimum, maximum, step size, and initial value were defined. Some of the variable parameters are given in Table 4-3. The cost function in this optimization, Equation 4.3, remained this throughout all simulations for consistency.

The resulting solution space for 10 parameters was $2.4 \times 10^{20}$. With a total of 20,000 unique iterations, the portion of the sample space explored was $8.33 \times 10^{-17} \%$ for the 10 parameter simulations, and $0.6 \%$ for the 3 parameter simulations. As a result of simulating a small portion of the sample space, a smaller problem can be scaled to determine the validity of the optimization results. 
Many optimization configurations will vary depending on the methods chosen. The maximum number of iterations and number of times a previous value can be obtained are present in all methods because they are the criteria for ending the optimization process. When using PSO, the neighborhood topology, neighborhood size, number of particles, number of generations, cognitive acceleration, social acceleration, maximum velocity gain continuous, maximum velocity gain discrete, and constriction gain must be defined. Most of these parameters were set to recommended values from similar optimization problems [12] [42], and are shown in Table 4-4.

Studies of optimal PSO parameters are the topic of extensive research, and are not a focal point of this thesis. Parameters that were tailored for this specific problem were the neighborhood topology, neighborhood size, number of particles, and number of generations. To achieve the best accuracy from the preliminary PSO analysis, the "lbest" or local best sub-method was chosen. This sub-method within PSO determines the optimal value based on each evaluation's interaction with previous local evaluations which will hereafter be referred to as particles. The neighborhood size defines the largest group of local particles that can interact with each other. The population size defines the number of evaluations that the PSO method can execute before it will be forced to choose an optimal value to pass to the Hooke-Jeeves method. The number of generations defines the maximum number of times the PSO method can hone in on local minima and reduce the range of the social algorithm. For this optimization, the number of PSO particles was maximized until it caused issues with the stability of TRNOpt, which was found to occur over 1000 particles. In contrast to the PSO method, the Hooke-Jeeves method only has 4 parameters, all of which have common recommended values for stable use [12] [42]. A 
screen shot of the TRNOpt interface is provided in Figure 4-6 to provide context to the description.

Table 4-3: Typical TRNOpt Variable Specifications

\begin{tabular}{c|ccccc}
\hline Name & Type & Minimum & Maximum & Step Size & Initial Value \\
\hline Booster Power & Continuous & $180 \mathrm{~W}$ & $18,000 \mathrm{~W}$ & $10 \mathrm{~W}$ & $180 \mathrm{~W}$ \\
Booster Set-point & Continuous & $55^{\circ} \mathrm{C}$ & $80^{\circ} \mathrm{C}$ & $0.1^{\circ} \mathrm{C}$ & $55^{\circ} \mathrm{C}$ \\
Booster Length & Continuous & $10 \mathrm{~cm}$ & $140 \mathrm{~cm}$ & $10 \mathrm{~cm}$ & $10 \mathrm{~cm}$ \\
Cold Water Set-point & Continuous & $1{ }^{\circ} \mathrm{C}$ & $30^{\circ} \mathrm{C}$ & $1{ }^{\circ} \mathrm{C}$ & $1{ }^{\circ} \mathrm{C}$ \\
Heat Pump Power & Continuous & $100 \mathrm{~W}$ & $10,000 \mathrm{~W}$ & $100 \mathrm{~W}$ & $2500 \mathrm{~W}$ \\
Heat Pump Set-point & Continuous & $55^{\circ} \mathrm{C}$ & $70^{\circ} \mathrm{C}$ & $0.1^{\circ} \mathrm{C}$ & $55^{\circ} \mathrm{C}$ \\
Heat Pump Length & Continuous & $10 \mathrm{~cm}$ & $140 \mathrm{~cm}$ & $10 \mathrm{~cm}$ & $10 \mathrm{~cm}$ \\
Evaporator Air Flow & Continuous & $100 \mathrm{l} / \mathrm{s}$ & $1000 \mathrm{l} / \mathrm{s}$ & $101 / \mathrm{s}$ & $1001 / \mathrm{s}$ \\
Tank Insulation & Continuous & $\mathrm{R}-1$ & $\mathrm{R}-10$ & $\mathrm{R}-0.1$ & $\mathrm{R}-1$ \\
Tank Volume & Continuous & $100 \mathrm{~L}$ & $1000 \mathrm{~L}$ & $1 \mathrm{~L}$ & $100 \mathrm{~L}$ \\
\hline
\end{tabular}


Table 4-4: Particle Swarm and Hooke-Jeeves Parameters

\begin{tabular}{|c|c|c|}
\hline Parameter & Optimization Type & Value \\
\hline Neighborhood Topology & Particle Swarm & lbest \\
\hline Neighborhood Size & Particle Swarm & 10 \\
\hline Number of Particles & Particle Swarm & 1000 \\
\hline Number of Generation & Particle Swarm & 10 \\
\hline Seed & Particle Swarm & 1 \\
\hline Cognitive Acceleration & Particle Swarm & 2 \\
\hline Social Acceleration & Particle Swarm & 2 \\
\hline Max Velocity Gain Continuous & Particle Swarm & 0.5 \\
\hline Max Velocity Discrete & Particle Swarm & 4 \\
\hline Constriction Gain & Particle Swarm & 0.5 \\
\hline Mesh Size Divider & Hooke-Jeeves & 2 \\
\hline Initial Mesh Size Exponent & Hooke-Jeeves & 0 \\
\hline Mesh Size Exponent Increment & Hooke-Jeeves & 1 \\
\hline Number of Step Reduction & Hooke-Jeeves & 4 \\
\hline
\end{tabular}




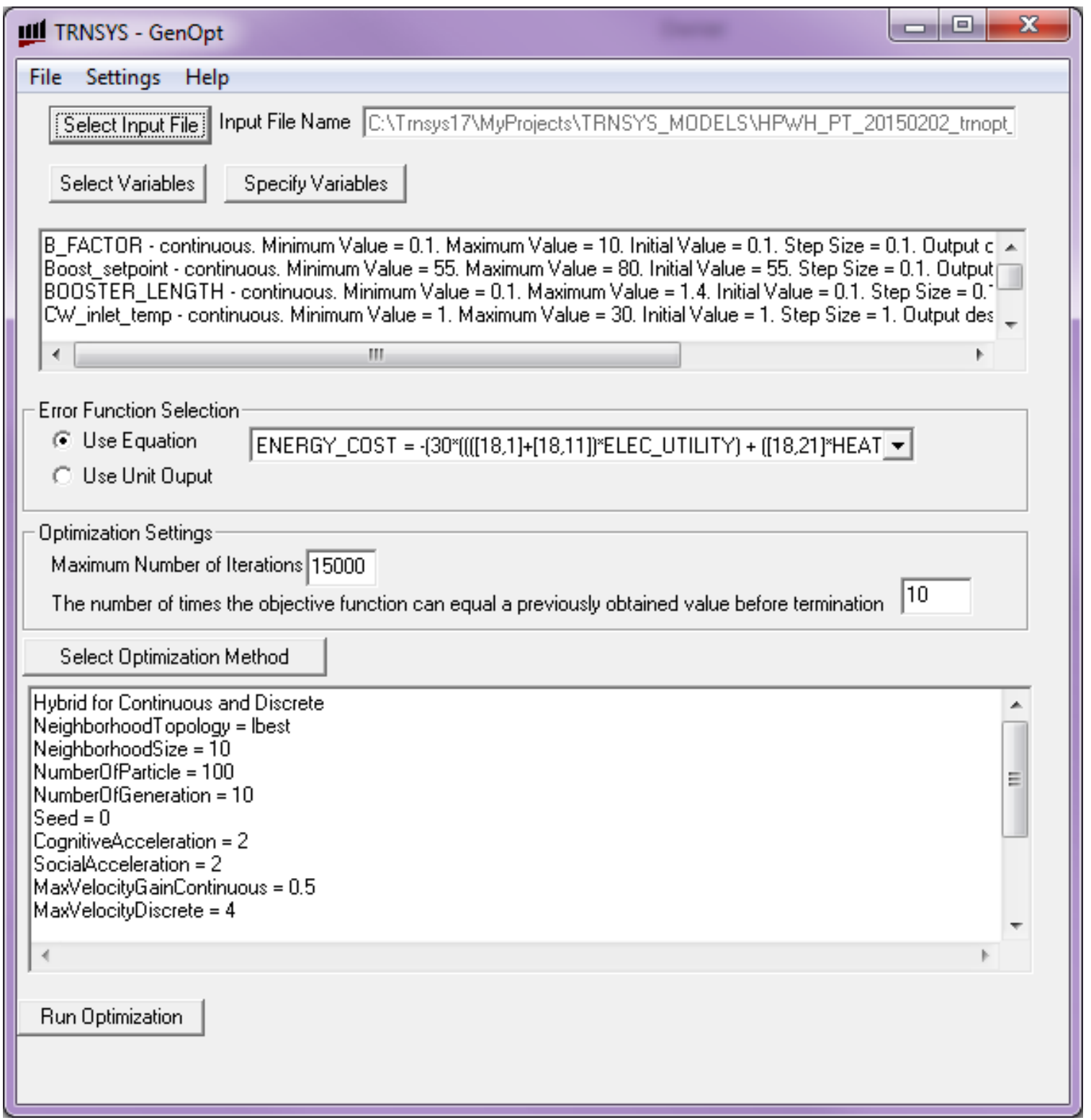

Figure 4-6: Configured TRNOpt User Interface

\subsection{Summary}

This chapter described the development of a TRNSYS model based on the experimental apparatus, the model calibration process, and the optimization techniques used to make design and usage recommendations. The next chapter will discuss the experimental results in detail. 


\section{Chapter: Results}

This project provided many opportunities to develop and showcase the results of a wide array of experiments and simulations. This chapter provides the details of the results that were used to determine optimal design and operational conditions with respect to energy for a HPWH unit in Canada. First, the experimental results are described, second, the modelling results, third, the optimization techniques and findings, and final, the sensitivity and uncertainty analysis is detailed.

\subsection{Experimental}

To verify models and extend results for further analysis using best practices, a set of experimental data was generated. The following sub sections describe the results used to generate the experimental data required to calibrate the TRNSYS model within $10 \%$ of the experimentally determined energy consumption for all tests.

\subsubsection{Experimental Results}

Several experimental runs were executed to characterize the HPWH performance parameters including power draw, energy consumption, and COP, as outlined in Table 4-1. To characterize the thermal response, the power demand and temperature profiles were plotted with respect to time. In conjunction, the COP and power demand were

plotted with respect to time to determine the heat pump performance with respect to fluid temperature. These plots were generated for all experimental runs, but only the high and 
low set-point temperature runs will be highlighted. Sensor types and locations are described in Section 3.3.

Set-point draw profile variation was used to characterize the thermal and electrical response of the HPWH unit for calibration purposes. Low temperature $\left(50^{\circ} \mathrm{C}\right.$ heat pump set-point) and high temperature $\left(62^{\circ} \mathrm{C}\right.$ heat pump set-point $)$ tests were used to define the boundary performance of the HPWH corresponding with the minimum temperature to prevent legionella growth and the maximum obtainable temperature of the heat pump [53]. These wave forms and the energy consumption of different components were used to determine the parameters of the heat transfer equations described in Section 4.6. The boundary test waveforms can be seen in Figure 5-1 and Figure 5-2 for CSAF379.1 Schedule C draw profiles, and two different booster/heat pump set-points.

Figure 5-1 and Figure 5-2 show the temperature increases that are experienced by the tank from the booster, the heat pump, and both simultaneously. They also show how the tank reacts during periods without heating, which proved useful in the calibration process to determine tank thermal properties with a black box approach. It is apparent from the figures that the tank is affected by the different heating equipment combinations, and that the tank was well insulated. This was reflected in the model and confirmed through the calibration process. The different regimes for the booster and heat pump can be seen by observing the temperature differences above and below the $105 \mathrm{~cm}$ node. 

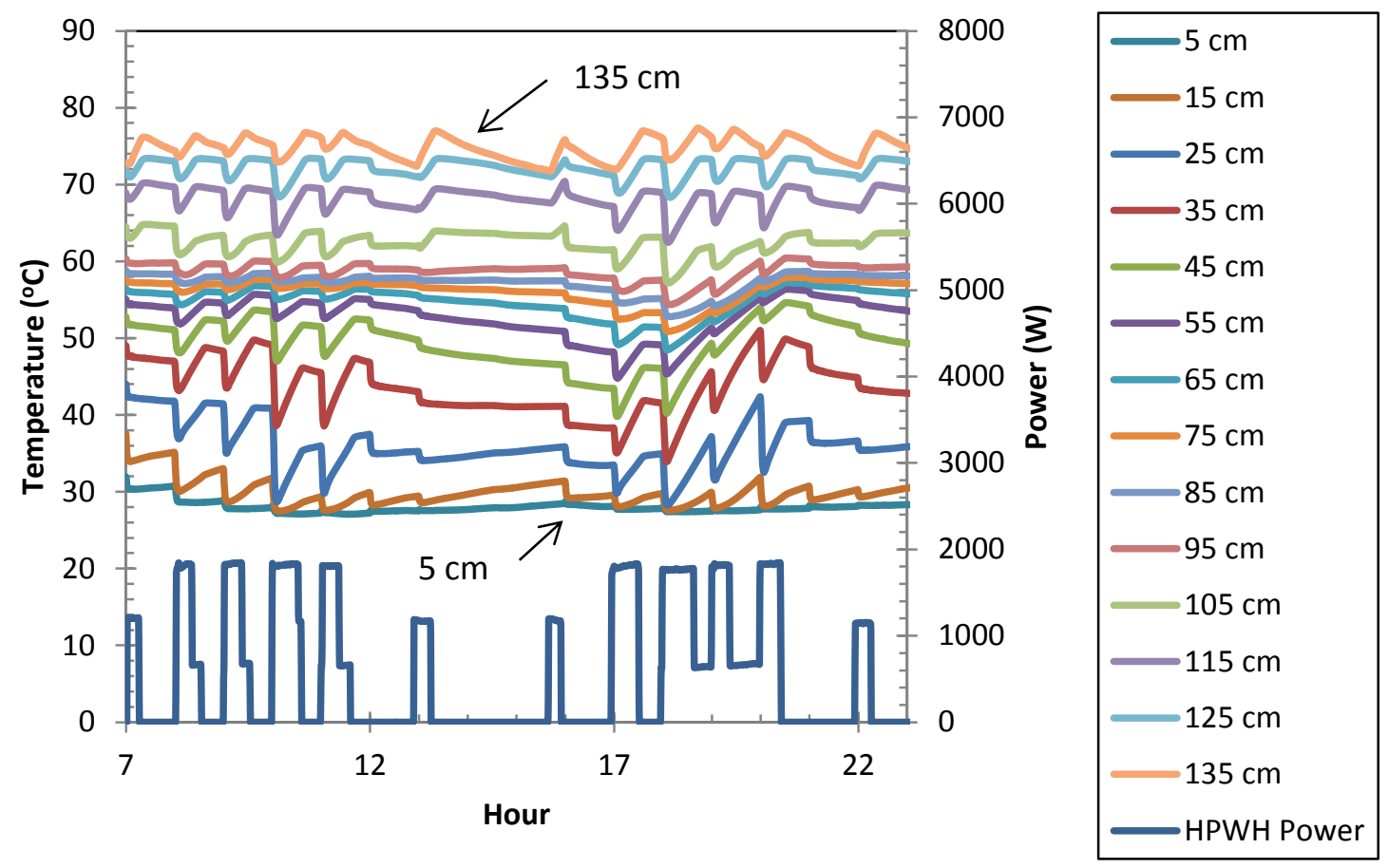

Figure 5-1: HPWH Temperature and Power Profile for Schedule $\mathrm{C}$ and $72^{\circ} \mathrm{C}$ Booster and $62^{\circ} \mathrm{C} \mathrm{Heat}$ Pump Set-points

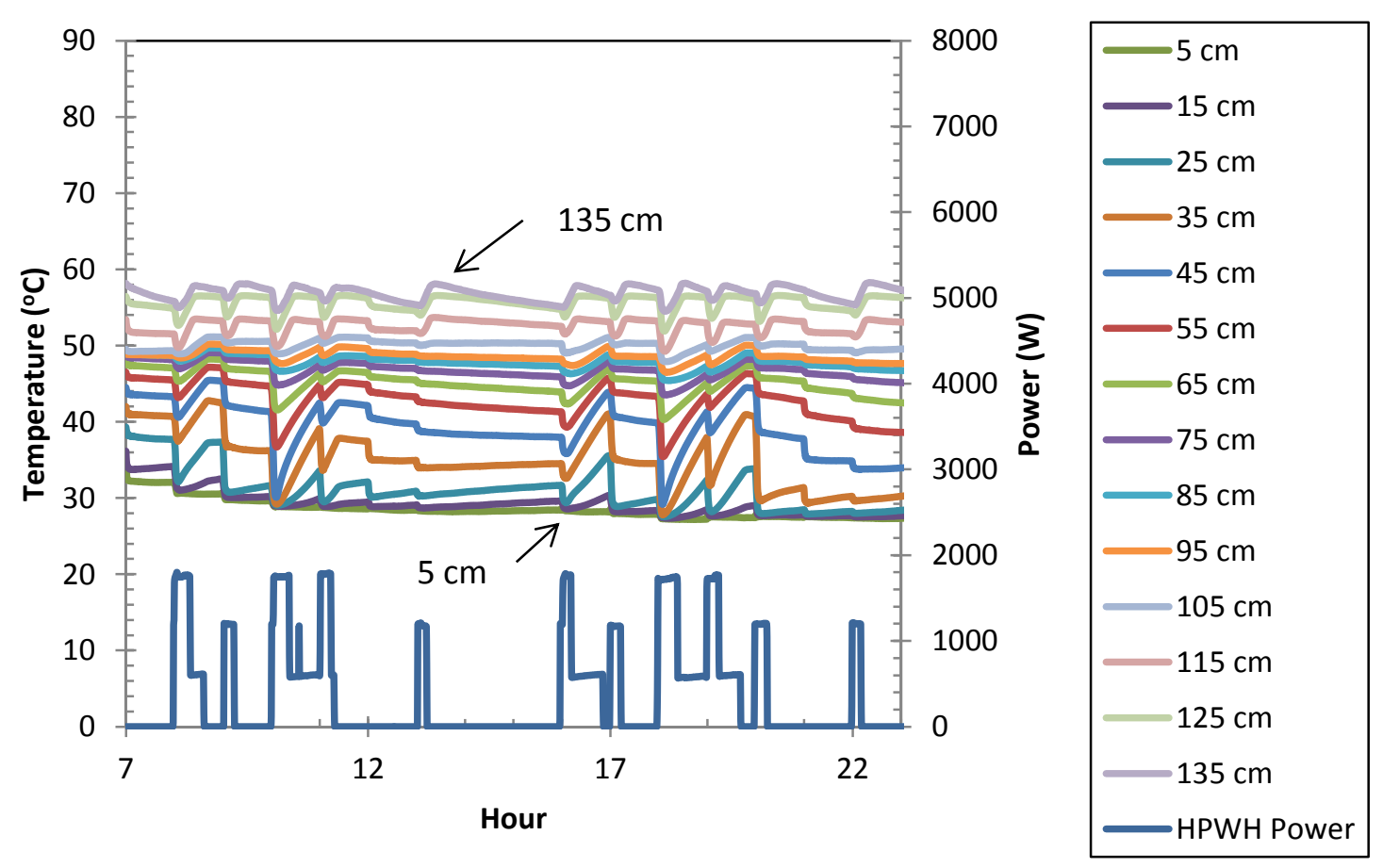

Figure 5-2: HPWH Temperature and Power Profile for Schedule $\mathrm{C}$ and $55^{\circ} \mathrm{C}$ Booster and $50^{\circ} \mathrm{C}$ Heat Pump Set-points 
The primary metrics that were calculated and analyzed in this thesis were the HPWH net energy use and COP. Net energy use was found by taking into account the

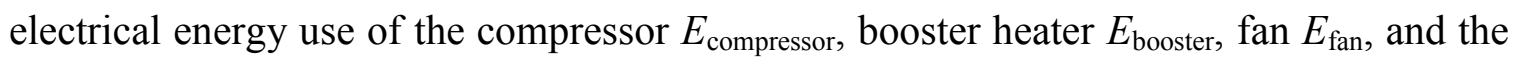
change of energy in the surrounding space, $\Delta E_{\text {space. }} \Delta E_{\text {space }}$ was defined as the difference between the thermal energy added to the water, $E_{\text {therm, }}$ and the electrical energy draw of the HPWH, $E_{\text {elec. }}$ The energy balance of the HPWH is shown in Equations 5.1 and 5.2.

$$
\begin{gathered}
\Delta E_{\text {space }}=E_{\text {therm }}-E_{\text {elec }} \\
E_{\text {net }}=E_{\text {compressor }}+E_{\text {booster }}+E_{\text {fan }}+\Delta E_{\text {space }}
\end{gathered}
$$

The result of these equations can be used to find the energy used by the HPWH over a period of time when applied to the experimental data. Also of interest is the instantaneous COP of the unit over various operating conditions. To find the COP, an equation based on a first order backward difference approach that included the sum of $E_{\text {therm }}$ over all the node and $E_{\text {elec }}$ was implemented, as shown in Equation 5.3. A backward difference approach was selected for simplicity. To find $E_{\text {therm }}$ from the experimental data, the thermal energy of each node was calculated where $\rho$ is the fluid density, $V$ is the node volume, $c_{\mathrm{p}}$ is the constant pressure coefficient, and $T_{\mathrm{n}, \mathrm{i}}$ and $T_{\mathrm{n}-1, \mathrm{i}}$ are the temperatures at the core of the node at the current and previous time step respectively.

$$
\mathrm{COP}=\frac{\sum \Delta E_{\text {therm }}}{\Delta E_{\text {elec }}}=\frac{\sum_{\mathrm{i}=1}^{13} \rho V c_{\mathrm{p}}\left(T_{\mathrm{n}, \mathrm{i}}-T_{\mathrm{n}-1, \mathrm{i}}\right)}{\Delta E_{\text {elec }}}
$$


The result of Equation 5.3 was used to instantaneously plot the COP of the HPWH unit over all experimental runs. Some limitations of this method are due to the simplification that the vertical nodes of the tank are at a constant temperature throughout their radial direction. This assumption was found to be valid in previous work by Cruickshank [39]. Power was averaged over 30 second intervals based on energy data from the power monitoring system. Producing these 2 metrics allowed the operating COP to be compared to the equipment in operation. As a result, when only the heat pump was running a COP between 1 and 3 was observed, and while when the booster heater was active, the COP was closer to 1 regardless of heat pump activity. Profiles of the COP and power draw of the tank are provided in Figure 5-3, Figure 5-4, Figure 5-5, and Figure 5-6 for Schedules A and C, as well as two different set-point conditions. For reference, the heat pump draws around $700 \mathrm{~W}$, the booster draws around $1200 \mathrm{~W}$, and both operating simultaneously draws around $1900 \mathrm{~W}$. Operating equipment can be identified from Figure 5-3, Figure 5-4, Figure 5-5, and Figure 5-6, based on the height of the waveform, and is further detailed in Appendix A. 


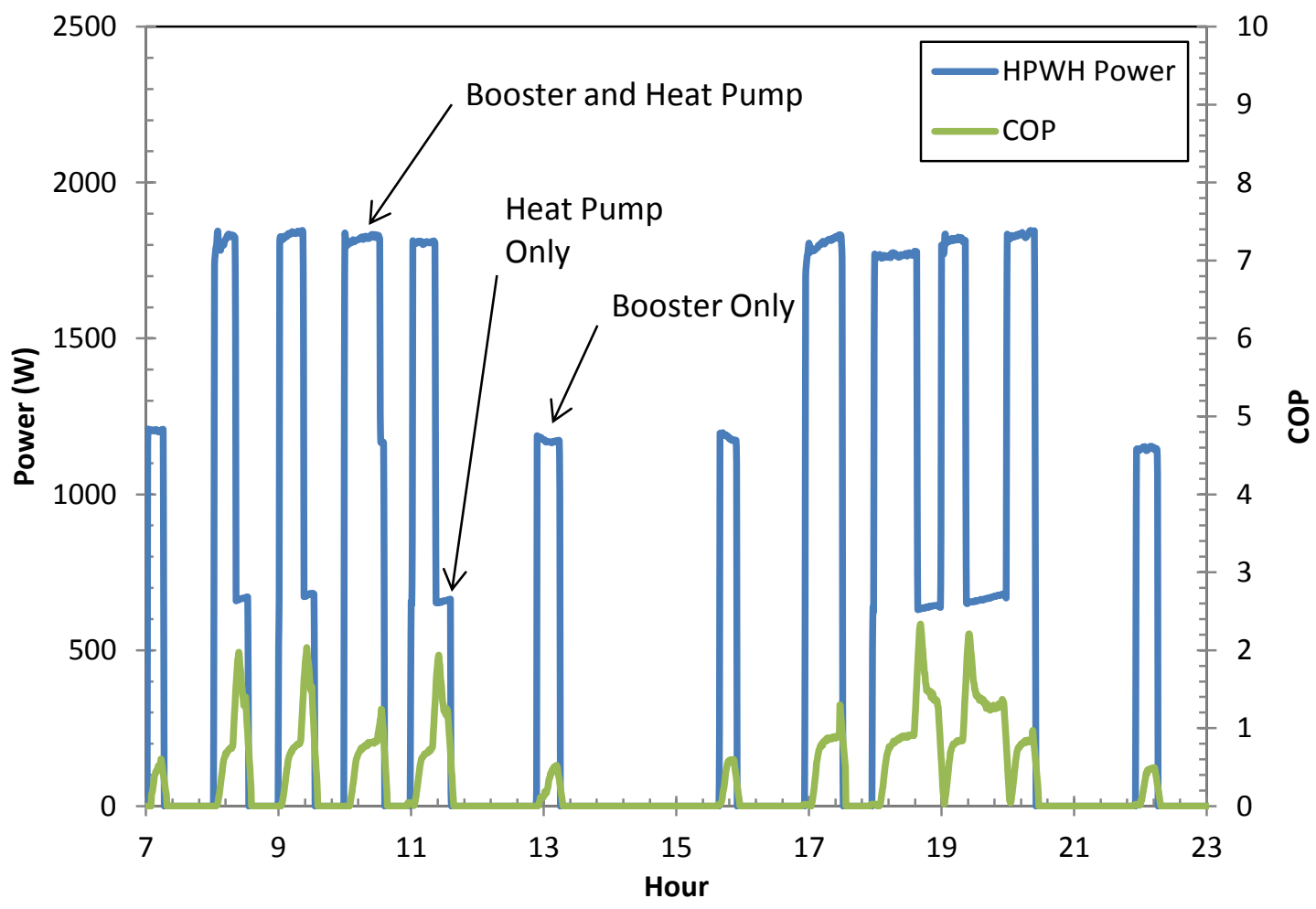

Figure 5-3: Schedule A for $72^{\circ} \mathrm{C}$ Booster and $62^{\circ} \mathrm{C}$ Heat Pump Set-points

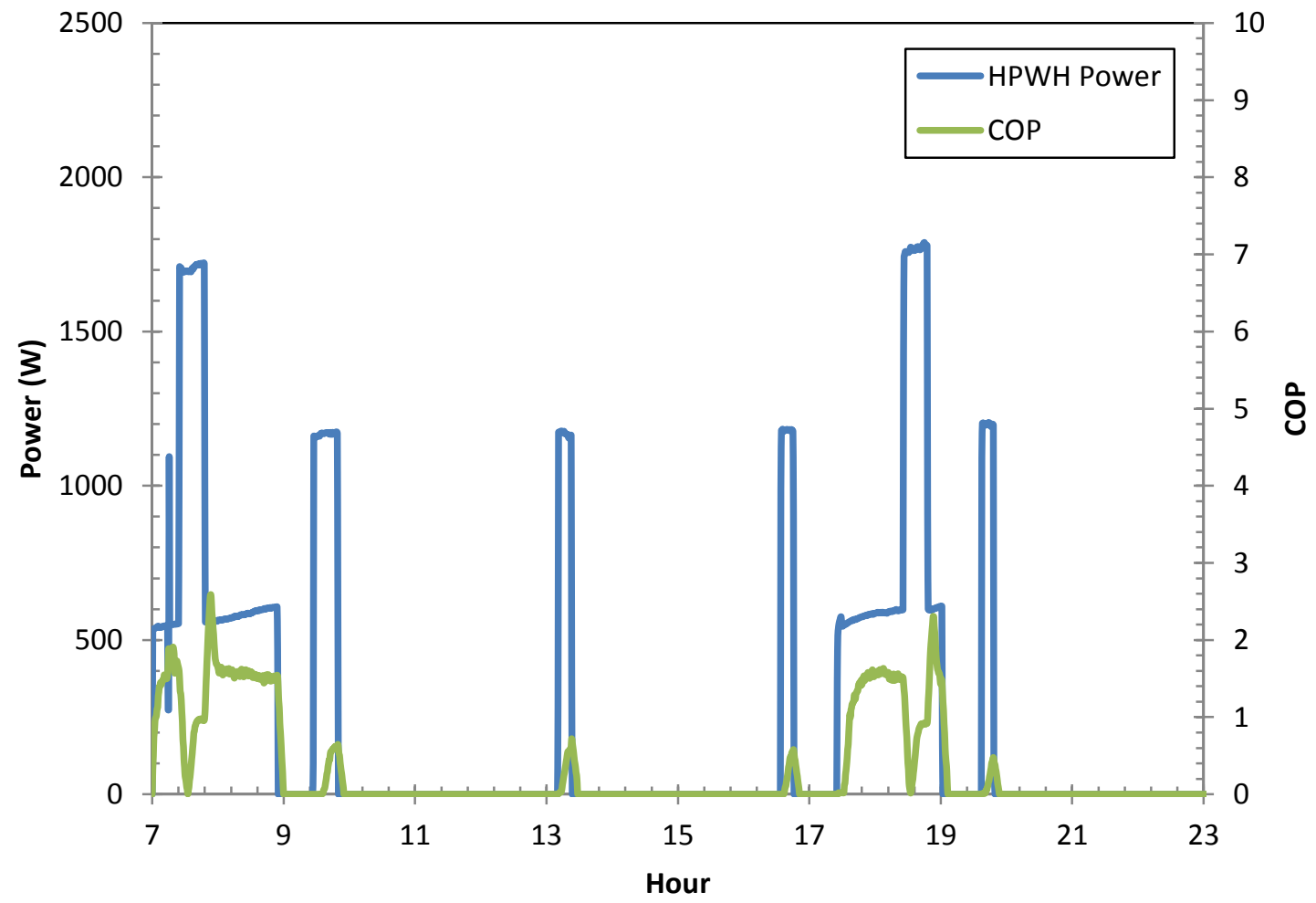

Figure 5-4: Schedule A for $55^{\circ} \mathrm{C} \mathrm{Booster}$ and $50^{\circ} \mathrm{C}$ Heat Pump Set-points 


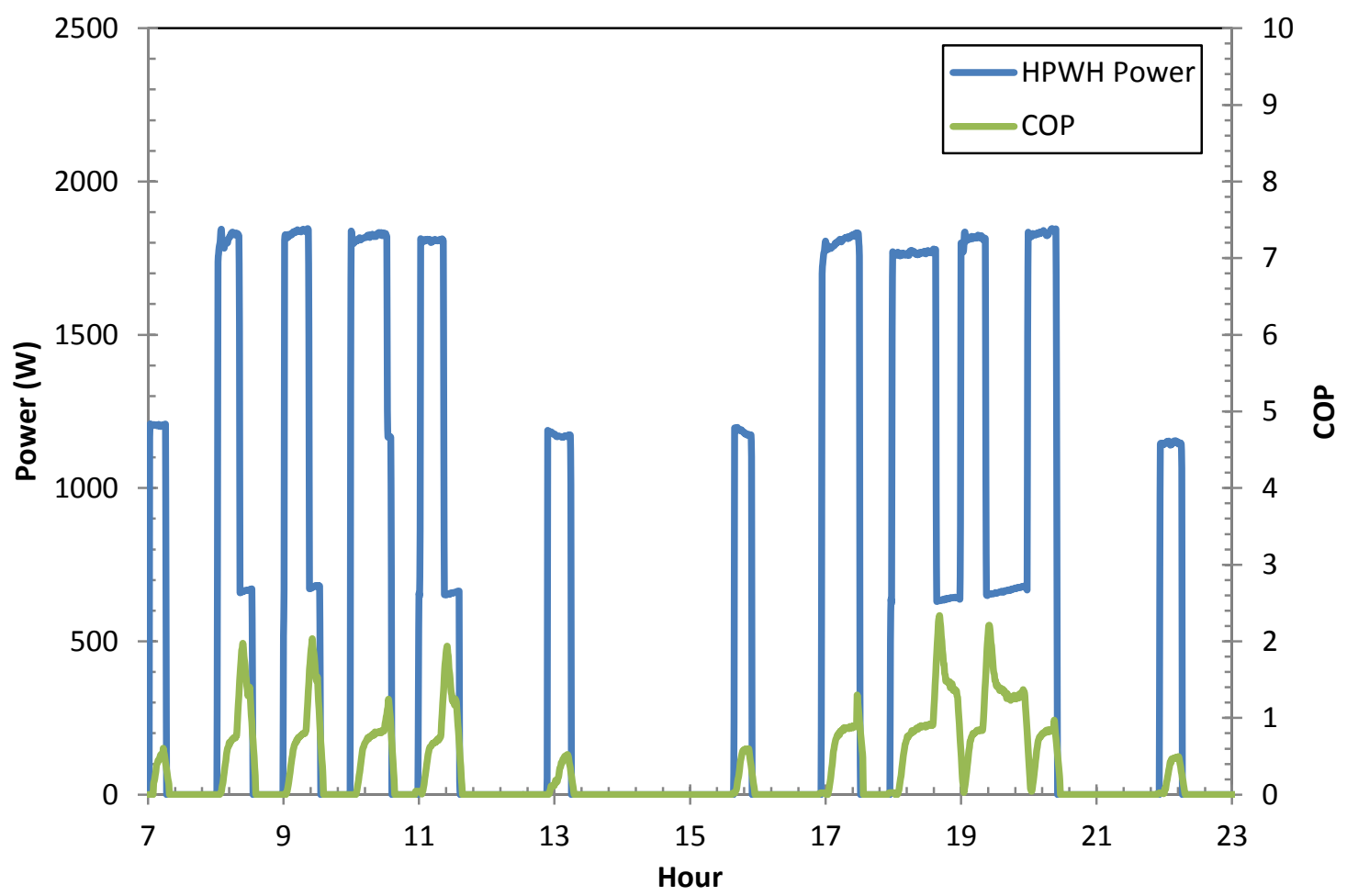

Figure 5-5: Schedule $\mathrm{C}$ for $72^{\circ} \mathrm{C}$ Booster and $62^{\circ} \mathrm{C}$ Heat Pump Set-points

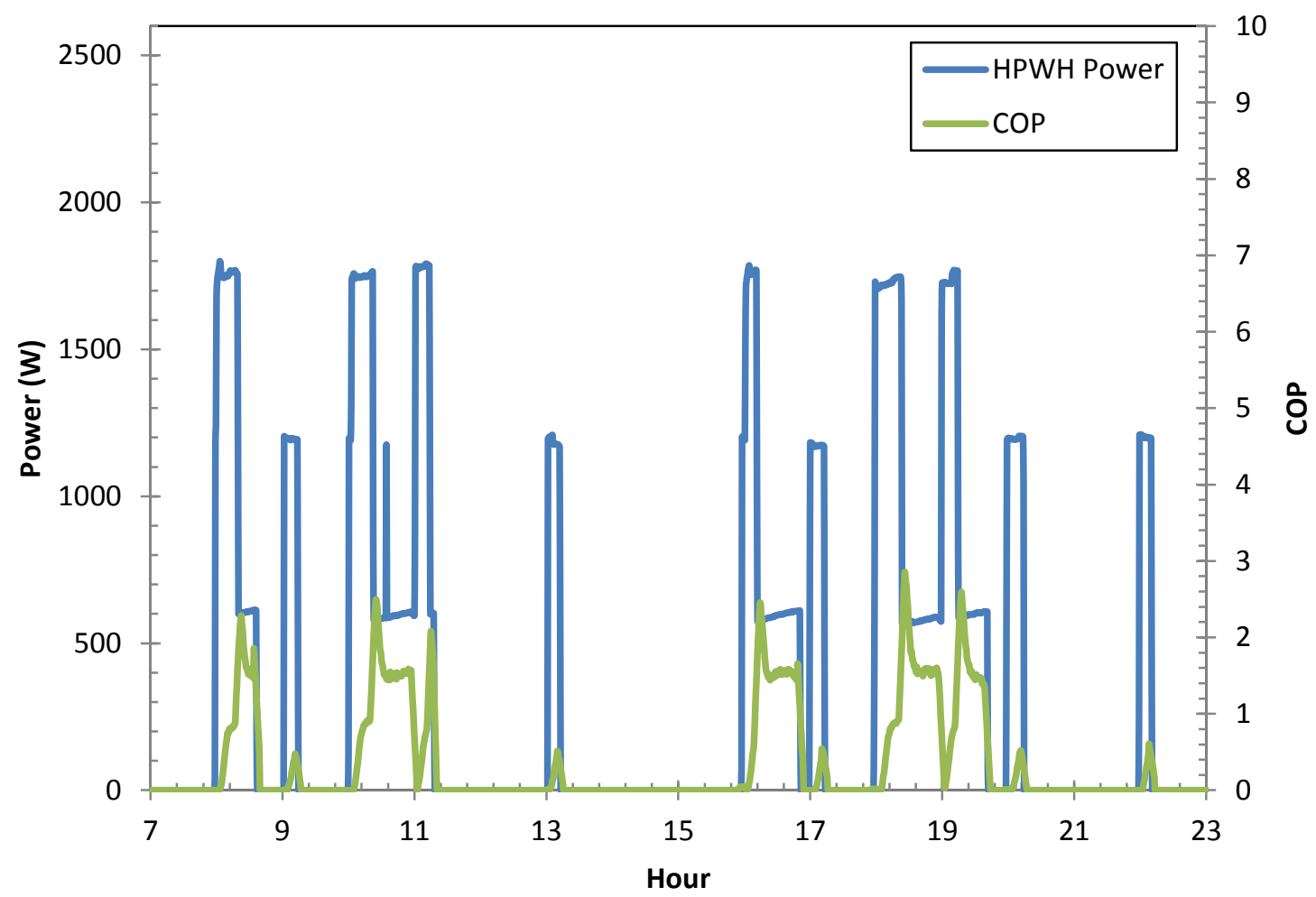

Figure 5-6: Schedule $\mathrm{C}$ for $5^{\circ} \mathrm{C}$ Booster and $50^{\circ} \mathrm{C}$ Heat Pump Set-points 
As expected, the unit obtained higher COP values when the set-point temperature was lower, and the COP would decrease as the tank temperature got closer to the setpoint. The spikes in the COP in Figure 5-3, Figure 5-4, Figure 5-5, and Figure 5-6 are a product of the temperature still rising from the booster heater being active and remaining at a high temperature, but only measuring the heat pump power. Shortly after the activation of the heat pump the COP begins to stabilize and decrease. Significant noise was present in the COP due to temperature fluctuations and the conglomerate measurement of all the node temperatures. This was mitigated by adding a black moving average trend line to highlight the average COP over several data points.

Under the conditions present in the laboratory where the $\mathrm{HPWH}$ was tested $\left(22^{\circ} \mathrm{C}\right.$ and $30 \%$ relative humidity), the COP rarely went above 2 , even in the $50^{\circ} \mathrm{C}$ heat pump set-point case. In the higher temperature case, when the heat pump set-point was $62^{\circ} \mathrm{C}$, the COP did not go above 1.5. During booster heater only operation the COP stabilized around 0.7, indicative of inefficiencies in the electrical system and heat losses from the tank to the surrounding space. When both heating sources were active, the COP was roughly an interpolation of the two heating systems based on the quantity of heat supplied. As a result, the booster heater had a dominating effect on the COP of the whole unit when active. In all test cases, the COP observed during the laboratory experiments was significantly lower than the COP provided in the manufacturer data.

The temperature difference between the condenser and the media being operated upon (the tank water in this case) has a large effect on the COP as well. As the water in the tank approaches the set-point, the COP will degrade, as shown in Figure 5-3 to Figure 5-6. The nominal COP of 3.18 given in the manufacturer literature is likely a product of 
heating the tank water from room temperature to a low set-point with higher air humidity than tested in this experiment. Realistic performance on a whole was found to be approximately a COP of 2 under light load (CSA-F379.1 Schedule A) and when the tank was maintaining a minimal set-point temperature.

The most energy efficient runs were at lower set-points $\left(55^{\circ} \mathrm{C}\right.$ for the booster, $50^{\circ} \mathrm{C}$ for the heat pump) and with smaller hot water draw profiles. This would take advantage of the tank's ability to store the heat added to the water and deliver it on demand. Lowering the difference between the booster heater and heat pump set-points also had a positive impact on the energy performance, as further detailed in Section 5.2.3.

Five different heat pump and booster heater set-point combinations were tested using CSA-F379.1 Schedules A and C for the purpose of calibrating the TRNSYS model. They included the set-point combinations and electrical energy use results seen in Table 5-1 and Table 5-2. Equipment activity is provided as a percentage of total testing time.

Additional points were desired to generate a more complete performance map, but equipment malfunctions rendered extended testing impossible.

Table 5-1: Experimental Energy Results Summary (Schedule A)

\begin{tabular}{c|ccccc}
\hline $\begin{array}{c}\text { HP/Booster } \\
\text { Set-point }\end{array}$ & Energy Consumption (MJ) & HP Activity & Booster Activity & Both Activity & Inactivity \\
\hline $50 / 55$ & 15.3 & $16.4 \%$ & $7.1 \%$ & $4.4 \%$ & $72.0 \%$ \\
$55 / 60$ & 19.6 & $19.2 \%$ & $4.8 \%$ & $8.5 \%$ & $67.3 \%$ \\
$55 / 65$ & 19.7 & $9.3 \%$ & $6.6 \%$ & $9.1 \%$ & $74.8 \%$ \\
$60 / 70$ & 22.9 & $9.4 \%$ & $6.4 \%$ & $13.6 \%$ & $70.5 \%$ \\
$62 / 72$ & 19.6 & $8.6 \%$ & $7.3 \%$ & $11.8 \%$ & $72.2 \%$ \\
\hline
\end{tabular}


Table 5-2: Experimental Energy Results Summary (Schedule C)

\begin{tabular}{c|ccccc}
\hline $\begin{array}{c}\text { HP/Booster } \\
\text { Set-point }\end{array}$ & Energy Consumption (MJ) & HP Activity & Booster Activity & Both Activity & Inactivity \\
\hline $50 / 55$ & & & & & \\
$55 / 60$ & 21.7 & $16.3 \%$ & $7.1 \%$ & $10.2 \%$ & $66.3 \%$ \\
$55 / 65$ & 25.3 & $26.7 \%$ & $9.7 \%$ & $7.9 \%$ & $55.6 \%$ \\
$60 / 70$ & 33.6 & $14.2 \%$ & $10.5 \%$ & $16.9 \%$ & $58.3 \%$ \\
$62 / 72$ & 33.0 & $11.9 \%$ & $9.8 \%$ & $19.6 \%$ & $58.6 \%$ \\
\hline
\end{tabular}

Examining the equipment activity in Table 5-1 and Table 5-2, it becomes clear that the booster heater becomes dominant as the booster set-point increases and as the difference between the booster and heat pump set-points widen. This trend complies with the owner manual suggestion to keep the set-points near each other for optimal energy performance. Some runs may have also been affected by the timing of the draws, which may have increased the energy consumption of the HPWH.

To further illustrate the non-linear performance of the HPWH with respect to setpoint temperatures, a series of simulations were executed to complete the performance map with the calibrated energy model. The TRNSYS model was used for heat pump setpoints between $50^{\circ} \mathrm{C}$ and $65^{\circ} \mathrm{C}$ at $1^{\circ} \mathrm{C}$ intervals, and booster set-points between $55^{\circ} \mathrm{C}$ and $75^{\circ} \mathrm{C}$ at $1{ }^{\circ} \mathrm{C}$ intervals. From combinatorial simulation, Figure 5-7 and Figure 5-8 were generated to graphically represent the relative energy performance of the HPWH using a surface and contour plot. The relative performance is the total energy use of the HPWH with respect to its use when the heat pump set-point is $50^{\circ} \mathrm{C}$ and the booster set-point is $55^{\circ} \mathrm{C}$. This is represented as a relative performance of 1 . Any simulations that resulted in less energy use than the reference case would have a value lower than 1, and any cases where the energy use was higher would have a value greater than 1 . As a result, lower values indicate lower overall energy consumption. The surface plots support the 
observation that the best performance is when the heat pump and booster set-points are near each other, and the booster set-point is slightly higher than the heat pump set-point. The rough gradient of incremental energy cost is also displayed where the energy use increases diagonally as the set-points increase simultaneously. Of the cases simulated, the best performance was observed when the heat pump and booster had set-points of $55^{\circ} \mathrm{C}$. Similar performance could also be found at adjacent set-point combinations.

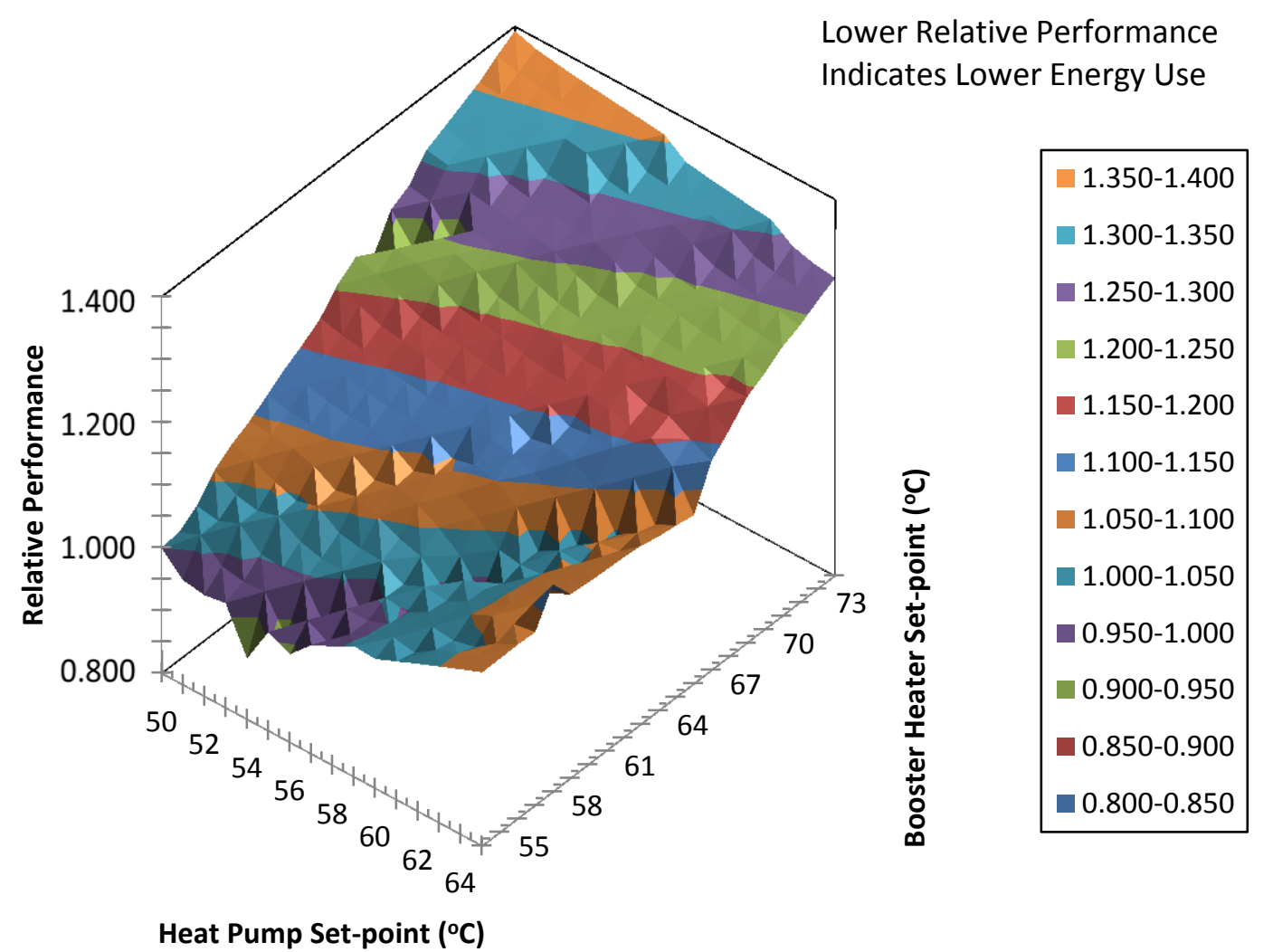

Figure 5-7: Relative HPWH Energy Usage for Various Set-point Combinations (3D) 


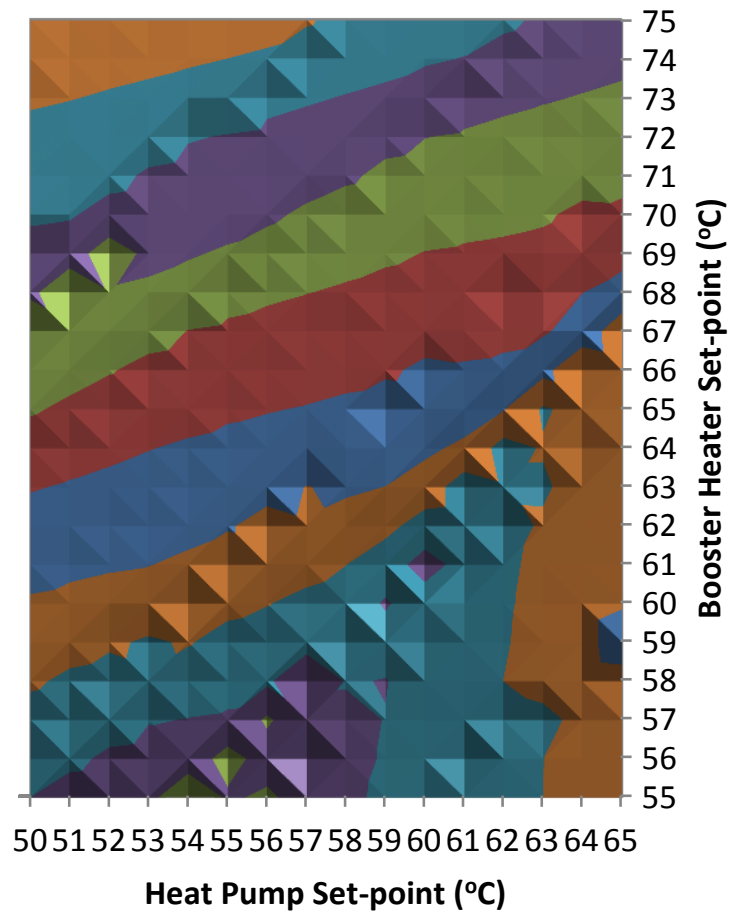

\begin{tabular}{|c|}
\hline $1.350-1.400$ \\
$1.300-1.350$ \\
$1.250-1.300$ \\
$1.200-1.250$ \\
$1.150-1.200$ \\
$1.100-1.150$ \\
$1.050-1.100$ \\
$1.000-1.050$ \\
$0.950-1.000$ \\
$0.900-0.950$ \\
$0.850-0.900$ \\
$0.800-0.850$
\end{tabular}

Heat Pump Set-point $\left({ }^{\circ} \mathrm{C}\right)$

Figure 5-8: Relative HPWH Energy Usage for Various Set-point Combinations (Contour)

To simulate the combinations of parameters in the surface plots of Figure 5-7 and Figure 5-8, GenOpt coupled with TRNSYS was utilized to automate the simulation process. Further details of the modelling results of optimization runs will be discussed in Section 5.2.

\subsection{Modelling}

In the presence of limited experimental data, modelling is a powerful tool. For this thesis, modelling was used to extend the findings from experimental apparatus to conditions that could not be tested with the existing equipment. The following sections detail the TRNSYS model outputs and their presentation format, the modelling procedure 
used to maintain consistency, the results of the GenOpt optimizations, and the sensitivity results that verified the findings of GenOpt.

\subsubsection{Model Outputs and Result Format}

The HPWH performance was evaluated through post-processing the energy data from the TRNSYS model. The thermal energy was monitored in the model with a mass balance of each node at each time step, and the values were summed to determine the total change in energy of the tank from the heating equipment. This is the same process that was used to calculate the thermal energy from the physical system.

Simulation results were sent to a spreadsheet where post processing could occur. The temperature and electrical data was used to determine the total net energy use and COP of the HPWH with respect to time. The thermal energy change of each node with respect to time was found using Equation 5.4, a slight modification of Equation 4.1 to accommodate energy rather than power.

$$
E_{\text {therm }}=\rho V c_{\mathrm{p}}\left(T_{\mathrm{n}, \mathrm{i}}-T_{\mathrm{n}-1, \mathrm{i}}\right) \Delta t
$$

This energy could then be applied to Equation 5.3 to determine the COP from both the model and the experimental data. Using consistent calculation methods for both the experimental and model data was important for data consistency in both model calibration and extension of the model to additional cases.

Additionally, the water draw volumes were monitored to confirm consistency with CSA-F379.1. In the experimental data there was some variation in the draw values due to pressure from the tank heating forcing flow at a higher rate than calibrated to by 
the throttling valve, so identifying the difference between the precise simulated values and actual experimental values in calibration was of significance. The variation ended up being less than $200 \mathrm{~mL}$ for each draw, which worked out to $4 \%$ for the smallest draw of $5 \mathrm{~L}$.

\subsubsection{GenOpt Results}

Optimization was conducted through simulation using GenOpt coupled with TRNSYS via TRNOpt. Further detail of the process is described in Section 2.5 of this thesis. This section outlines results from the design parameter, performance parameter, and utility rate ratio scenarios. The utility rate ratio is defined as the cost of heating fuel over the cost of electricity per joule of energy.

The design parameter runs of GenOpt focused on the 10 parameters listed in Table 5-3, based on the ranges of Table 4-3. The results of the GenOpt simulation with respect to energy consumption were monotonic (save for the evaporator air flow), because capital, maintenance, and operation costs were not accounted for. An additional weakness of using only energy use as the determining metric for these runs was the likelihood that the parameters would shift to values that were impractical for tank temperature recovery after large hot water draws. All of the parameters related to the booster size shifted towards their minima, as expected when trying to reduce expensive electricity consumption. Meanwhile, the heat pump shifted to a size that would likely be impractical for the installation space of a typical hot water heater. Additionally, the tank shifted toward the minimum size within the simulation range at $100 \mathrm{~L}$ and the tank 
insulation shifted toward the maximum of R-10. These shifts are visualized as simulated by GenOpt in Figure 5-9, with the resulting energy use progression shown in Figure 5-10.

Table 5-3: Summary of GenOpt Parameters Analyzed with Respect to Table 4-3

\begin{tabular}{c|c}
\hline Name & Optimal Value \\
\hline Booster Power & $180 \mathrm{~W}$ \\
Booster Set-point & $55^{\circ} \mathrm{C}$ \\
Booster Length & $10 \mathrm{~cm}$ \\
Cold Water Set-point & $30^{\circ} \mathrm{C}$ \\
Heat Pump Power & $10,000 \mathrm{~W}$ \\
Heat Pump Set-point & $55^{\circ} \mathrm{C}$ \\
Heat Pump Length & $140 \mathrm{~cm}$ \\
Evaporator Air Flow & $500 \mathrm{~L} / \mathrm{s}$ \\
Tank Insulation & $\mathrm{R}-10$ \\
Tank Volume & $100 \mathrm{~L}$ \\
\hline
\end{tabular}




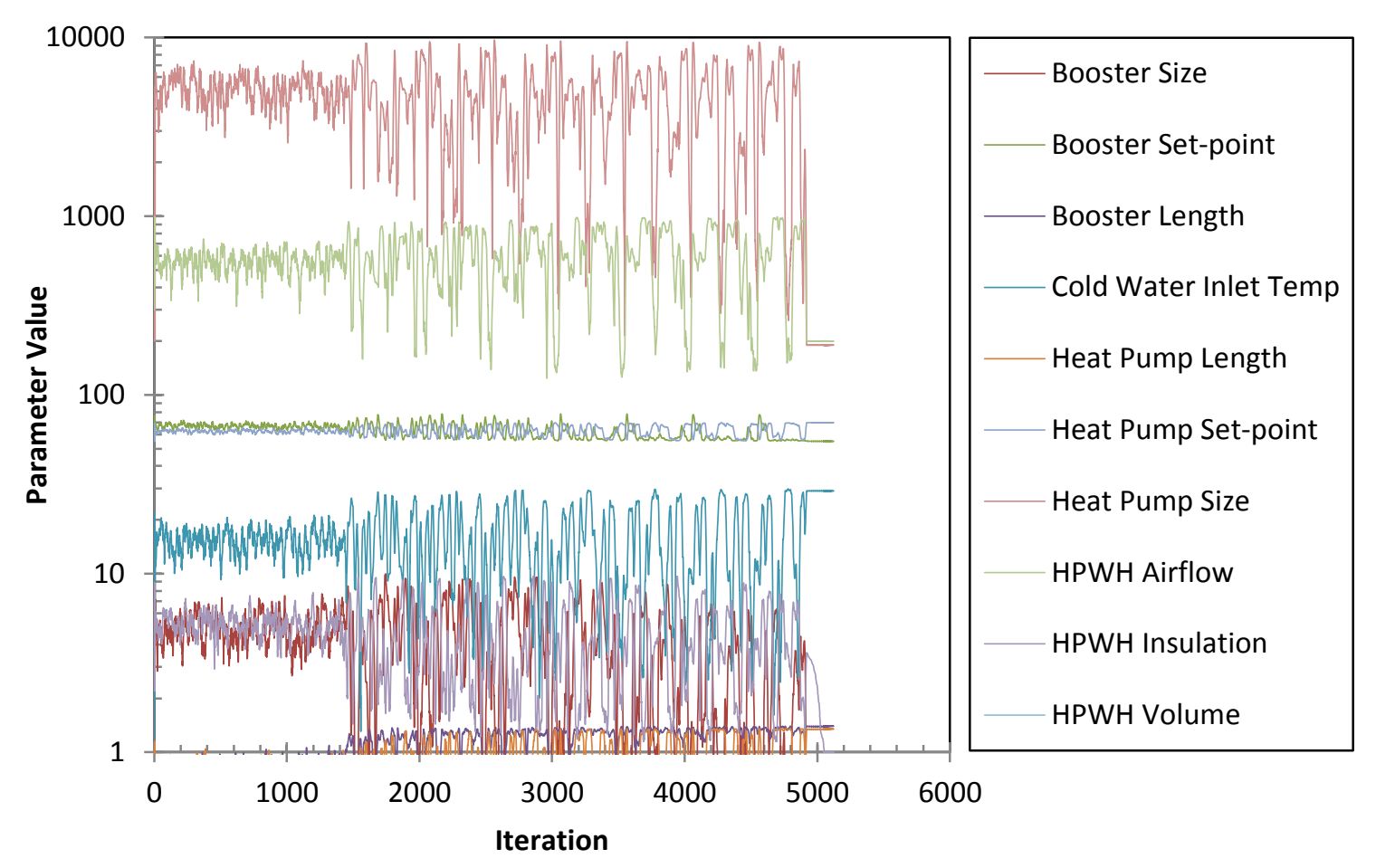

Figure 5-9: Parameter Progression for Design Optimization (Ottawa)

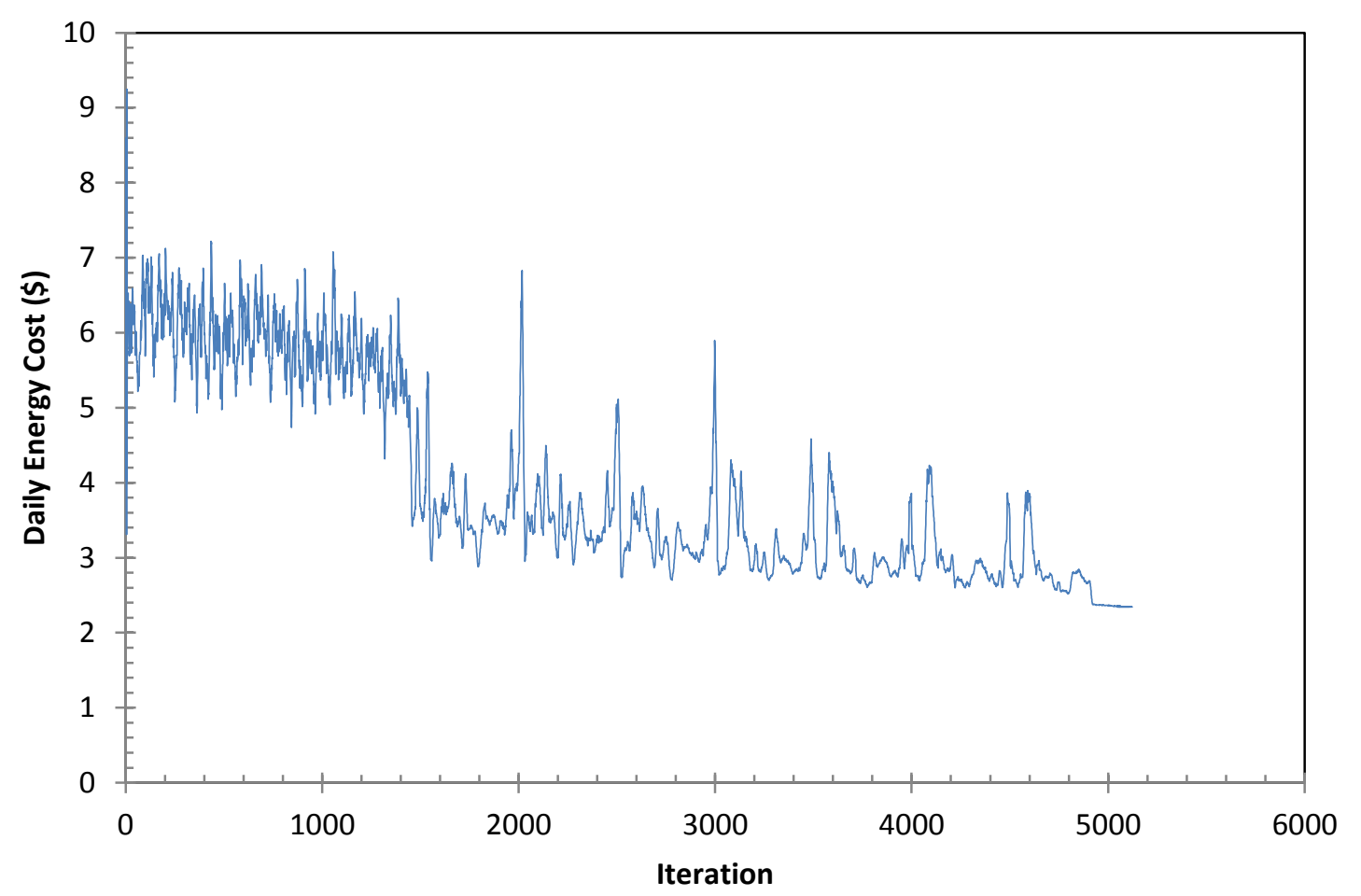

Figure 5-10: Result Progression for Design Optimization (Ottawa) 
Some of these trends could be incorporated into the HPWH design, but not without first analyzing capital costs and installation practicality. The booster heater is already quite small relative to most standard electric hot water heaters of $300 \mathrm{~L}$ volume, and is sized as it is to meet high demand in lieu of when the slow recovery heat pump cannot. For this reason, the booster heater should likely remain at its current size, but have the control adjusted to limit operation to only the highest of volume demands. The heat pump would not be easy to increase significantly in size due to the dimensional requirements of hot water heaters. Additionally, the temperature of the condenser is limited by the refrigeration properties, therefore the only true increase would be the heat transfer area of a surface at that temperature. Other heat pump water heaters have larger heat pumps that deliver more nominal heating power [54] [55], so it may be possible in future iterations to increase the capacity and heat transfer area of the wrap around heat exchanger. The volume of the tank is another parameter that would be difficult to change due to standardization of tank sizes. The optimization process identified a smaller tank as a more energy efficient option, likely due to reduced surface area for thermal losses to the environment. This works well in concert with the option of increasing the heat pump size, so choosing one or a combination of the two could yield better performance than the current design.

Tank insulation is a parameter that could be changed after manufacturing with reasonable success. Solutions are offered that allow hot water tank owners to add a wrap to hot water tanks to increase their R-value and reduce thermal losses. However, these 
options are more cumbersome and likely less effective than increasing the thickness of the surrounding insulation during manufacturing.

Many of the parameters tested in the design parameter runs would require permanent and invasive modifications to the HPWH unit, so their feasibility of lab testing was minimal. As a result, three parameters that could be actively varied were identified for experimental analysis and further simulation; booster set-point, heat pump set-point, and evaporator air flow.

For the performance parameter optimization, the temperature set-points moved toward their minimum values, while the evaporator air flow moved to a value in the middle of its range. This is indicative of the energy savings from keeping the heat pump set-point as low as possible to yield better performance, the minimization of the set-point differential between the booster heater and the heat pump to minimize the booster heater dominant regime, and an optimal evaporator air flow to satisfy the heat pump heat requirement prescribed by the experimental calibration. The temperature set-points in all cases will likely move toward the lowest values defined by the optimization boundaries, which confirms that low temperature hot water storage is the best option from an energy perspective. Meanwhile, the middling optimal value of the fan flow rate indicates that the fan on the stock HPWH was undersized for even the lowest possible temperature setting. This could have been a design decision made to either minimize fan costs, or to reduce turbulent air flow in the adjacent space to the HPWH. The progression of the GenOpt simulation is shown in Figure 5-11 and Figure 5-12. 


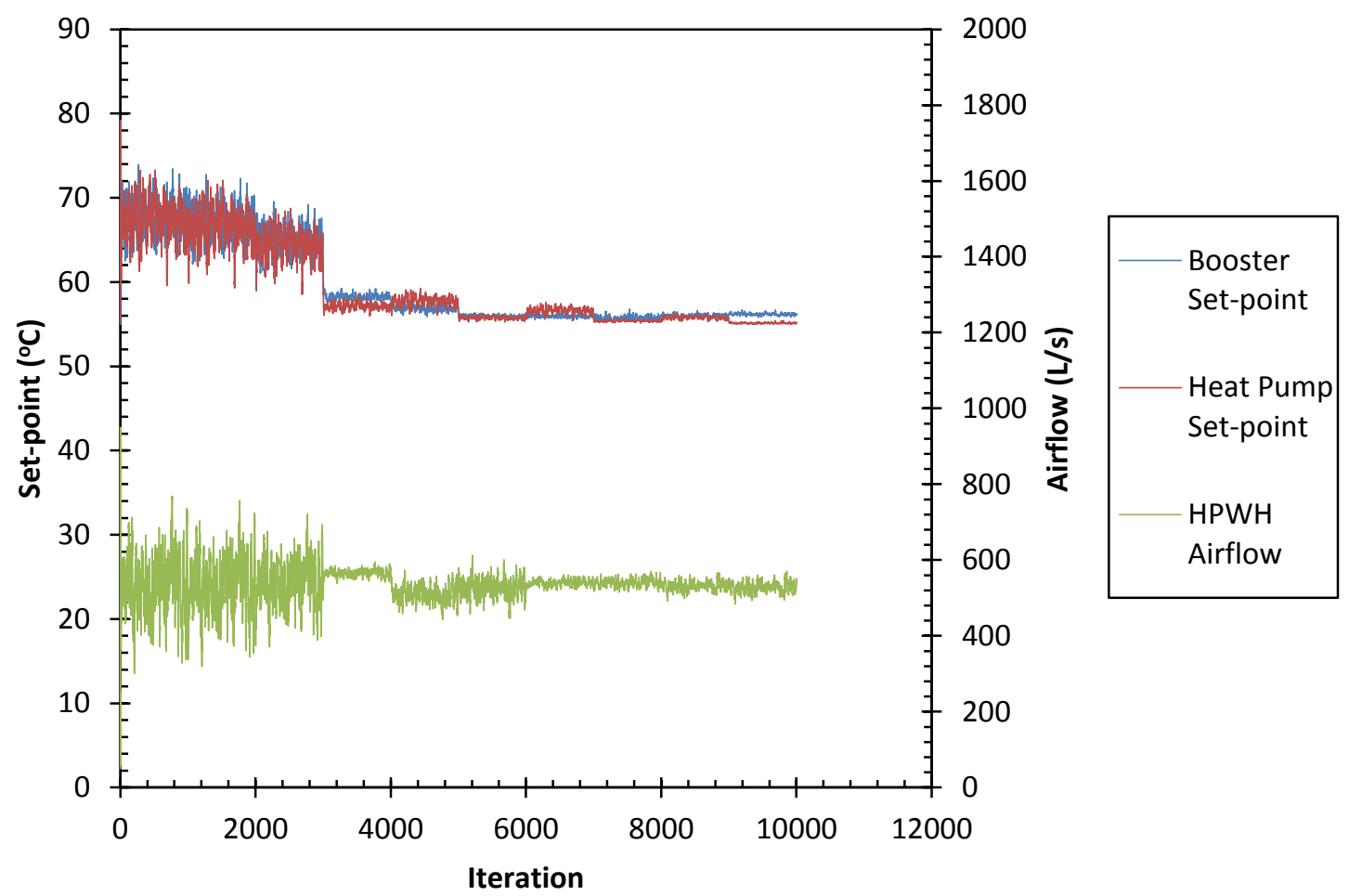

Figure 5-11: Parameter Progression for Performance Parameter Optimization (Ottawa)

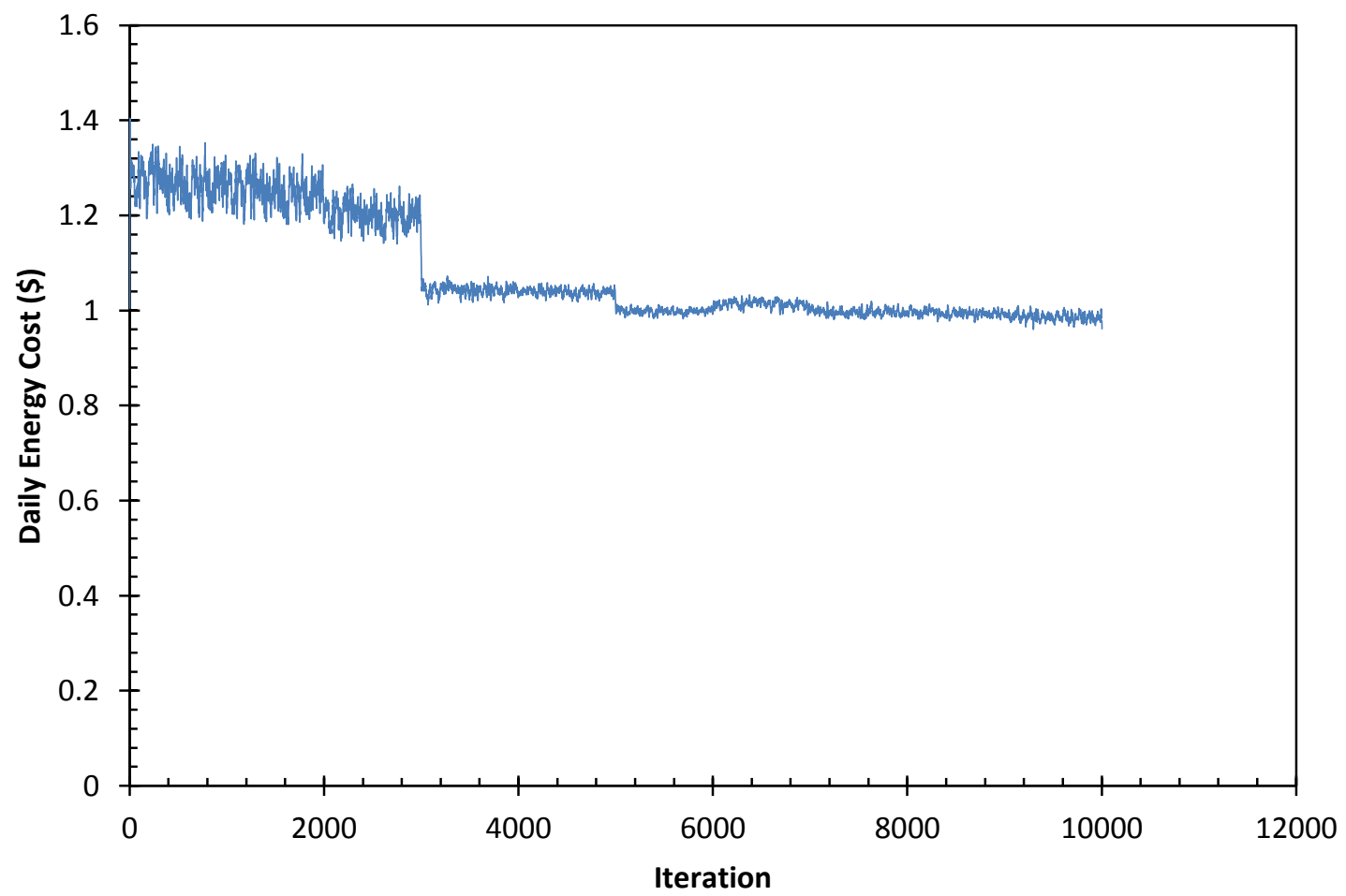

Figure 5-12: Result Progression for Performance Parameter Optimization (Ottawa) 
Further simulation with the electricity and heating utility rates as the variable parameters with the stock HPWH static parameters was executed to determine the optimal utility rate ratios for the unit. It was found that a utility rate ratio between electricity to power the HPWH and the primary heating fuel would yield the best energy performance for the HPWH at a value close to the nominal COP obtained from testing. This was under the assumption that the heating system for the surrounding space was supplying makeup heat for the environmental heat draw at the evaporator of the HPWH, and that the heating system was $100 \%$ efficient at converting that fuel into heating energy. Further analysis would be necessary to better characterize the optimal utility ratio for different space heating types. Of the regions analyzed, Edmonton, Vancouver, and Yellowknife had the most conducive utility rates in Canada for the HPWH tested, as visible in Table 4-2. This relationship also suggests that augmenting the HPWH performance to track utility rates could yield a net benefit in energy use performance.

\subsubsection{TRNSYS Sensitivity Results}

The optimal results indicated by GenOpt were further analyzed in TRNSYS, where additional model outputs beyond the characteristic equation could be assessed. Focus was made on the energy distribution between the heat pump and booster heater at several different set-point combinations, as well as total energy consumption at these conditions. The trends in energy consumption match the expectations of the surface plot performance map in Figure 5-7 and Figure 5-8, and provide further detail to the findings of the optimization process. 
Comparison of the energy use reduction potential of the 10 optimization parameters for the design cases was achieved using a local sensitivity analysis based upon the values of the existing unit. Increments and decrements of $25 \%$ and $50 \%$ of each parameter were adjusted individually, and the resulting energy consumption of each case was compared to the base energy consumption of the HPWH with stock parameters. This analysis is limited because it only examines single parameter variations, while unique outcomes can occur with different multiple parameter combinations. These combinations are assumed to have been partially accounted for within the GenOpt optimizations. A graphical representation of the variation in relative energy consumption (when compared with the base values with a relative energy consumption of 1) with respect to individual parameter variation is shown in Figure 5-13.

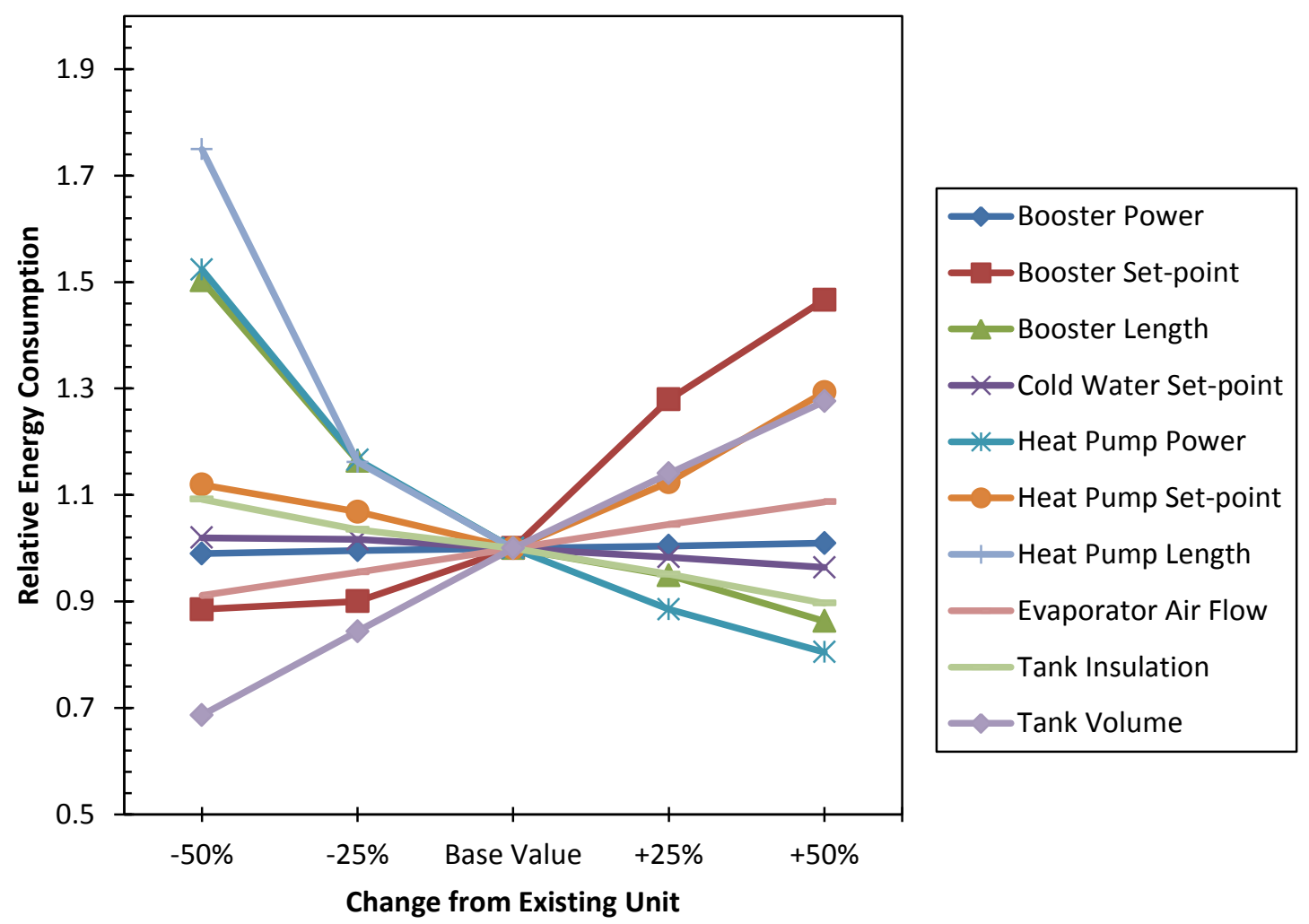

Figure 5-13: Sensitivity Results for Design Parameters 
The data points on the graph where each parameter experienced the greatest energy use reduction on the total system were used to rank the parameters relative to each other. The resulting maximum energy use reductions for each parameter are shown in Table 5-4.

Table 5-4: Energy Use Reduction of Design Parameters

\begin{tabular}{c|c}
\hline Parameter & Energy Use Reduction \\
\hline Tank Volume & $31.3 \%$ \\
Heat Pump Power & $19.5 \%$ \\
Booster Length & $13.7 \%$ \\
Booster Set-point & $11.5 \%$ \\
Tank Insulation & $10.3 \%$ \\
Evaporator Air & $8.9 \%$ \\
Flow & $3.6 \%$ \\
Cold Water Set- & \\
point & $1.0 \%$ \\
Booster Power & $0 \%$ \\
Heat Pump Length & $0 \%$ \\
Heat Pump Set- & \\
point &
\end{tabular}

It was determined that reducing the tank volume would have the largest effect on reducing energy consumption for the HPWH. Heat pump power, booster length, booster set-point, and tank insulation also demonstrated the ability to reduce total tank energy consumption by at least $10 \%$ with a $50 \%$ change in value. Moreover, heat pump length and heat pump set-point achieved the lowest HPWH energy consumption at the current value. This suggests that the heat pump geometry and temperature are dependent on other parameters to achieve minimal energy consumption.

In order to define the relationship between varying the booster and heat pump setpoints relative to each other, simulations were performed while holding one of the 
heaters' set-points static, and varying the other. Figure 5-14 shows the booster heater energy consumption at varying booster set-points in $1^{\circ} \mathrm{C}$ increments and static heat pump set-points at $5^{\circ} \mathrm{C}$ increments. A similar analysis was performed for heat pump energy consumption in Figure 5-15. The resulting trend shows that as the booster set-point rises relative to the heat pump set-point, the booster energy consumption increases logarithmically, and the heat pump energy consumption decreases logarithmically. This effect is interesting because it suggests that the largest increments in energy consumption occur during the first few degrees of deviation that the booster set-point gains from the heat pump. As such, thermal stratification of more than $1{ }^{\circ} \mathrm{C}$ between the two heating nodes that define the booster and heat pump set-points can have a significant increase in total unit energy consumption.

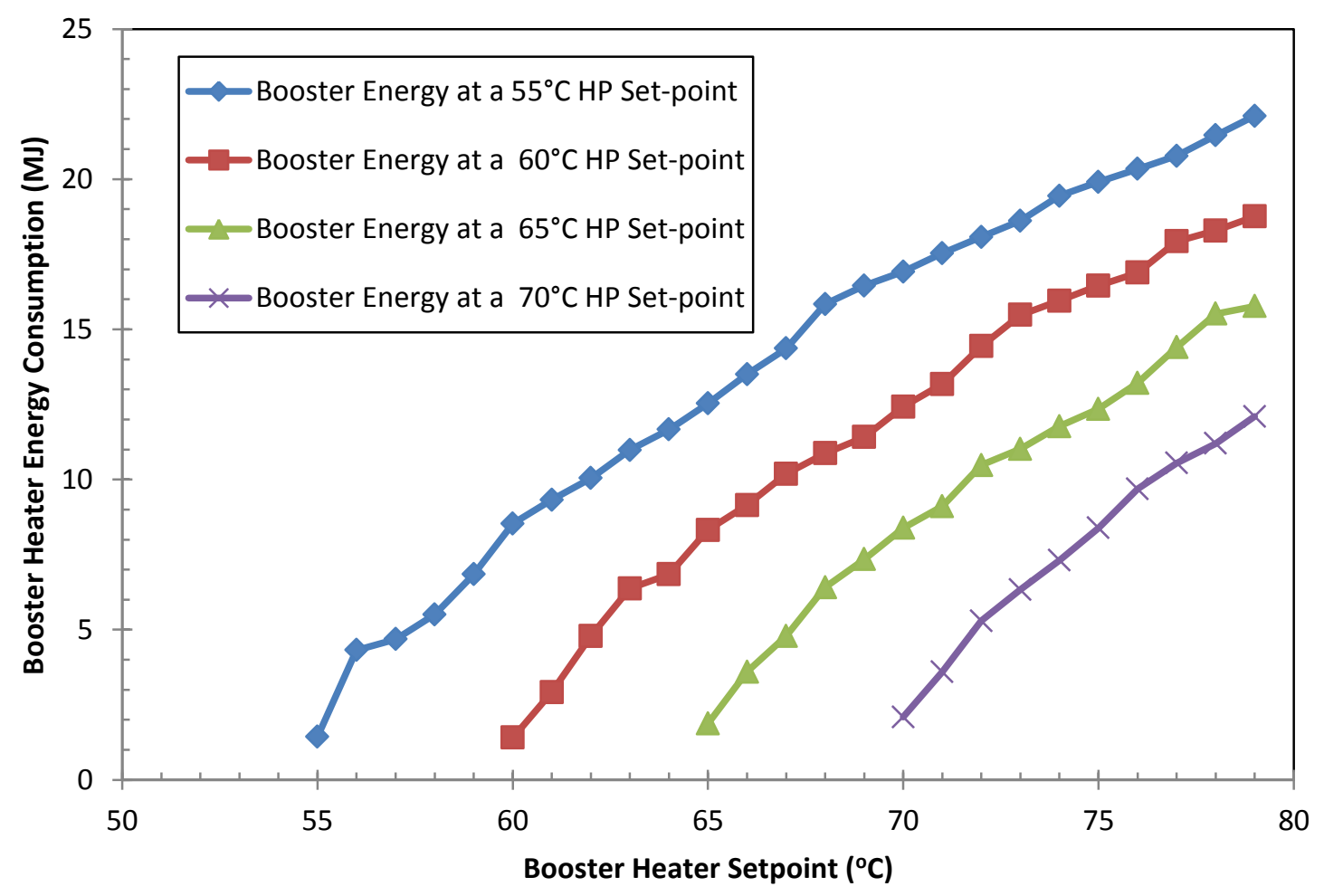

Figure 5-14: Booster Energy Use at Various Booster and HP Set-points 


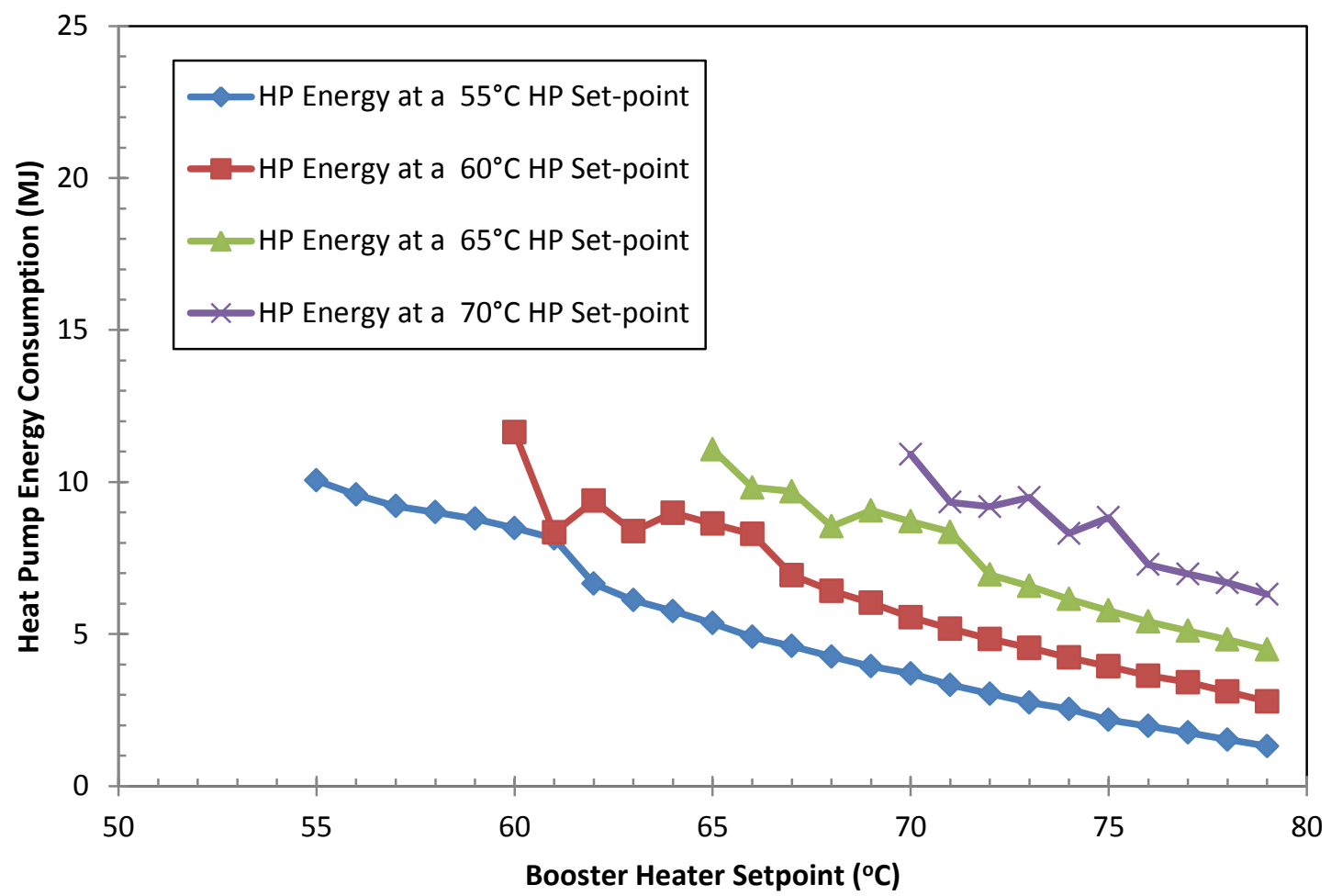

Figure 5-15: Heat Pump Energy Use at Various Booster and HP Set-points

The methods used in this analysis were extended to the total energy consumption of the unit, which unites both pieces of heating equipment and the environmental energy consumption of the heat pump evaporator from the surrounding space. It is expected that the trend for total energy use as seen in Figure $5-16$ for a booster set-point of $70^{\circ} \mathrm{C}$ is scalable to other booster heater temperatures, and that the data from Figure 5-17 can be interpolated for the HP set-points between the four provided if additional data is desired.

Improved performance was observed when the heat pump became the dominant heating equipment, which occurred with a heat pump set-point $6^{\circ} \mathrm{C}$ below the booster setpoint at $70^{\circ} \mathrm{C}$ as can be seen in Figure 5-17. Additionally, the energy drawn from the environment was small when compared to the energy used for heat input to the water tank. This corresponds with previous work from Maguire et al. [2] and confirms the 
validity of the DOE mandate for HPWH units to be used in place of electric water heaters in all US climates when DHW demands are over a certain size. Further economic analysis is required to determine if the substitution of a HPWH for an electric water heater can generate payback or a positive net present value.

While it was shown that a minimal difference between the booster and HP setpoint facilitated the best performance, there were periodical set-point combinations that provided local minima in energy consumption. Figure 5-17 shows these minima being roughly where the HP set-point is multiples of $5^{\circ} \mathrm{C}$ below the booster heater set-point. This phenomenon is likely a product of the hysteresis loop that is used to support a deadband of $1{ }^{\circ} \mathrm{C}$ on each side of the equipment set-point. If the temperatures of the nodes controlling the set-point do not drop to $1^{\circ} \mathrm{C}$ below it, the heating equipment will not trigger. Nearing this threshold, but not crossing it, is likely what produces these local minima and improved performance. Further analysis with differing hysteresis deadbands and other thermal storage properties could provide further evidence supporting this theory. 


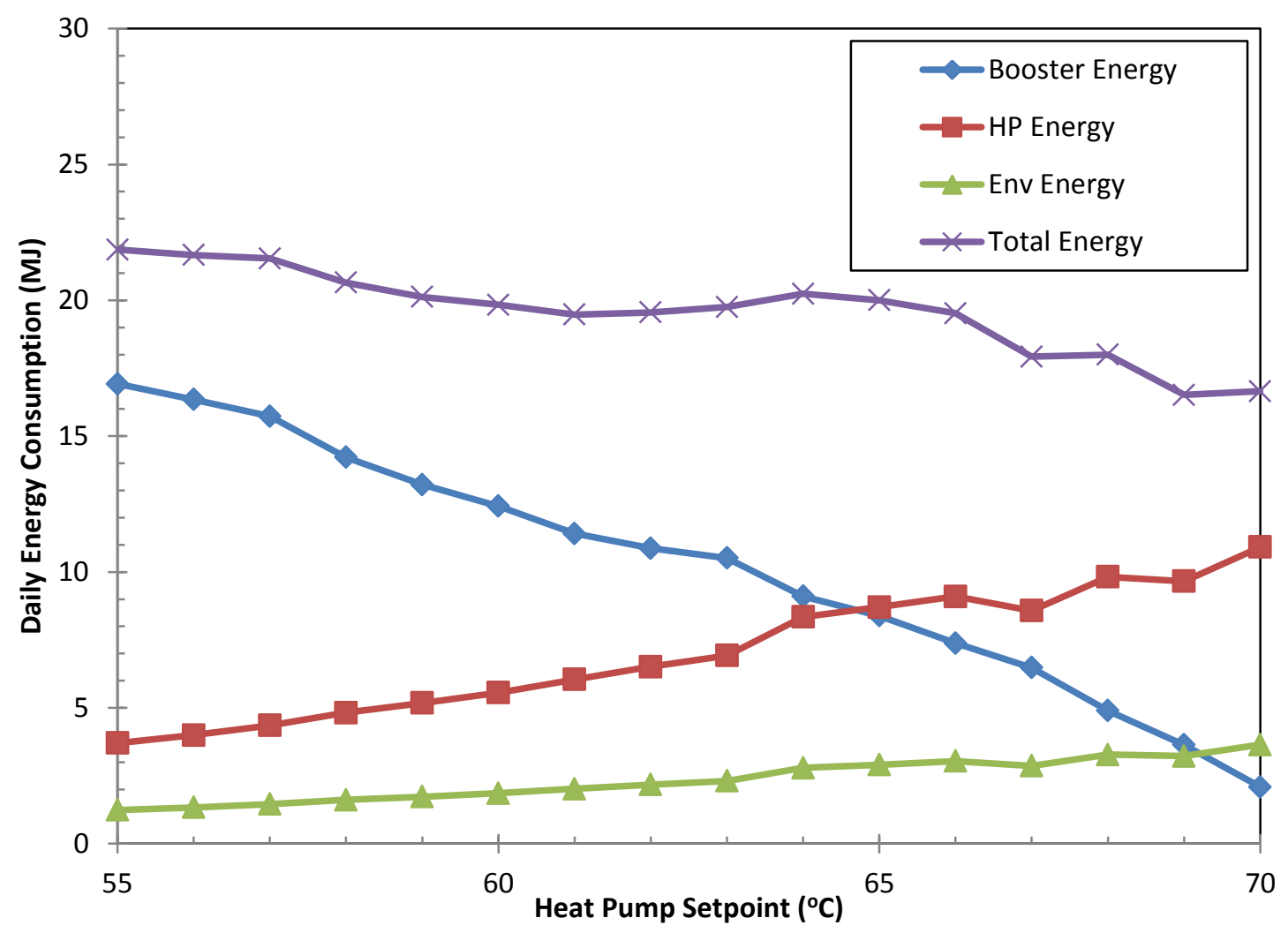

Figure 5-16: HPWH Energy Consumption Breakdown at a Booster Heater Set-point of $70^{\circ} \mathrm{C}$

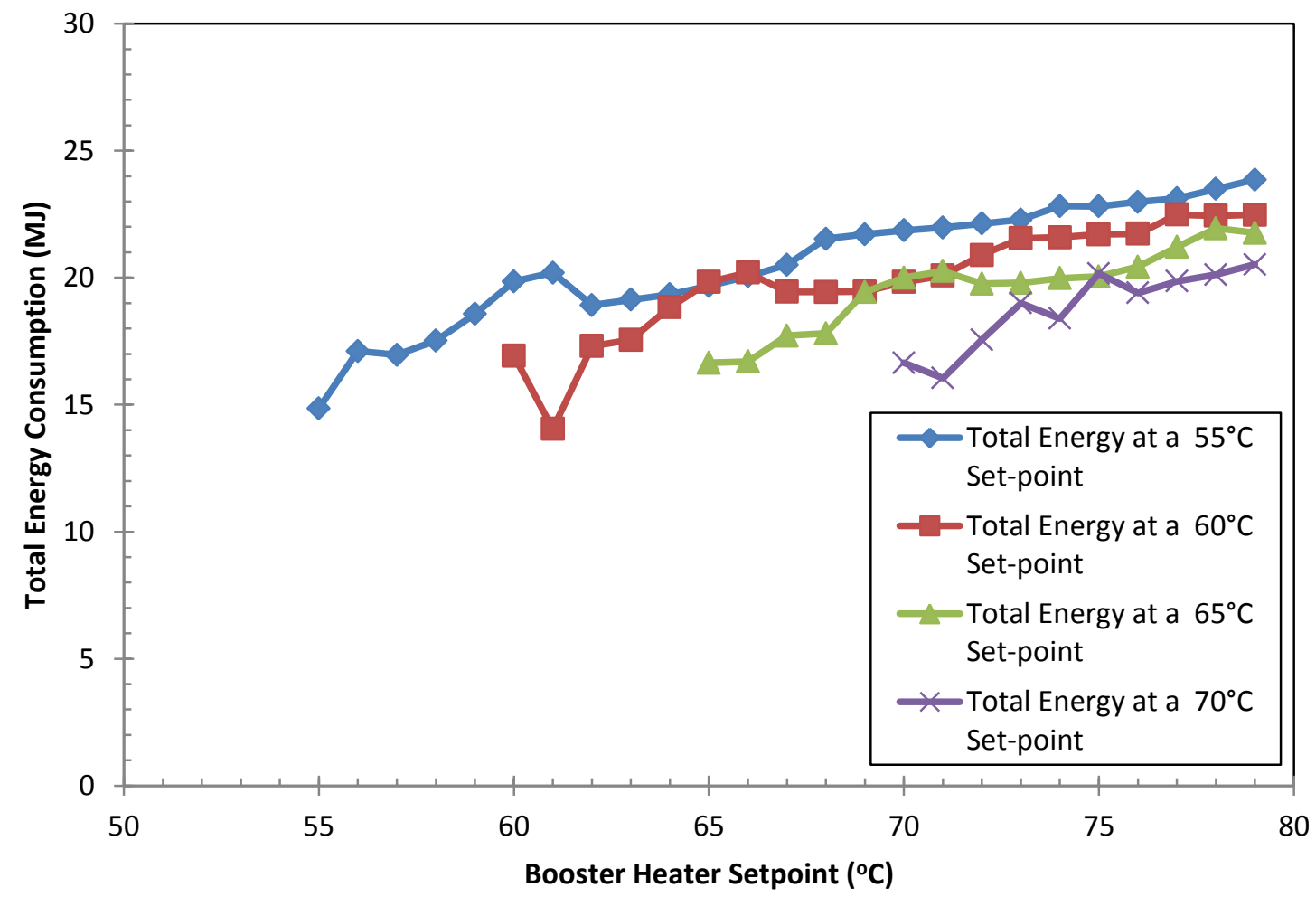

Figure 5-17: HPWH Energy Consumption at Various Booster and HP Set-points 


\subsection{Summary}

Chapter 5 presented the experimental and modelling results found from the HPWH test apparatus and simulations that followed. Optimization and sensitivity analyses were also included in this section. The next chapter will discuss the applicability of the findings from this chapter for Canada, and the uncertainty analysis techniques used to validate the results. 


\section{Chapter: Discussion}

This chapter discusses the relevance and applicability of the results of the experimental and simulation work of this thesis for applying HPWH technology to Canada, as well as the uncertainty analysis implemented to determine the validity of the experimental results.

\subsection{Applications for Canada}

The Canadian climate presents a unique challenge for HPWH technology due to the air source design of most units and the length and intensity of the heating seasons. Several factors can have weight on the effectiveness of selecting a HPWH over more traditional forms of water heating such as electric resistance and natural gas. Some factors that can have the largest effect on the energy consumption of HPWH units in Canada include set-points, tank insulation, utility rates, equipment control strategies, free cooling, and refrigerant selection.

Set-point control was a significant point of analysis in this thesis. The results section detailed the importance of keeping the set-points both low (while still high enough to prevent legionella growth) and within $1^{\circ} \mathrm{C}$ between the electric booster heater and the heat pump. This principle should remain a rule of thumb for most water heating applications, and be used to adapt to other hot water heating units with different equipment and geometries. The fundamental principle is to not create unnecessary stratified regimes that could cause one piece of heating equipment to operate longer than necessary. The balance of relying on the heat pump for low to medium hot water demand, 
and the upper tank serving electrical heater for high demand can provide energy efficient hot water while meeting the hot water load. For this reason, careful set-point control should be implemented on all water heaters, while potentially implementing advanced algorithms to optimize the set-point for the demand in more advanced systems and future work.

A component of the design optimizations simulations, tank insulation was identified as a non-invasive opportunity to conserve energy in a water heating system. The effectiveness of this strategy would be largely dependent on the conditions of the surrounding environment that houses the HPWH, and thus was not explored in depth in this thesis. However, after market external tank insulation provides an opportunity to improve system performance by a greater margin if the tank is stored in a cold environment (as generated by the evaporator in indoor installations), while also reducing the direct heat loss from the wrap-around heat exchanger of the heat pump. This would be effective in a similar fashion to home insulation that is added external to the building slab, which serves to contain thermal energy within the target space and increase the temperature of material surrounding the heating equipment.

Virtually all engineering design decisions are primarily driven by capital costs, and domestic hot water heating is no different. As indicated by the utility rate optimization simulations, a utility rate ratio between electricity used in heat pump operation and heating fuel used in space heating near the nominal COP will provide the lowest energy consumption when the indoor space surrounding the HPWH is used as the heat pump thermal energy source as demonstrated by the GenOpt simulations. This indicates some Western Canadian cities such as Edmonton, Calgary, and Vancouver 
would realize better energy performance based on energy costs alone. The favorable utility rates in these regions are largely due to the low heating fuel (natural gas in this case) costs relative to electricity, which is frequently not the case when denser heating fuel sources are used such as fuel oil. Dependence on this ratio could be eliminated by drawing and rejecting air from outside the occupied space, however, this would then shift the performance dependence from heating fuel to outdoor air conditions. An analysis of the effect of this change would be of value in future work, both simulation and experimental based.

Using the experimental setup as the base configuration, there are limited opportunities to alter control strategies to yield significant energy use reduction. A weakness of this HPWH configuration is that during the heating season (i.e, the majority of the year for most Canadian cities), energy will be taken from the space heating system to serve the hot water heating system. From a purely energy perspective, this appears redundant, but it does in fact allow for the lower cost heating fuel to provide energy to the HPWH. Conversely, the HPWH will help the space cooling system in the cooling season. This is part of why the majority of HPWH installations are in humid southern climates, where the heat of fusion from water vapor can provide additional energy to the heat pump on concert with the sensible heat of the warm air. On design days in Canada this benefit can be observed, but for the most part would not outweigh the additional energy draw during the heating season. Employing different control strategies to increase the reliance on the electric heating system during the heating season would reduce the HPWH performance, but depending on utility rates could yield better energy performance of the hot water and space heating system inclusively. 
Refrigerant selection presents a unique opportunity to improve energy performance of air source heat pumps with only minor changes to typical operation. The changes become significantly more complicated on the design side due to the infancy of cold climate refrigeration technology. Current HPWH designs are optimized for temperature ranges typically observed in climates similar to the southern United States and the moderate regions of Europe, as indicated by their primary regions of use and locations of manufacture.

\subsection{Uncertainty Analysis}

Determining uncertainty of experimental apparatus is an important element in proving the validity of results. Error in measurement can propagate throughout an experiment, and have a significant effect on calculated values. For this reason, the separation of variables technique was chosen to find the accumulated uncertainty for the primary metrics, energy use and COP. This technique takes into account both the systematic and random error experienced by the whole system. Systematic error is introduced from the uncertainty of the measuring devices, and is given with manufacturer data, while random error is caused by the random scatter of measured data from the measurement devices.

A separation of variables approach was taken to determine the experimental uncertainty of the results from the HPWH experimental apparatus used for this thesis. This approach is achieved through the use of Equation 6.1 to find the total uncertainty as a collection of the uncertainty generated from each term of a characteristic equation, adapted from Figliola and Beasley [56]. 


$$
\begin{gathered}
u_{R}=\left[\sum_{\mathrm{i}=1}^{N}\left(\theta_{\mathrm{i}} u_{\mathrm{i}}\right)^{2}\right]^{0.5} \\
\theta_{i}=\frac{\partial R}{\partial x_{\mathrm{i}}} \quad \mathrm{i}=1,2,3, \ldots . . L
\end{gathered}
$$

From Equation 6.2, the $\theta_{\mathrm{i}}$ term, known as the sensitivity factor, is found by taking the partial derivative of the characteristic equation with respect to each variable and summarizing, while the $u_{i}$ term of Equation 6.1 is the systematic error from the equipment manufacturer or other sources of standard values for natural phenomena [38].

The characteristic equations chosen for the uncertainty analysis were the total net energy consumption and the $\mathrm{COP}$ of the $\mathrm{HPWH}$, as given in Equations 5.2 and 5.3 respectively. The sensitivity factors of the independent variables of Equation 5.2 were found using Equations 6.3 to 6.7 .

$$
\begin{gathered}
\theta_{\rho}=\frac{\partial \mathrm{COP}}{\partial \rho}=\frac{V c_{\mathrm{p}} \delta T}{E_{\text {elec }}} \\
\theta_{\mathrm{V}}=\frac{\partial \mathrm{COP}}{\partial V}=\frac{\rho c_{\mathrm{p}} \delta T}{E_{\text {elec }}} \\
\theta_{C_{\mathrm{p}}}=\frac{\partial \mathrm{COP}}{\partial c_{\mathrm{p}}}=\frac{\rho V \delta T}{E_{\text {elec }}} \\
\theta_{\delta T}=\frac{\partial \mathrm{COP}}{\partial \delta T}=\frac{\rho V c_{\mathrm{p}}}{E_{\text {elec }}} \\
\theta_{E_{\text {elec }}}=\frac{\partial \mathrm{COP}}{\partial E_{\text {elec }}}=-\frac{\rho V c_{\mathrm{p}} \delta T}{E_{\text {elec }}^{2}}
\end{gathered}
$$


The sensitivity factors for Equation 5.3 were found using Equations 6.8 to 6.13.

$$
\begin{aligned}
& \theta_{\rho}=\frac{\partial E_{\mathrm{net}}}{\partial \rho}=V c_{p} \delta T \\
& \theta_{\mathrm{V}}=\frac{\partial E_{\mathrm{net}}}{\partial V}=\rho c_{p} \delta T \\
& \theta_{c_{\mathrm{p}}}=\frac{\partial E_{\mathrm{net}}}{\partial c_{\mathrm{p}}}=\rho V \delta T \\
& \theta_{\delta T}=\frac{\partial E_{\mathrm{net}}}{\partial \delta T}=\rho V c_{\mathrm{p}}
\end{aligned}
$$

Systematic error for the series of equations, and their sample values found at extreme operating conditions, are summarized in Table 6-1 and Table 6-2. These values were found from experimental run data and equipment catalog information. 
Table 6-1: Systematic Error and Sample Values for Experimental Equipment

\begin{tabular}{c|cc}
\hline Source of Error & Sample Value & Systematic Error $\left(u_{i}\right)$ \\
\hline Density $(\rho)$ & $1000 \mathrm{~kg} / \mathrm{m}^{3}$ & $0.245 \mathrm{~kg} / \mathrm{m}^{3}$ \\
Volume $(V)$ & $0.300 \mathrm{~m}^{3}$ & $0.00450 \mathrm{~m}^{3}$ \\
Constant Pressure Coefficient $\left(c_{\mathrm{p}}\right)$ & $4.186 \mathrm{~kJ} / \mathrm{kg}-\mathrm{K}$ & $0.02 \mathrm{~kJ} / \mathrm{kg}-\mathrm{K}$ \\
Temperature Change $(T)$ & $40.0^{\circ} \mathrm{C}$ & $0.470^{\circ} \mathrm{C}$ \\
Electrical Power $\left(E_{\text {elec }}\right)$ & $15,800 \mathrm{~kJ}$ & $158 \mathrm{~kJ}$ \\
Space Power Draw $\left(E_{\text {space }}\right)$ & $34,400 \mathrm{~kJ}$ & $344 \mathrm{~kJ}$ \\
\hline
\end{tabular}

Table 6-2: Sensitivity Factor Roots for Net Power and COP

\begin{tabular}{c|cc}
\hline Source of Error & $\theta_{i} u_{i}$ (Net Power) & $\theta_{i} u_{i}(\mathrm{COP})$ \\
\hline Density $(\rho)$ & $515 \mathrm{~kJ}-\mathrm{m}^{3} / \mathrm{kg}$ & $7.79 \times 10^{-4} \mathrm{~kJ}-\mathrm{m}^{3} / \mathrm{kg}$ \\
Volume $(V)$ & $1260 \mathrm{~kJ} / \mathrm{m}^{3}$ & $4.77 \times 10^{-2} \mathrm{~kJ} / \mathrm{m}^{3}$ \\
Constant Pressure Coefficient $\left(c_{\mathrm{p}}\right)$ & $742 \mathrm{~kg}-\mathrm{K}$ & $1.52 \times 10^{-2} \mathrm{~kg}-\mathrm{K}$ \\
Temperature Change $(T)$ & $1092 \mathrm{~kJ} / \mathrm{K}$ & $3.74 \times 10^{-2} \mathrm{~kJ} / \mathrm{K}$ \\
Electrical Power $\left(E_{\text {elec }}\right)$ & 158 & $3.18 \times 10^{-2}$ \\
Space Power Draw $\left(E_{\text {space }}\right)$ & 344 & N/A \\
\hline
\end{tabular}

Equations 6.3 to 6.11 yield absolute uncertainty values of $31,600 \mathrm{~kJ}$ and 0.07 for the net energy consumption and COP respectively. Using extreme values of 31,600 kJ of net energy consumption and a nominal COP of 2 , overall uncertainties of $1.5 \%$ and $3.5 \%$ were found. In both cases the uncertainty is well under $10 \%$ indicating reasonable experimental accuracy of the instrumentation configuration. 


\subsection{Summary}

Chapter 6 discussed the potential for HPWH technology to be used in Canada and the methods used to quantify the uncertainty in the results from the experimental apparatus. The next chapter will provide concluding remarks and an outline of the future work that is recommended. 


\section{Chapter: Conclusions and Future Work}

\subsection{Conclusions}

For market penetration in cool climates, HPWH technology would require redesign of controls and heat sourcing for the heat pump. The heat draw from the surrounding space during the heating season, coupled with the high initial costs of these units, gives little ground for the cooling savings in the cooling season to be realized. Further testing of alternate energy sources for the heat pump and more advanced control strategies may prove useful in adapting this technology for long Canadian winters. This thesis focused on the design, construction, and instrumentation of a domestic hot water testing apparatus, the development of a calibrated TRNSYS model for further analysis, optimization techniques implemented through GenOpt for a commercial HPWH unit, and applications of HPWH technology in cool climates. The $300 \mathrm{~L}$ unit tested and modelled in this research was sized for the average 4 person dwelling in the residential market.

The domestic hot water testing apparatus was designed to provide the energy model of the system with data to calibrate a performance map, as well as a way to iteratively verify modifications to the model. The design of the HPWH tested provided 3 inputs to the system that could be varied, the heat pump set-point, electrical booster heater set-point, and the evaporator air flow. To prevent unnecessary equipment wear due to high temperatures, the evaporator air flow was not altered from factory specifications. This system was used to test thermal and electrical performance of the HPWH unit using CSA-F379.1 hot water draw profiles. The results of these tests suggest that the HPWH performed worse than the manufacturer specifications. The maximum COP of the unit 
during all test runs was found to be just above 2 , while the catalog data advertises a COP of 3.18. While air-side conditions were not identical, the difference is larger than could be accounted for with just air temperature and moisture content.

The results from combinations of draw profiles and equipment set-points were used to characterize the TRNSYS model by fitting the experimental results for the domestic hot water apparatus test runs to allow extension to further test scenarios. Existing TRNSYS library components were not robust enough to simply input the physical properties found in testing and process the data to anticipated results, thus a heat transfer approach was taken to allow for more transparent calibration of the model to experimental data. Once the model was calibrated within $10 \%$ of total and electrical energy consumption for multiple experimental set-point and draw combinations, all combinations of heat pump and booster heater set-point were modelled with $1^{\circ} \mathrm{C}$ resolution from $50^{\circ} \mathrm{C}$ to $65^{\circ} \mathrm{C}$ for the heat pump and $55^{\circ} \mathrm{C}$ to $70^{\circ} \mathrm{C}$ for the booster heater. A complete performance map was generated to identify trends which could be exploited to minimize energy consumption. Further analysis was executed to determine how individual heating equipment energy use varied while moving around the regimes identified in the simulation performance map.

Optimization using GenOpt techniques was implemented to test a wide range of multi-parameter scenarios, and determine the minimal energy use configurations accounting for both current and future HPWH design. The optimization was limited such that only energy consumption was minimized. The design optimizations varied 10 parameters - most of which could only be changed in unit manufacture and design - and provided guidelines for how to change the system properties to reduce energy use. 
Performance optimizations through simulation were centered upon the 3 parameters of the physical system that could be varied in a lab setting after manufacture, the heat pump and booster heater set-points and the evaporator air flow. The minimum energy consumption occurred when the set-points were maintained as low as possible, which is in opposition to best health practices in preventing water-borne diseases such as Legionella. The air flow rate of the evaporator settled at optimal values at roughly $40 \%$ higher than the system design.

Heating dominated climates present significant challenges for HPWH technology adoption. Adaptation for Canadian implementation of HPWH technology will require significant redesign of the refrigeration system, as well as augmented control strategies with a possibility of ducting the air side of the heat pump to the outdoor environment. Under current conditions, some regions can better support HPWH technology than others in Canada - Western Canada in particular.

\subsection{Future Work}

This work is the beginning of an extended study into the feasibility of HPWH technology in cool climates. The current experimental apparatus will be expanded to include an air handling unit, and a new HPWH unit will be installed and instrumented to replace the previous unit that malfunctioned. Additionally, a solar thermal loop will be added to mimic various solar collector types and arrangements. Experimental testing will continue using this new configuration and more advanced control strategies.

The TRNSYS program will be used to extend the simulation to different time of use conditions, and coupling with photovoltaics and solar thermal technology. New, 
calibrated solar thermal models will be able to accurately extend predictions of energy performance of numerous hydronic and air side system configurations that are not possible with the current equipment.

Further testing and simulation of the thermal energy storage capacity and performance of HPWH units will be undertaken, and stratification analysis of newer HPWH units will provide information on the heater geometry and performance. The temperature probes have also been modified to minimize the risk of corrosion by no longer replacing the sacrificial anode of the tank. While this may not have been the cause of failure for the previous HPWH tank, it will eliminate that method of failure from being reasonably possible.

On a larger scale, the TRNSYS model of the HPWH could be coupled with a building simulation model, or database of models, to determine the performance of various HVAC systems with indoor non-ducted installations. In this thesis, the effect of the HPWH evaporator is only examined with respect to the environmental energy draw, and a heating system efficiency of $100 \%$ is assumed using the primary heating fuel of each region. A more detailed analysis or the effect of different space heating systems could provide more insight into where the most viable markets for HPWH technology in Canada exist.

A full economic analysis of the HPWH unit would provide the necessary information to conclusively determine if the technology is suitable for Canada. In this thesis only energy consumption was analyzed in detail, and the consideration of capital, maintenance, and operational costs would likely change the monotony of the values found in the GenOpt simulations. 
Combination systems could present a unique opportunity to both reduce the capital costs associated with the heat pump compressor, and decrease the energy use of the system overall via a higher COP. Additional performance increments could also be observed with multi-stage compressors, where the equipment is sized for both space heating and hot water. Further testing of this technology in consort with domestic hot water systems and economic analysis could verify the applicability of this technology in Canada. 


\section{References}

[1] A. Hepbasli and Y. Kalinci, "A Review of Heat Pump Water Heating Systems," Renewable and Sustainable Energy Reviews, vol. 13, pp. 1211-1229, 2009.

[2] J. Maguire, X. Fang and a. E. Wilson, "Comparison of Advanced Residential Water Heating Technologies in the United States," NREL, Golden, 2013.

[3] K. Hudon, B. Sparn and a. D. Christensen, "Heat Pump Water Heater Technology Assessment Based on Laboratory Research and Energy Simulation Models," NREL, Golden, 2012.

[4] U.S. Department of Energy, "Residential Water Heater Standards," U.S. Department of Energy, Washington, D.C., 2014.

[5] Natural Resources Canada, "Energy Use Handbook - 1990 to 2010," Office of Energy Efficiency, Ottawa, 2012.

[6] Independant Electric Service Operator, "18-Month Outlook - From June 2013 to November 2014," 2013. [Online]. Available: http://www.ieso.ca/imoweb/pubs/marketReports/18MonthOutlook_2013may.pdf. [Accessed 20 March 2015].

[7] Ontario Hydro, "Ontario Hydro Rates," [Online]. Available: http://www.ontariohydro.. [Accessed 2 February 2015].

[8] S. Klein and e. al, "TRNSYS 17 - a TRaNsient SYstem Simulation Program," University of Wisconsin-Madison Solar Energy, Madison, Wisconsin, 2009.

[9] Canadian Standards Association, "CAN/CSA-F379.1-88: Solar Domestic Hot 
Water Systems (Liquid to Liquid Heat Transfer)," Canadian Standards Association, Mississauga, ON, 2004.

[10] J. Maguire, J. Burch, T. Merrigan and S. Ong, "Energy Savings and Breakeven Cost for Residential Heat Pump Water Heaters in the United States," NREL, Golden, 2013.

[11] ClearSky Advisors Inc., "Survey of Active Solar Thermal Collectors, Industry and Markets in Canada (2012)," NRCan, Ottawa, 2013.

[12] M. Wetter, "GenOpt Manual," University of California, Berkeley, 2011.

[13] J. Maguire, J. Burch, T. Merrigan and S. Ong, "Regional Variation in Residential Heat Pump Water Heater Performance in the U.S.," NREL, Golden, 2014.

[14] United States Government Publishing Office, "Code of Federal Regulations," 2012.

[15] J. Maguire, Interviewee, Permission to Reference Report Content. [Interview]. 13 June 2014.

[16] R. M. Dickinson, Analysis and Development of Draw Strategies for a Multi-Tank Thermal Storage System for Solar Heating Applications, Ottawa: Carleton University, 2012.

[17] G. Morrison, T. Anderson and M. Behnia, "Seasonal Performance Rating of Heat Pump Water Heaters," Solar Energy, vol. 76, pp. 147-152, 2004.

[18] G. Morrison, "Packaged Solar Heat-pump Water Heaters," Solar Energy, vol. 53, pp. 249-257, 1994.

[19] J. Guo, J. Wu, R. Wang and S. Li, "Experimental Research and Operation Optimization of an Air-source Heat Pump Water Heater," Applied Energy, vol. 88, 
pp. 4128-4138, 2011.

[20] G. Groff, "Heat Pumps in North America 2014," in 11th IEA Heat Pump Conference, Montreal, 2014.

[21] G. Panaras, E. Mathioulakis and V. Belessiotis, "Investigation of the Performance of a Combined Solar Thermal Heat Pump Hot Water System," Solar Energy, vol. 93, pp. 169-182, 2013.

[22] G. Bourke and P. Bansal, "Energy Consumption Modeling of Air Source Electric Heat Pump Water Heaters," Applied Thermal Engineering, vol. 30, pp. 1769-1774, 2010.

[23] L. Aye, W. W. S. Charters and C. Chaichana, "Solar Heat Pump Systems for Domestic Hot Water," Solar Energy, vol. 73, no. 3, pp. 169-175, 2002.

[24] C. Lloyd and A. Kerr, "Performance of Commercially Available Solar and Heat Pump Water Heaters," Energy Policy, vol. 36, pp. 3807-3813, 2008.

[25] J. Chu, "Evaluation of a Dual Tank Indirect Solar-Assisted Heat Pump System for a High Performance House," MASc. thesis, Carleton University, Ottawa, 2014.

[26] T. Merrigan and D. Parker, "Electrical Use, Efficiency, and Peak Demand of Electric Resistance, Heat Pump, Desuperheater, and Solar Hot Water Systems," in American Council for an Energy Efficient Economy, Pacific Grove, 1990.

[27] M. Beshr, V. Aute, O. Abdelaziz, B. Fricke and R. Radermacher, "A Tool for Life Cycle Climate Performance (LCCP) Based Design of Residential Air Source Heat Pumps," in 11th IEA Heat Pump Conference 2014 Proceedings, Montreal, 2014.

[28] I. Aho, H. Klapuri, J. Saarinen and E. Makinen, "Optimal load clipping with time 
of use rates," Electrical Power \& Energy Systems, vol. 20, no. 4, pp. 269-280, 1998.

[29] M. Bazilian, I. Onyeji, M. Liebreich, I. MacGill, J. Chase, J. Shah, D. Gielen, D. Arent, D. Landfear and Z. Shi, "Re-Considering the Economics of Photovoltaic Power," Renewable Energy, vol. 53, pp. 329-338, 2013.

[30] D. Parker and J. Dunlop, "Solar Photovoltaic Air Conditioning of Residential Buildings," American Council for Energy-Efficient Economy, Washington, 1994.

[31] A. Genkinger, R. Dott and T. Afjei, "Combining Heat Pumps with Solar Energy for Domestic Hot Water Production," Energy Procedia, vol. 30, pp. 101-105, 2012.

[32] P. Luukkonen, P. Bateman, J. Hiscock, Y. Poissant, D. Howard and L. DignardBailey, "National Survey Report of PV Power Applications in Canada 2012," International Energy Agency, 2013.

[33] W. Weiss and F. Mauthner, "Solar Heat Worldwide Markets and Contribution to the Energy Supply 2010," IEA Solar Heating \& Cooling Programme, 2012.

[34] H. Ren, W. Gao and Y. Ruan, "Economic Optimization and Sensitivity Analysis of Photovoltaic System in Residential Buildings," Renewable Energy, vol. 34, pp. 883-889, 2009.

[35] H. Li and H. Yang, "Study on Performance of Solar Assisted Air Source Heat Pump Systems for Hot Water Production in Hong Kong," Applied Energy, vol. 87, pp. 2818-2825, 2010.

[36] S. Sterling and M. Collins, "Feasibility Analysis of an Indirect Heat Pump Assisted Solar Domestic Hot Water System," Applied Energy, vol. 93, pp. 11-17, 2012. 
[37] G. L. Morrison, "Simulation of Packaged Solar Heat-pump Water Heaters," Solar Energy, vol. 53, no. 3, pp. 249-257, 1994.

[38] C. Baldwin, Design and Construction of an Experimental Apparatus to Assess the Performance of a Solar Absorption Chiller with Integrated Thermal Storage, Ottawa: Carleton University, 2013.

[39] C. A. Cruickshank, Evaluation of a Stratified Multi-tank Thermal Storage for Solar Heating Applications, PhD. Thesis, Kingston: Queen's University, 2009.

[40] G. L. Morrison, "TRNAUS - 14.1 TRNSYS Extensions for Solar Water Heating," University of New South Wales, Sydney, 2014.

[41] R. M. Dickinson, C. A. Cruickshank and S. J. Harrison, "The Effect of Discharge Configurations on the Thermal Behaviour of a Multi-tank Storage System," Energy Procedia, vol. 30, pp. 215-224, 2012.

[42] L. Peeters, "The Coupling of ESP-R and Genopt: A Simple Case Study," in Simulation Buildings 2010 Conference, 2010.

[43] University of Strathclyde, "ESP-r," [Online]. [Accessed 4 September 2015].

[44] J. Chinneck, in Practical Optimization: a Gentle Introduction, Carleton University, 2014, pp. 1-7.

[45] National Instruments, "Labview Version 8.0," National Instruments, Austin, Texas, 2005

[46] Brultech Research Inc, "Greeneye Monitor Manual," Brultech Research Inc, 2012.

[47] Stiebel Eltron, "Operation and Installation Manual," Stiebel Eltron.

[48] Omega Controls, "Revised Thermocouple Reference Tables - Type T Refence 
Tables," [Online]. Available: http://www.omega.ca/temperature/Z/pdf/z207.pdf. [Accessed 24 January 2014].

[49] Brooks-Oval, "Brooks-Oval Models: BM04, BM07, BM10, BM40 \& BM50," [Online]. Available:

http://www.brooksinstrument.com/downloads/Product\%20Documentation/Oval\%2 0Gear\%20Meters/Data\%20Sheets/ds-pd-bm-ovals-eng.pdf.

[50] Thermal Energy Systems Specialists, Storage Tank Library Mathematical Reference, Madison: Thermal Energy Systems Specialists, 2012.

[51] M. Moran and H. Shapiro, Fundamentals of Engineering Thermodynamics, 6th edition, John Wiley \& Sons, Inc, 2008.

[52] R. Spur, D. Fiala, D. Nevrala and D. Probert, "Performances of Modern Domestic Hot-water Stores," Applied Energy, vol. 83, pp. 893-910, 2006.

[53] ASHRAE, "Standard 188-2015," ASHRAE, Atlanta, 2015.

[54] Electrolux, "Electric Hybrid Heat Pump Water Heater," Electrolux, [Online]. Available: http://www.electroluxappliances.com/Homecare/WaterHeaters/EE66WP30PS/. [Accessed 23 June 2015].

[55] Rheem, "Professional Prestige Series: Hybrid Heat Pump," [Online]. Available: http://www.rheem.com/product/water-heating-heat-pump-professional-prestigeseries-hybrid-heat-pump. [Accessed 23 June 2015].

[56] R. Figliola and D.Beasley, Theory and Design for Mechanical Measurements Fifth Edition, John Wiley \& Sons, Inc, 2011.

[57] S. Borenstein, "Electricity Rate Structures and the Economics of Solar PV: Could 
Mandatory Time-of-Use Rates Undermine California's Solar Photovoltaic Subsidies?," CSEM, Berkeley, 2007.

[58] S. Borenstein, "Valuing the Time-Varying Electricity Production of Solar Photovoltaic Cells," CSEM, Berkeley, 2005.

[59] S. J. Sterling, Feasibility Analysis of Two Indirect Heat Pump Assisted Solar Domestic Hot Water Systems, Waterloo: University of Waterloo, 2011.

[60] NREL, "Performance of a Heat Pump Water Heater in the Hot-Humid Climate," US DOE, 2013.

[61] US Department of Energy, "Water Heater Market Profile," US Department of Energy, Washington, DC, 2009.

[62] US Environmental Protection Agency, "Global Warming Potentials of ODS Substitutes," [Online]. Available: http://www.epa.gov/ozone/geninfo/gwps.html.

[63] T. Anderson and G. Morrison, "Effect of Load Pattern on Solar-Boosted Heat Pump Water Heater Performance," Solar Energy, vol. 81, pp. 1386-1395, 2007.

[64] J. Chyng, C. Lee and B. Huang, "Performance Analysis of a Solar-assisted Heat Pump Water Heater," Solar Energy, vol. 74, pp. 33-44, 2003.

[65] C. A. Cruickshank and S. Harrison, "Analysis of a Modular Thermal Storage for Solar Heating Systems," in Canadian Solar Buildings Conference, Montreal, 2004.

[66] C. Geelen, K. Braber and O. Kleefkens, "Efficiencies of Domestic Hot Water Production," in 11th IEA Heat Pump Conference 2014 Proceedings, Montreal, 2014.

[67] A. Biaou and M. Bernier, "Achieving Total Domestic Hot Water Production with 
Renewable Energy," Building and Environment, vol. 43, pp. 651-660, 2008.

[68] T.-Y. Lee and C.-L. Chen, "Wind-photovoltaic Capacity Coordination for a Timeof-use Rate Industrial User," IET Renewable Power Generation, vol. 3, no. 2, pp. 152-167, 2009.

[69] T. Makin, "Legionella Bacteria and Conditions for its Growth and Thermal Disinfection in Stored, Pre-heated Water for Domestic Purposes.," 2014.

[70] J. Zhang, R. Wang and J. Wu, "System Optimization and Experimental Research on Air Source Heat Pump Water Heater," Applied Thermal Engineering, vol. 27, pp. 1029-1035, 2007. 


\section{Appendix A Equipment Operation}

Equipment utilization for different draw profiles and set-points was monitored to gain an understanding of how the heating unit activation varied with respect to the system conditions. The system was monitored for the period of a draw test, which was 13 hours for Schedule A, 15 hours for Schedule B, and 15 hours for Schedule C. In the case of this experimental setup, only Schedules A and C were tested. Schedule B was intended to be tested as well, but an equipment malfunction rendered this impossible.

Pie charts were used to demonstrate the distribution of equipment operation as a percentage of the total run time over the conditions tested. As expected, inactivity decreased with both increasing set-points and total draw volumes. The shift between the operation of only the heat pump, only the booster heater, and both simultaneously, was largely dependent upon the differential between the two heating set-points. As the differential shifted upwards, the heat pump would operate less and the boost would operate more. Additionally, this resulted in more frequent simultaneous operation as well, because the likelihood of the booster being on was much higher. The data is presented in Figure A-0-1, Figure A-0-2, Figure A-0-3, Figure A-0-4, and Figure A-0-5 for Schedule A and Figure A-0-6, Figure A-0-7, Figure A-0-8, Figure A-0-9, and Figure A-0-10 for Schedule C. 


\section{A.1 Schedule A}

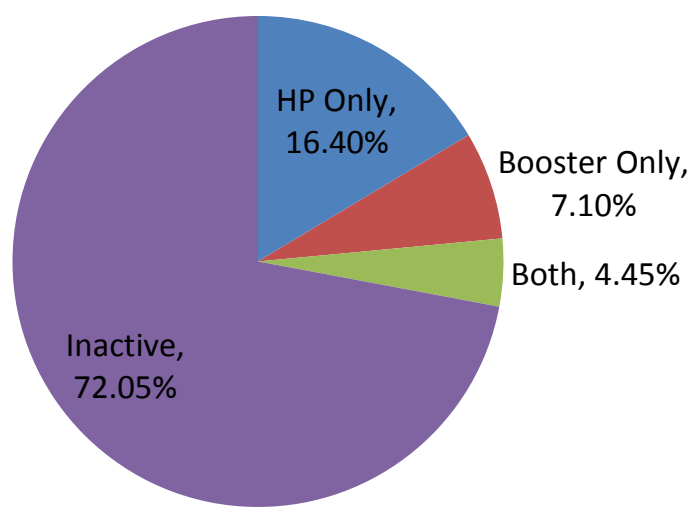

Figure A-0-1: Equipment Utilization for $50^{\circ} \mathrm{C} \mathrm{HP}$ and $55^{\circ} \mathrm{C}$ Booster Set-point Test (Schedule A)

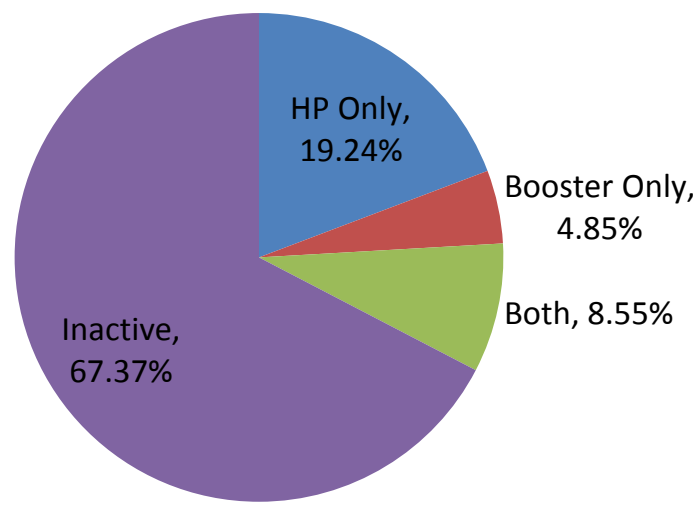

Figure A-0-2: Equipment Utilization for $55^{\circ} \mathrm{C}$ HP and $60^{\circ} \mathrm{C}$ Booster Set-point Test (Schedule A) 


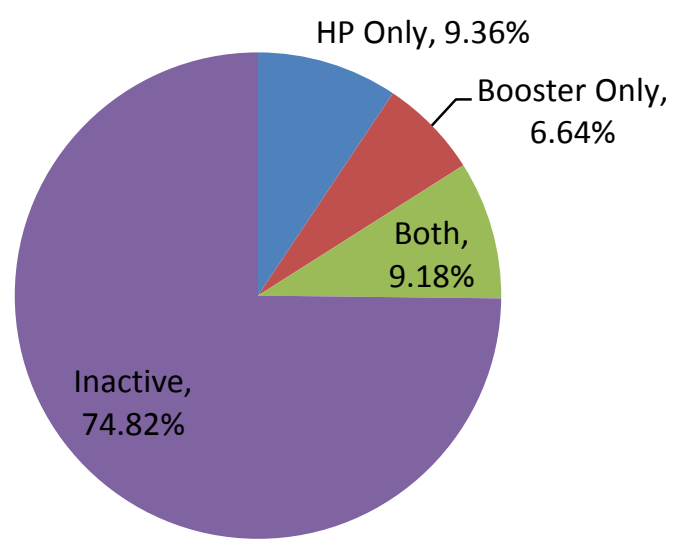

Figure A-0-3: Equipment Utilization for $55^{\circ} \mathrm{C} \mathrm{HP}$ and $65^{\circ} \mathrm{C}$ Booster Set-point Test (Schedule A)

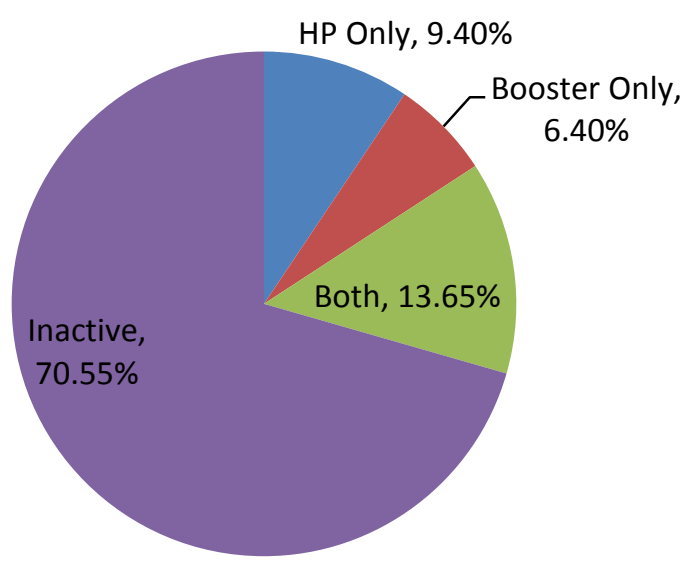

Figure A-0-4: Equipment Utilization for $60^{\circ} \mathrm{C} \mathrm{HP}$ and $70^{\circ} \mathrm{C}$ Booster Set-point Test (Schedule A) 


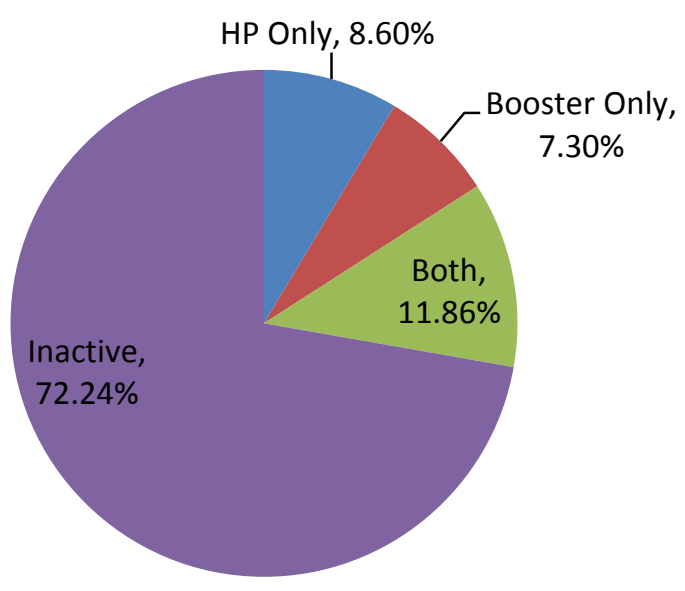

Figure A-0-5: Equipment Utilization for $62^{\circ} \mathrm{C} \mathrm{HP}$ and $72^{\circ} \mathrm{C}$ Booster Set-point Test (Schedule A)

\section{A.2 Schedule C}

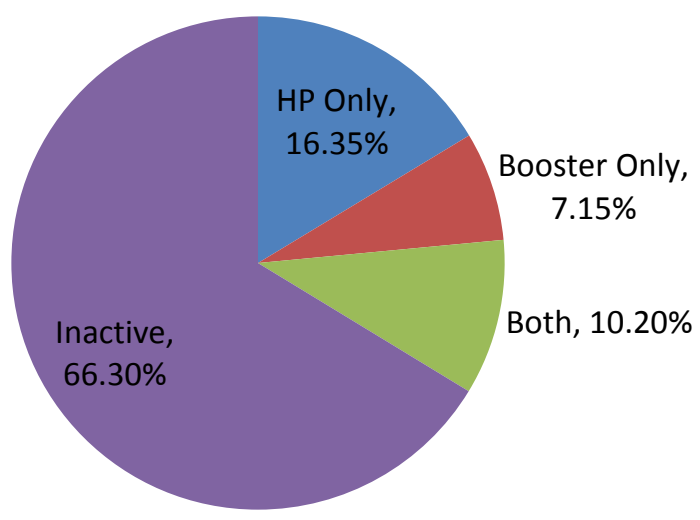

Figure A-0-6: Equipment Utilization for $50^{\circ} \mathrm{C}$ HP and $55^{\circ} \mathrm{C}$ Booster Set-point Test (Schedule C) 


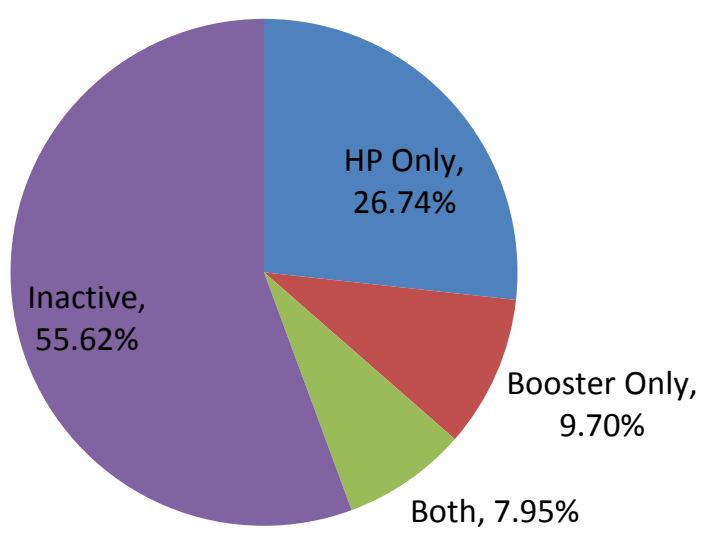

Figure A-0-7: Equipment Utilization for $55^{\circ} \mathrm{C} \mathrm{HP}$ and $60^{\circ} \mathrm{C}$ Booster Set-point Test (Schedule C)

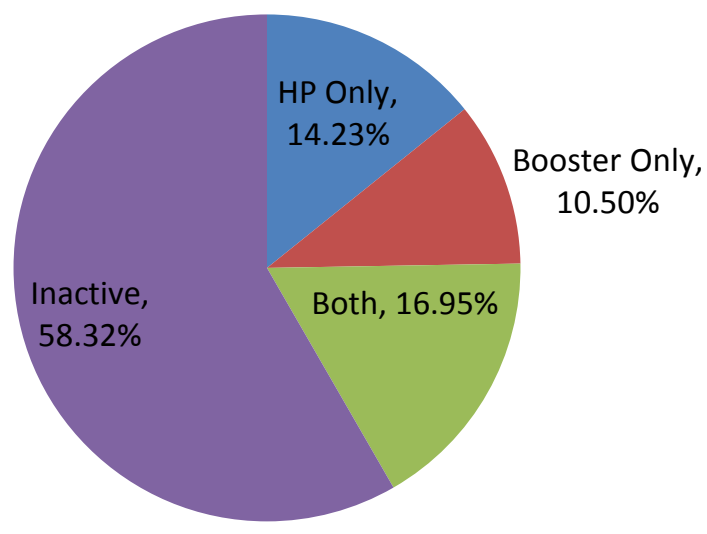

Figure A-0-8: Equipment Utilization for $55^{\circ} \mathrm{C} \mathrm{HP}$ and $65^{\circ} \mathrm{C}$ Booster Set-point Test (Schedule C) 


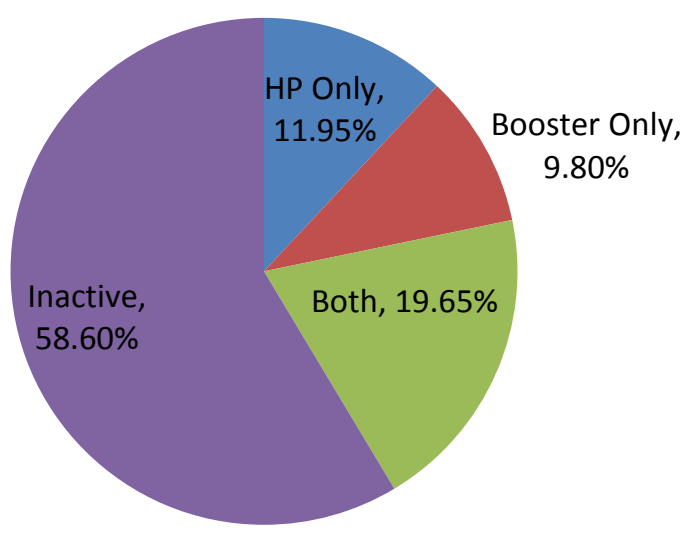

Figure A-0-9: Equipment Utilization for $60^{\circ} \mathrm{C} \mathrm{HP}$ and $70^{\circ} \mathrm{C}$ Booster Set-point Test (Schedule C)

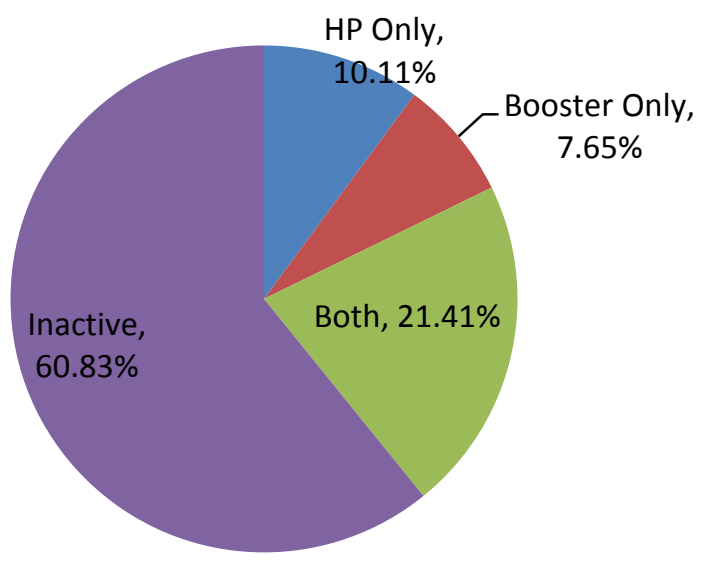

Figure A-0-10: Equipment Utilization for $62^{\circ} \mathrm{C}$ HP and $72^{\circ} \mathrm{C}$ Booster Set-point Test (Schedule C) 


\section{Appendix B TRNSYS Deck File}

Simulations in TRNSYS require a file called a Deck file that contains the simulation conditions, types, connections, and initial conditions within the simulation. The Deck file is read into TRNSYS using the simulation engine, where the data is processed and the necessary outputs are written to an output file. It is necessary for a new Deck file to be created for each simulation. The following material is a sample Deck file that was used to identify the optimal utility rate ratio via GenOpt coupling. The heating and electrical utility rates were varied until a minimum energy cost was reached. The simulation executed at 30 second time steps for 24 hours with booster and heat pump setpoints of $60^{\circ} \mathrm{C}$. Large portions of the TRNSYS Deck file code had to be operated within customized calculator subroutines in order to better reflect the physical phenomena observed during testing and to ease with calibration.

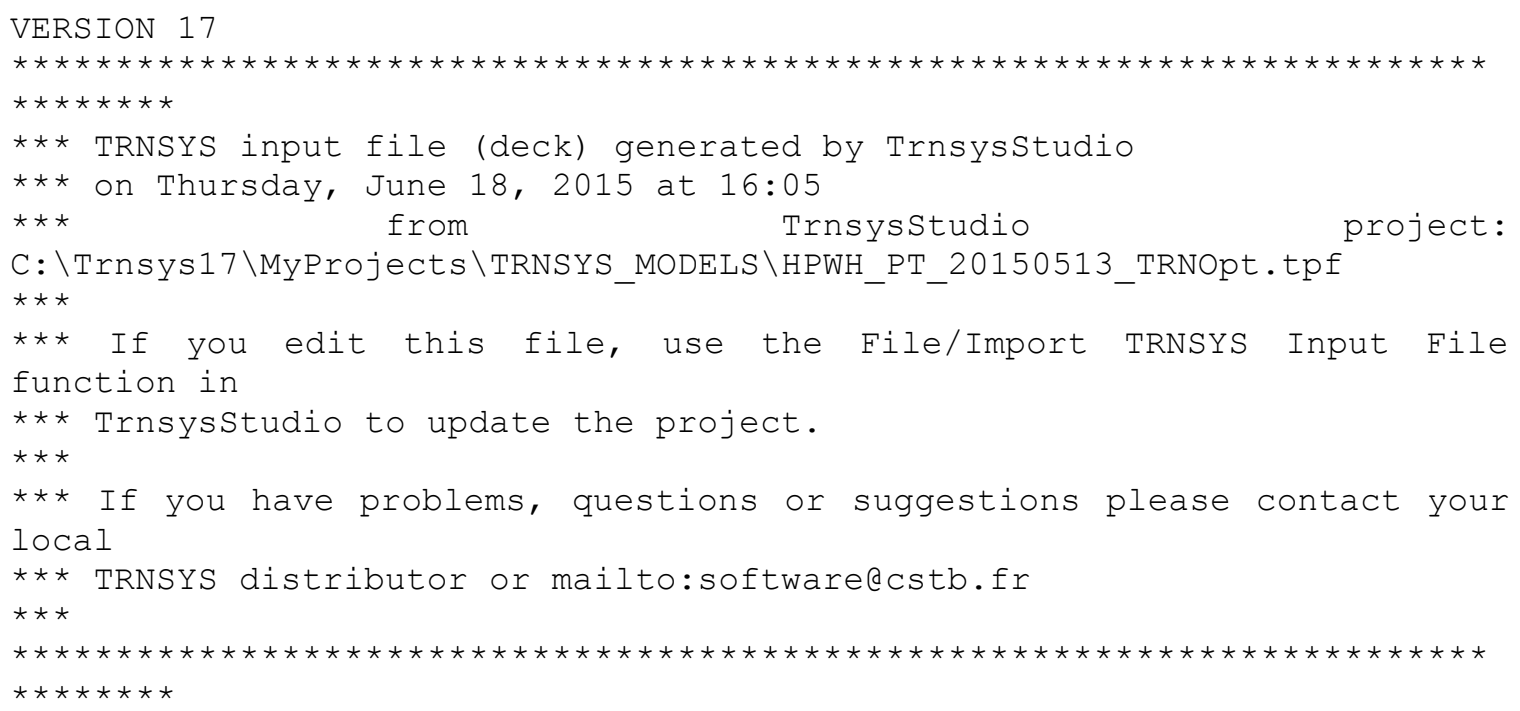




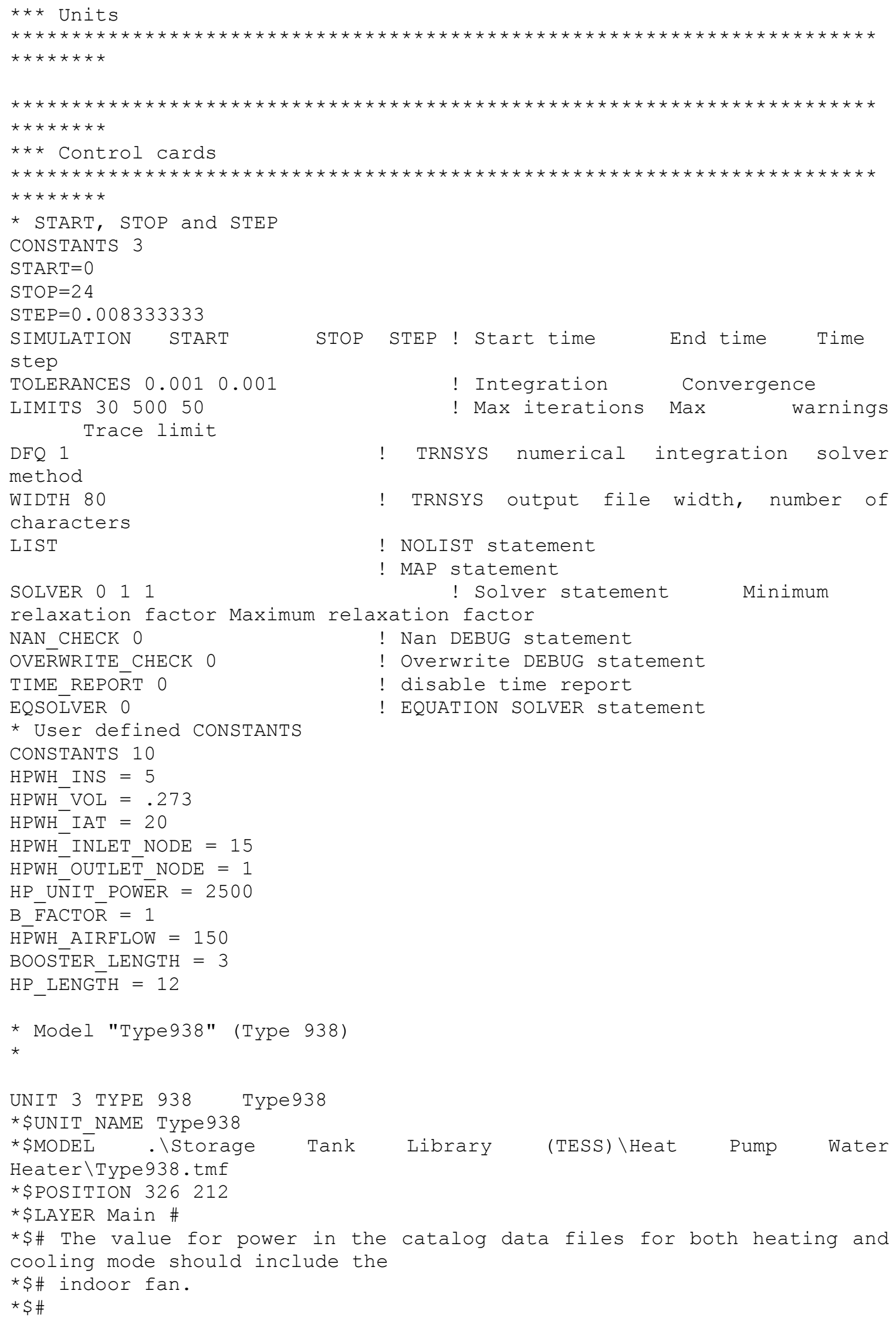




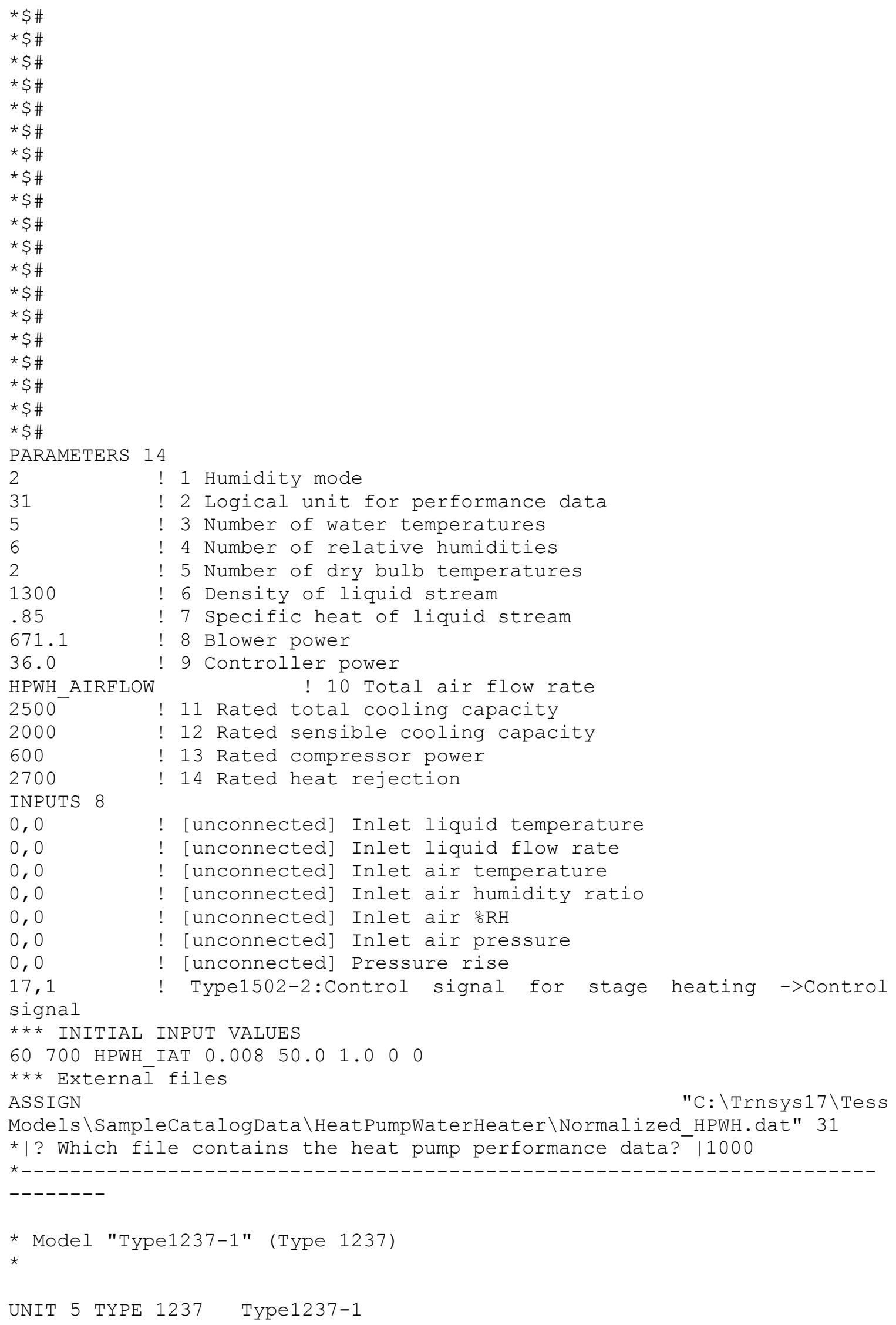




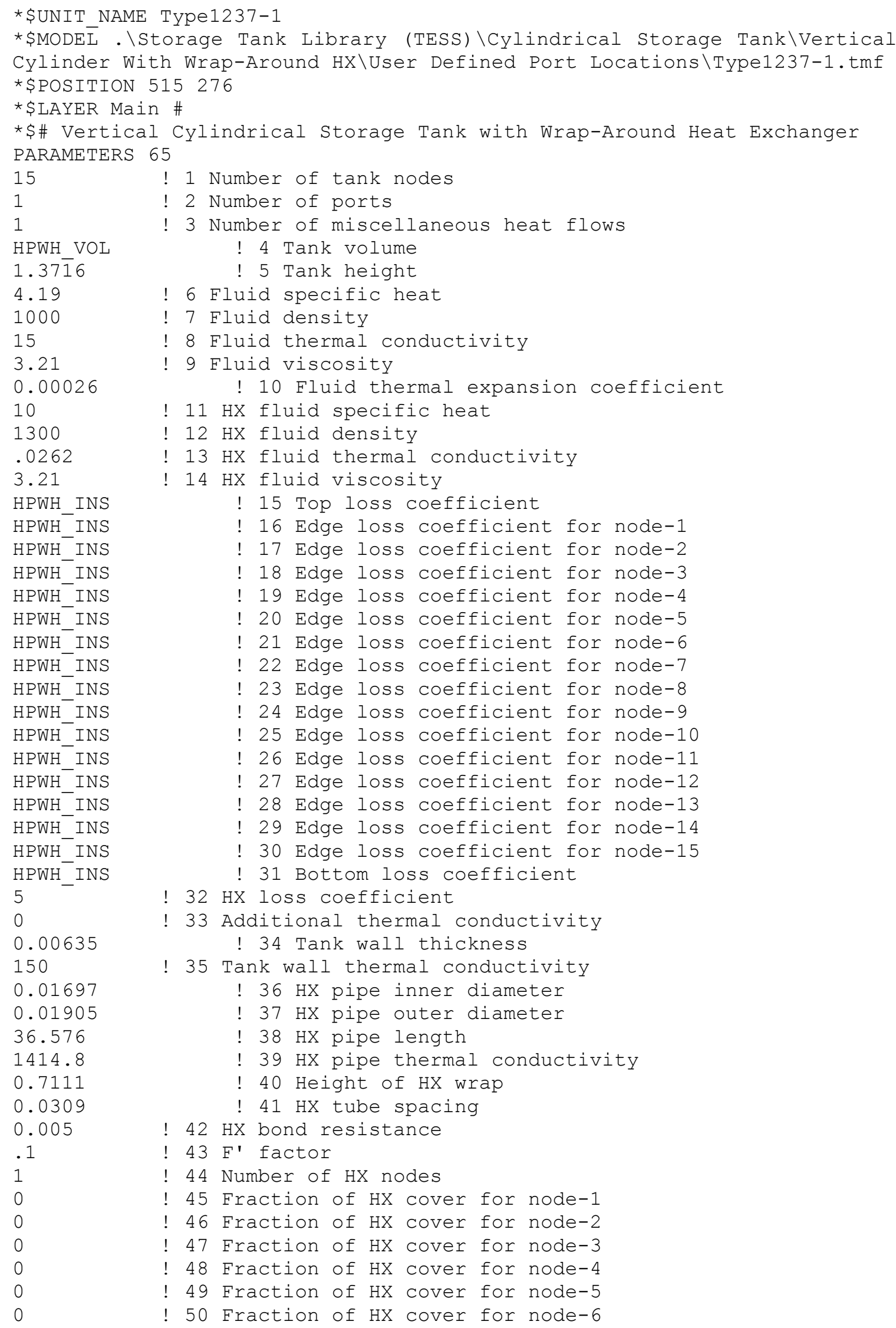




\begin{tabular}{|c|c|c|}
\hline 0 & 51 & Fraction of HX cover for node-7 \\
\hline 0 & 52 & Fraction of HX cover for node-8 \\
\hline 0 & 53 & Fraction of HX cover for node-9 \\
\hline 0 & 54 & Fraction of HX cover for node-10 \\
\hline 0 & 55 & Fraction of HX cover for node-11 \\
\hline ! & 56 & Fraction of HX cover for node-12 \\
\hline 0 & 57 & Fraction of HX cover for node-13 \\
\hline ! & 58 & Fraction of HX cover for node-14 \\
\hline ! & 59 & Fraction of HX cover for node-15 \\
\hline 1 & 60 & Tank node adjacent to HX node \\
\hline .14 & 61 & Fraction of HX length for HX node \\
\hline 5 & 62 & Node for miscellaneous heat gain \\
\hline 1 & 63 & Inlet flow mode \\
\hline PWH_INLET_NO & & ! 64 Inlet node \\
\hline PWH_OUTLET_N & & ! 65 Exit node \\
\hline
\end{tabular}

INPUTTS 38

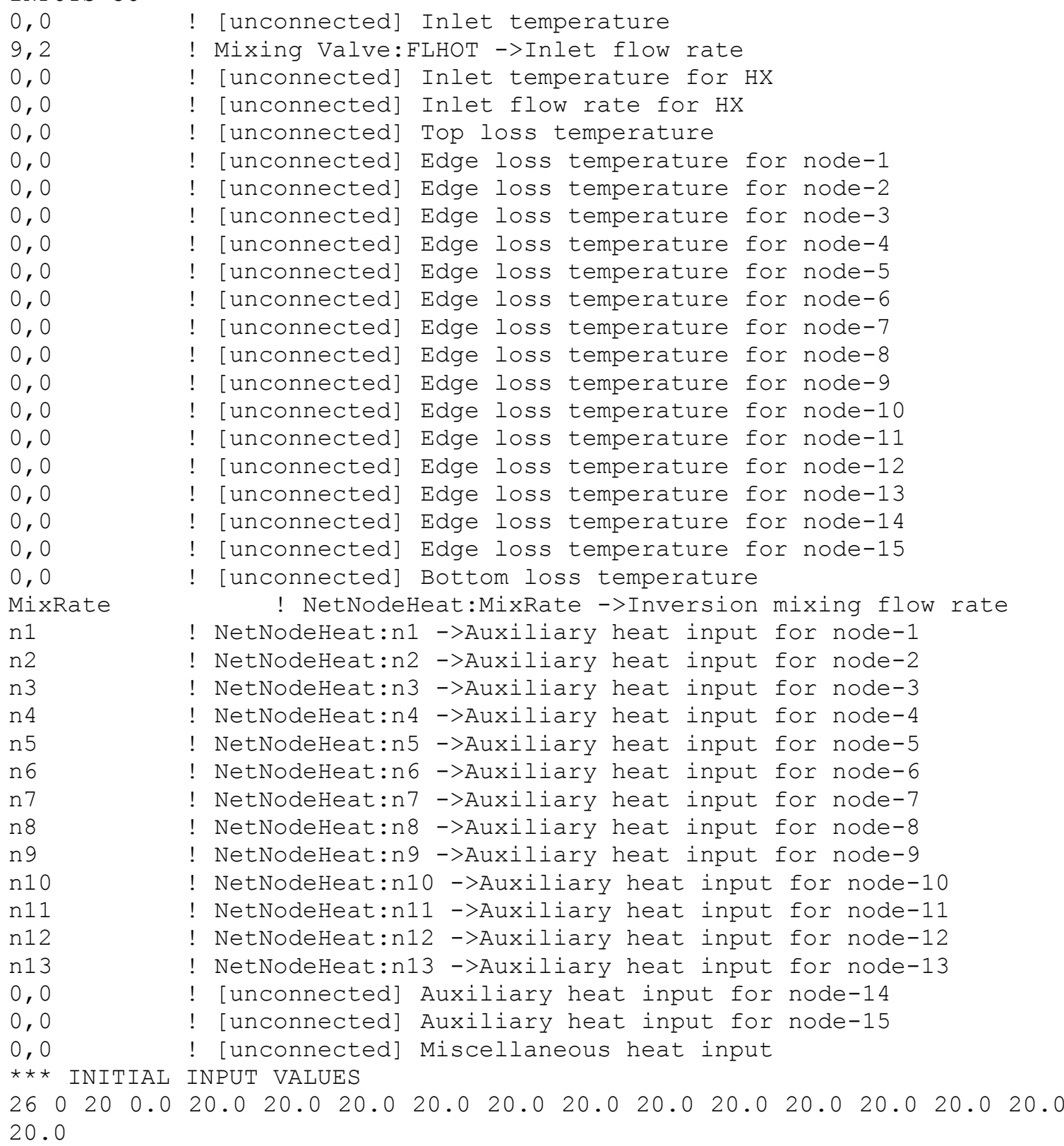




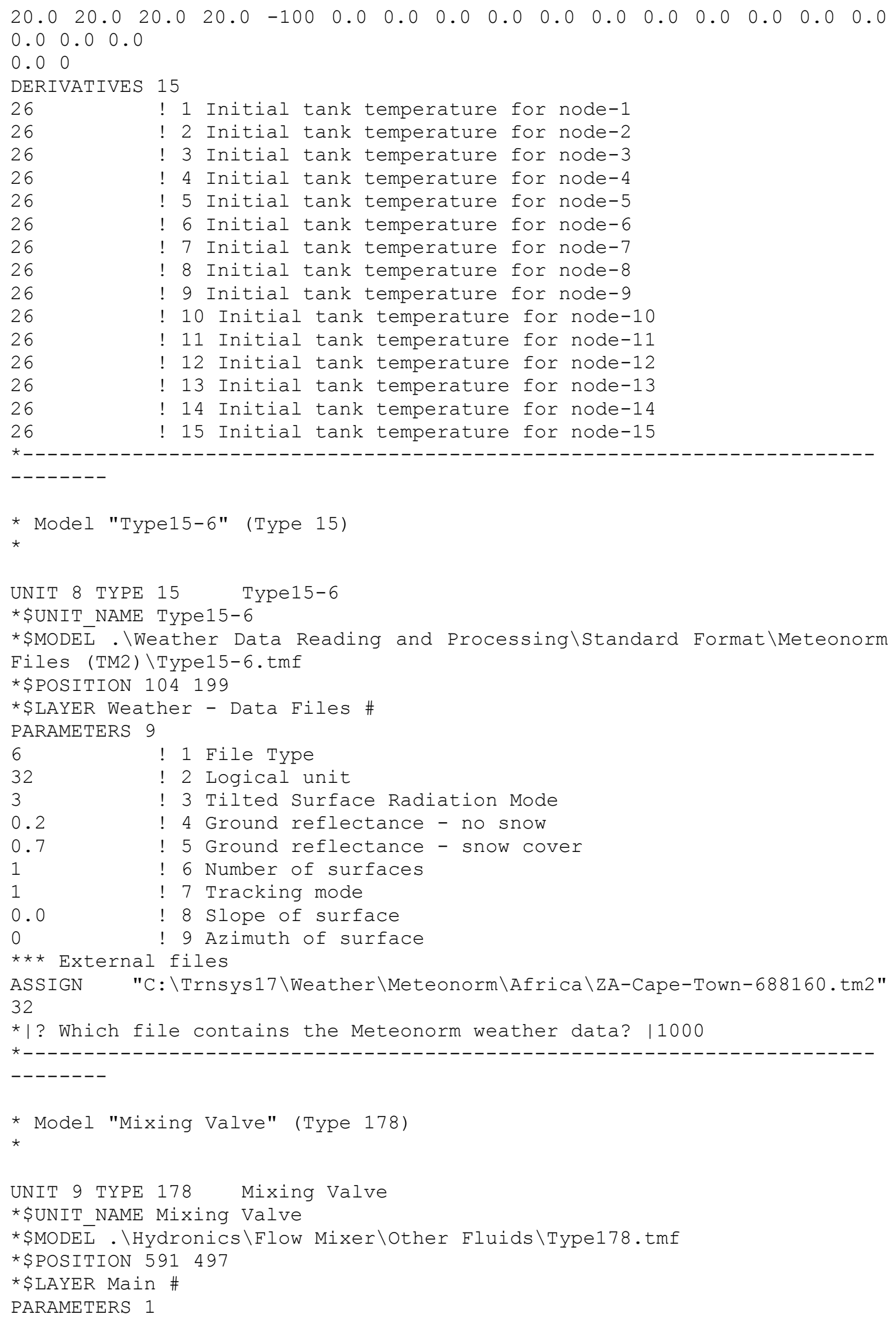




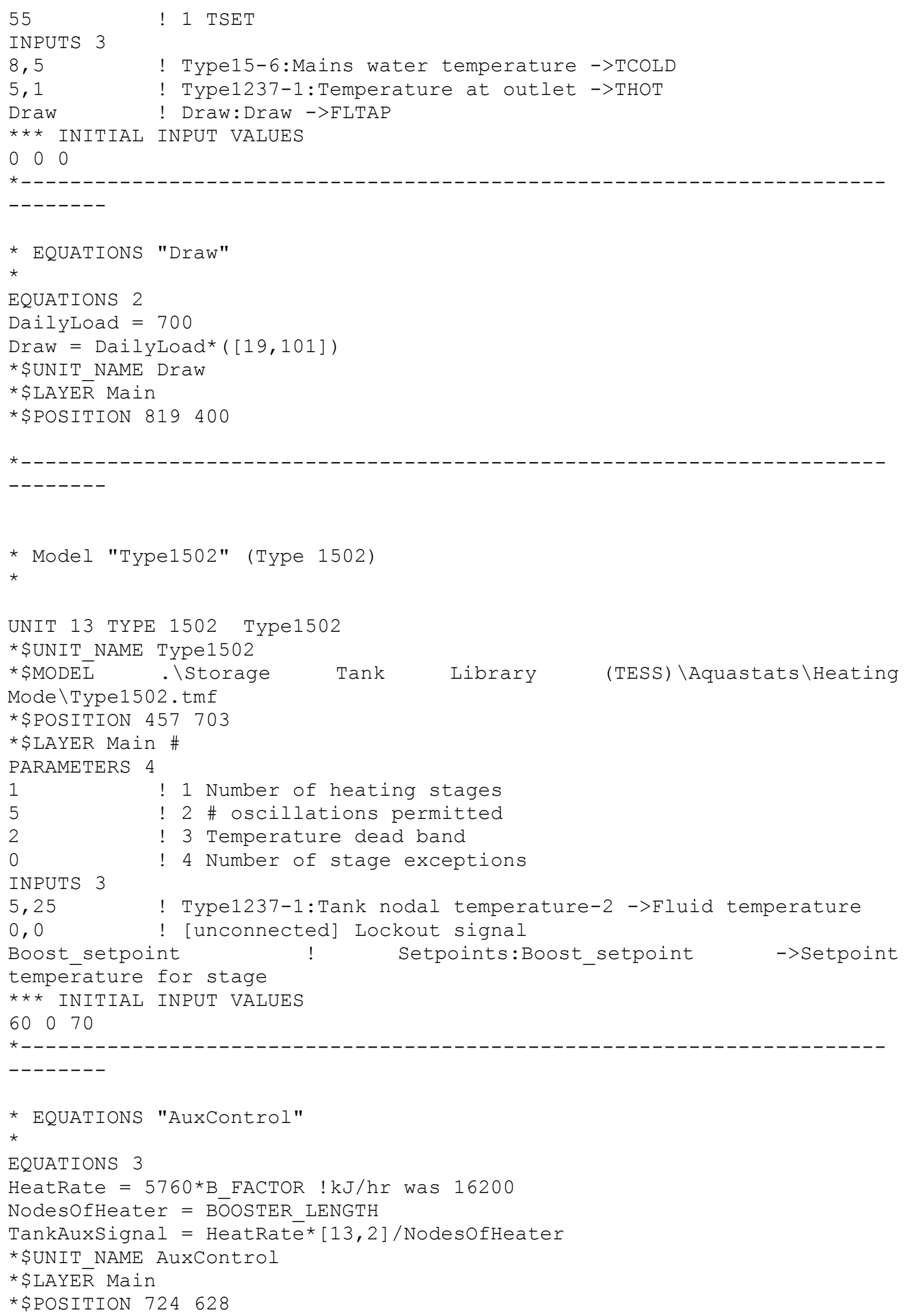




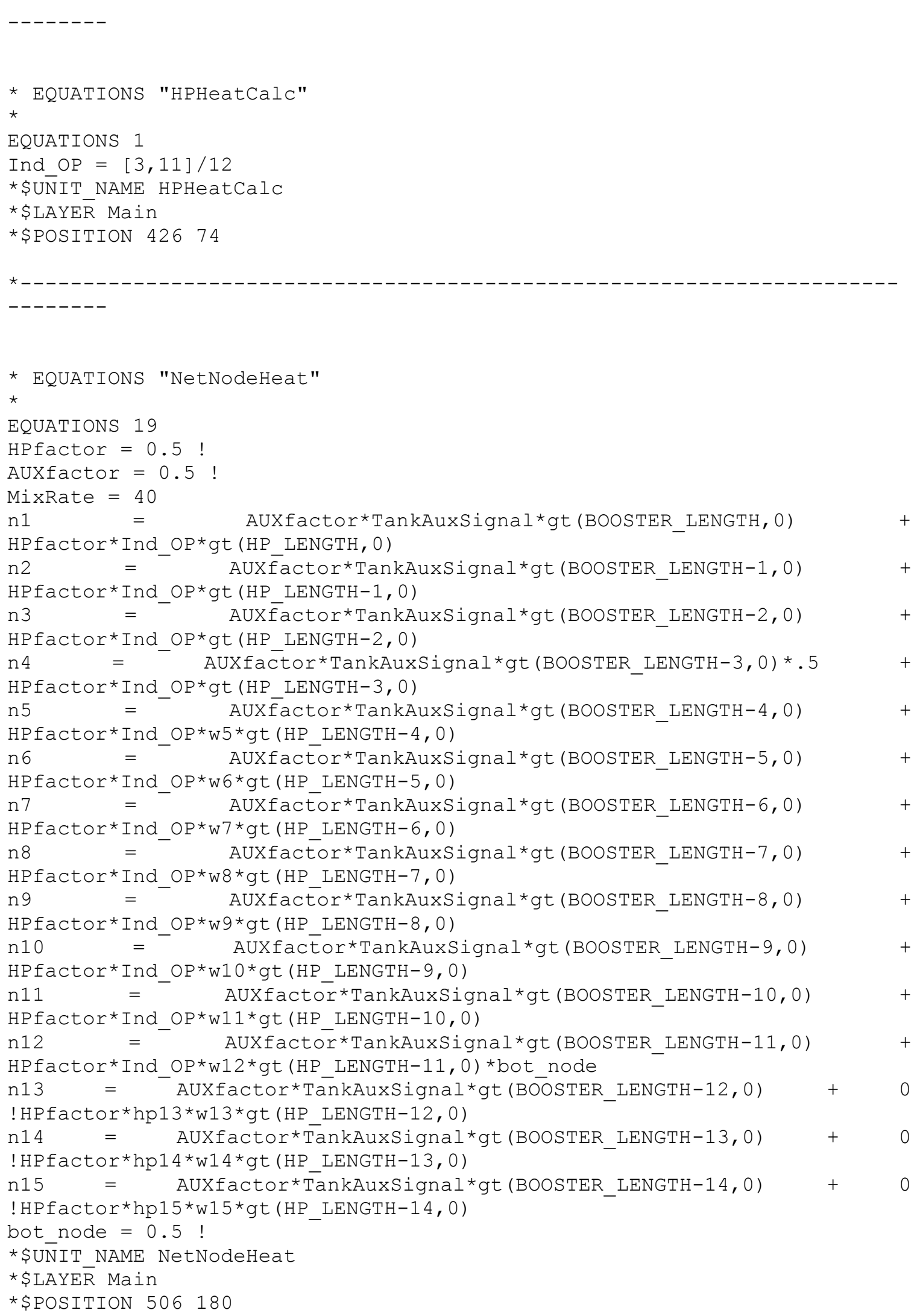




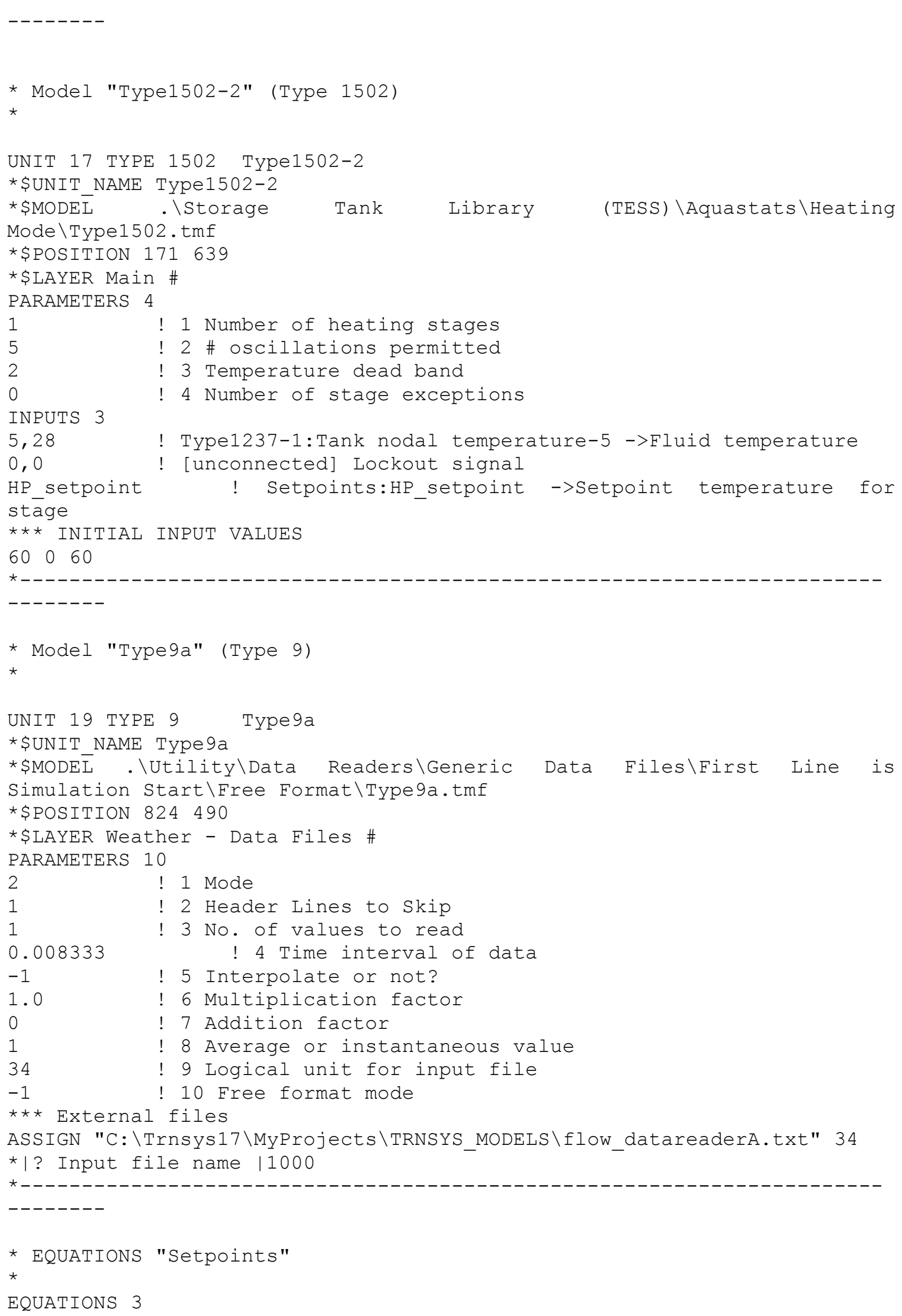




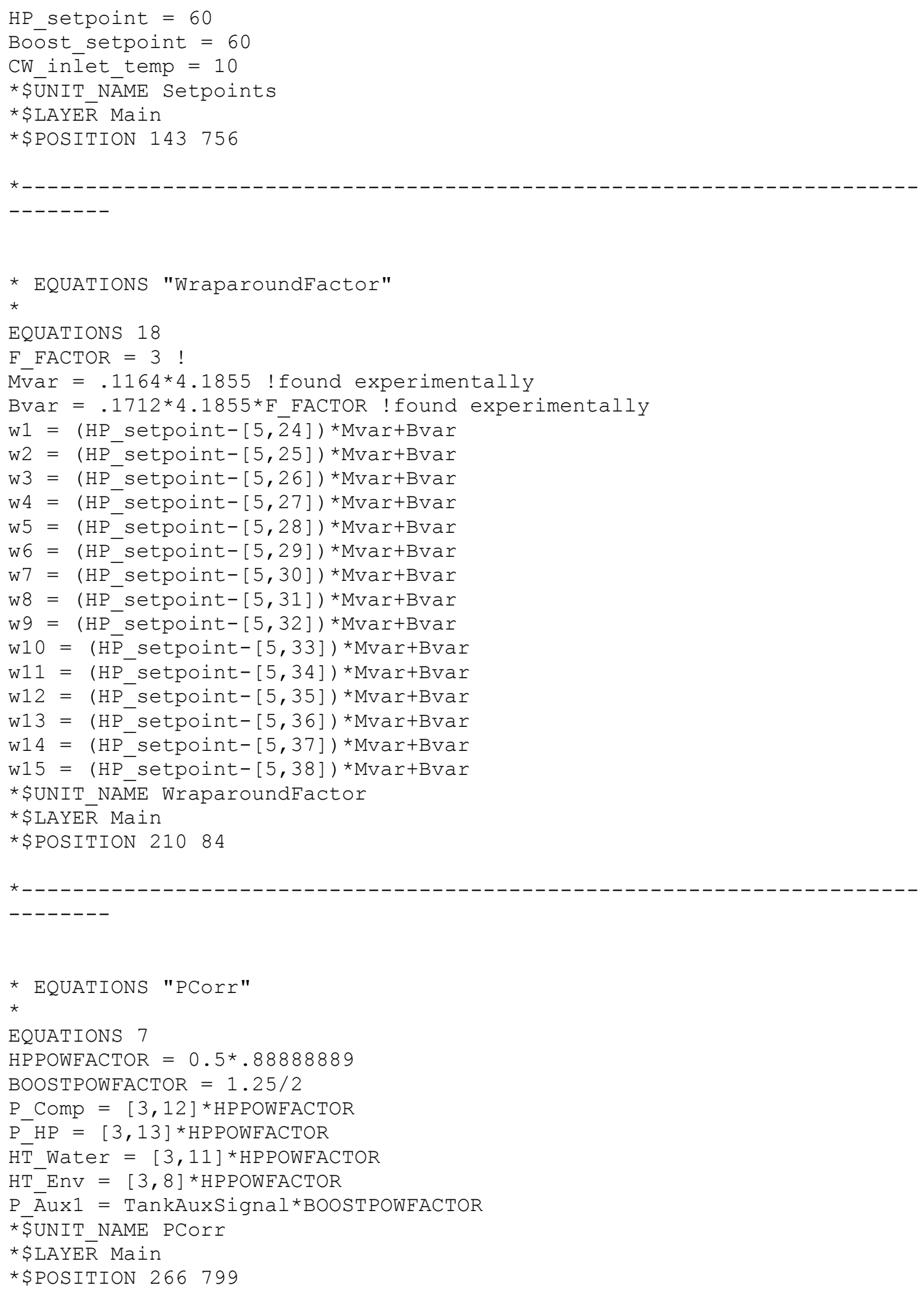




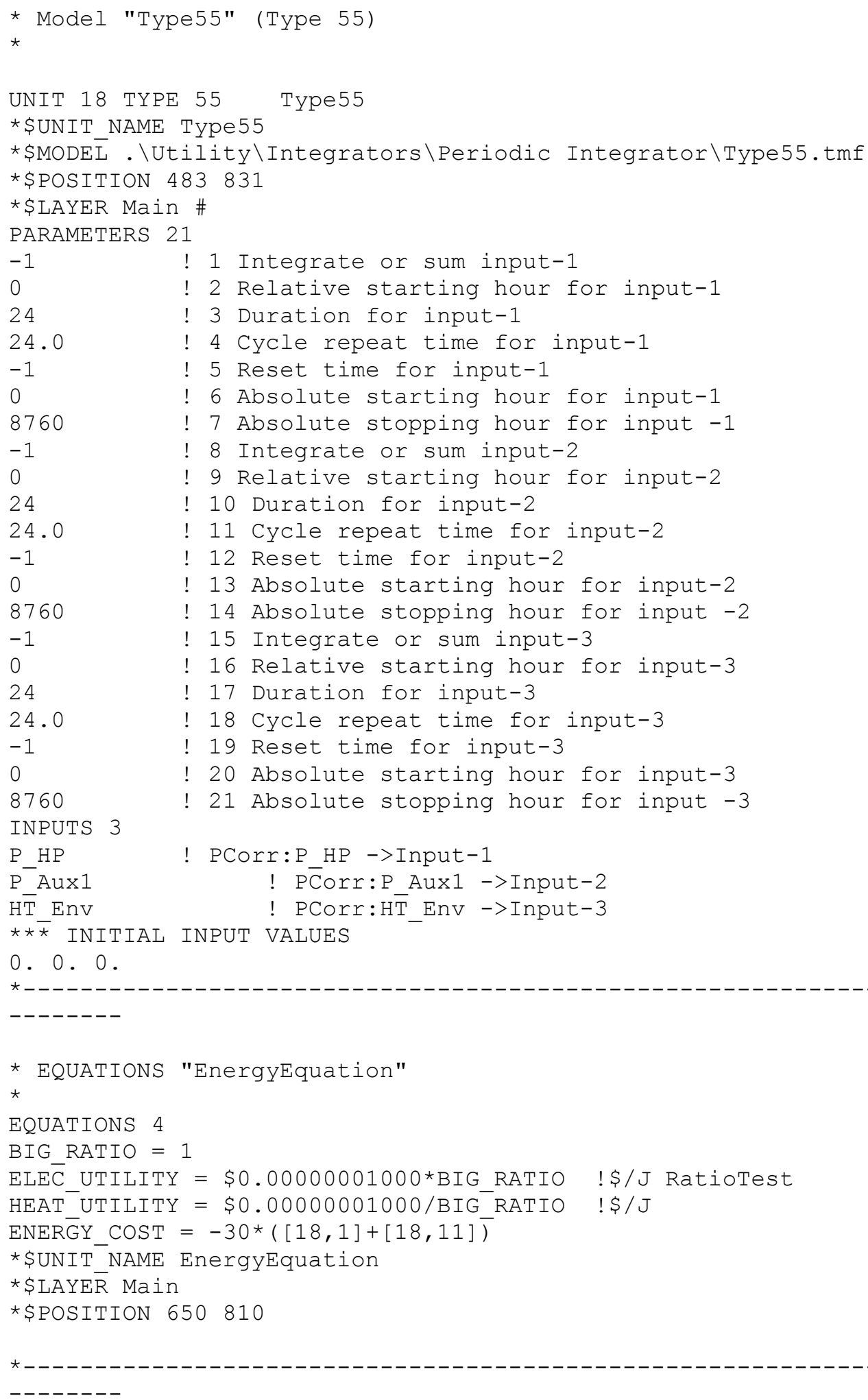

END 